\title{
Gemma
}

Utrecht University

$\left.\mathcal{U} g^{r}\right|_{\substack{\text { Universidad } \\ \text { de Granada }}}$

\section{Let me tell you our story: On how women in my family disrupt menstrual tales in the process of telling stories.}

Main Supervisor: Prof. Dr. Domitilla Olivieri (UU)

Support Supervisor: Dra. Rosa Medina-Doménech (UGR)

This thesis was written in completion of the GEMMA Erasmus Mundus Master's Degree in

Women's and Gender Studies

Utrecht University \& University of Granada

Dresda Emma Méndez de la Brena

August, 2016 


\section{Let me tell you our story: On how women in my family disrupt menstrual tales in the process of telling stories.}

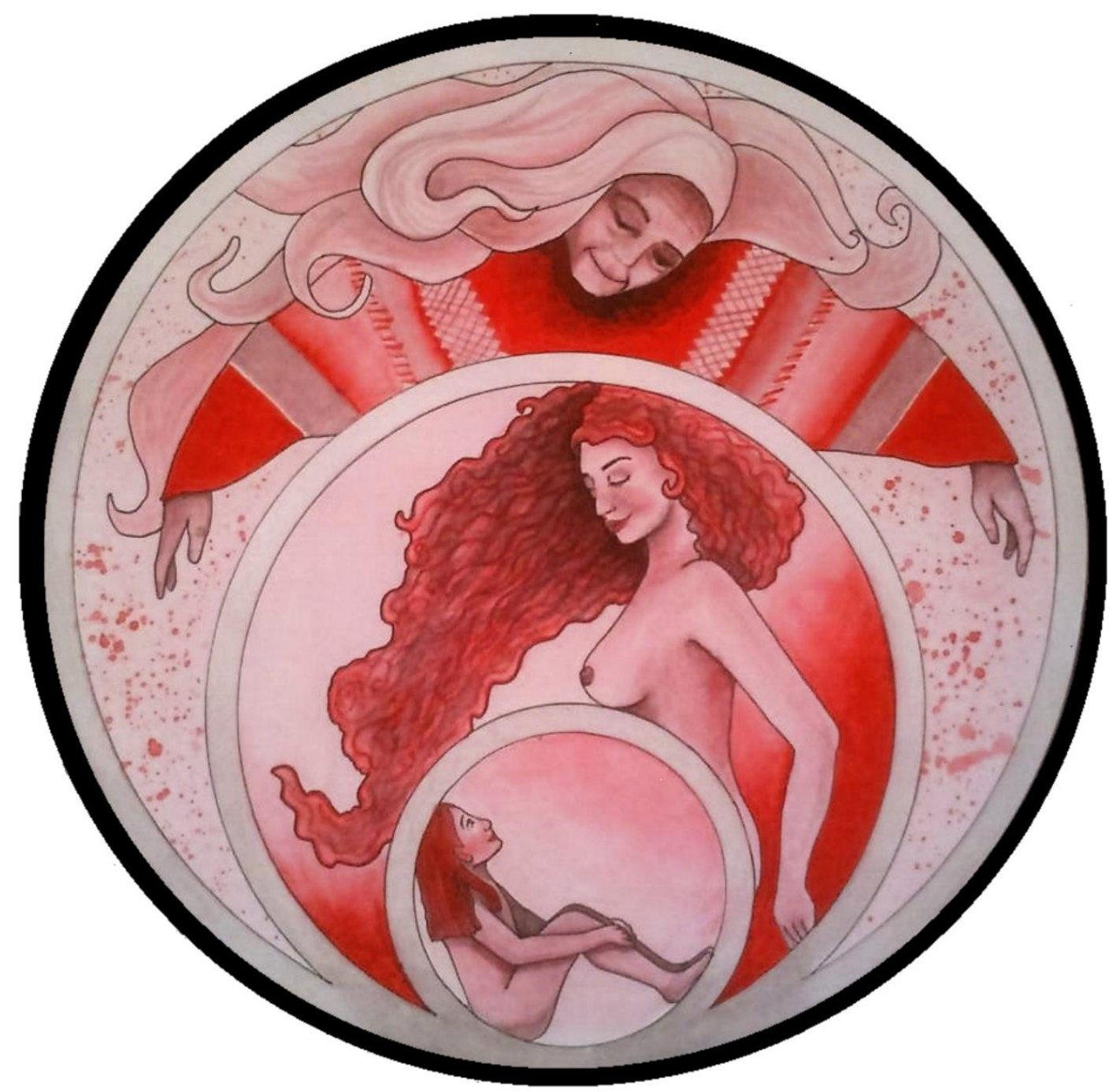

Illustration courtesy of Spanish artist Laia Gimeno Algaba. All Copyrights Reserved to the artist.

By:

Dresda Emma Méndez de la Brena

Main Supervisor: Prof. Dr. Domitilla Olivieri (UU)

Support Supervisor: Dra. Rosa Medina-Doménech (UGR) 
What blood does not provide, narrative can Black Sheep and Kissing Cousins

Elizabeth Stone

In Memoriam

Elena de la Brena Dartiz

(1950-2014) 


\section{Content}

Acknowledgements ............................................................................................

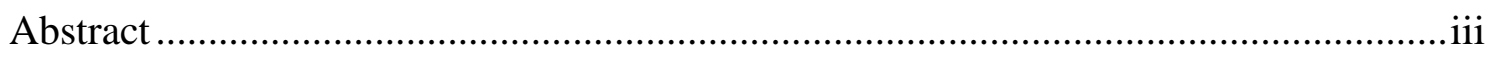

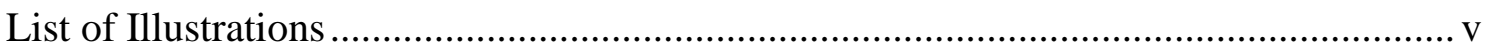

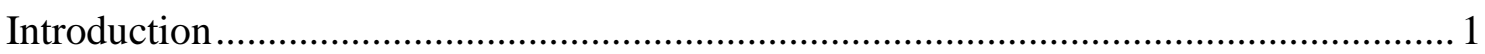

Chapter I. Performance, Performativity, and Storytelling: A Frame of Analysis..............5

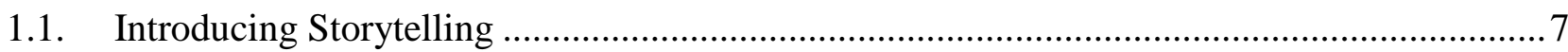

1.1.1. Family Storytelling. ......................................................................................

1.1.2. Women's Stories in a Family Context...................................................................11

1.1.3. Mother and Daughter Storytelling. .......................................................................... 12

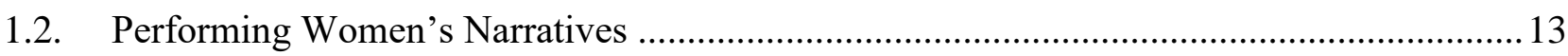

1.2.1. Narrative Embodied Perfomance............................................................................... 14

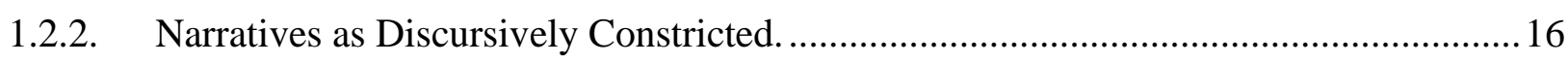

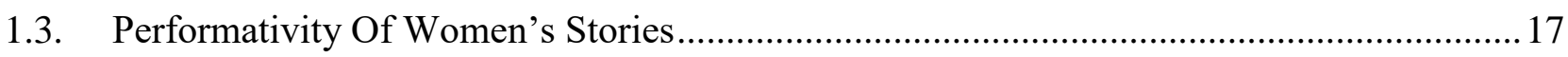

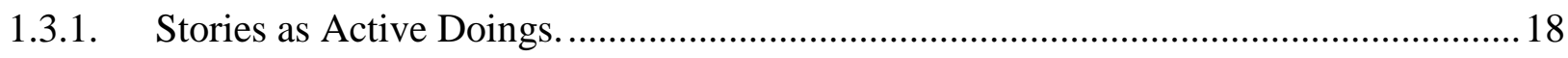

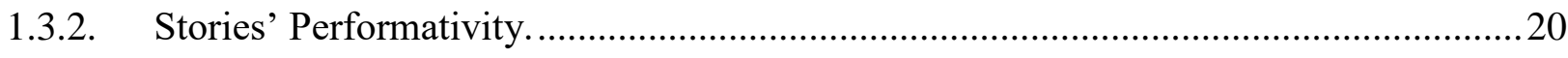

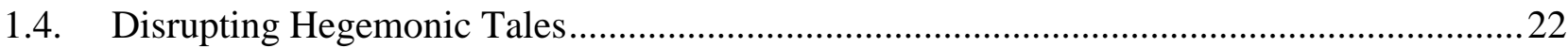

1.4.1. Retelling and Retold the 'Same Stories'......................................................................22

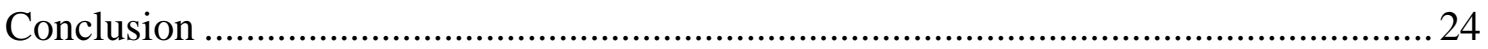

Chapter II. Writing Family Menstrual Stories: Methodology …………........................22

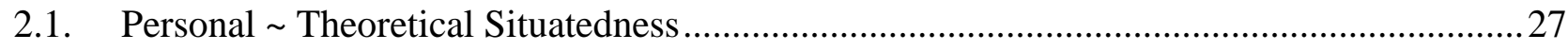

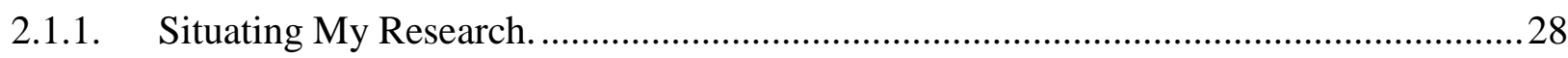

2.1.2. Situating Menstruation within Theoretical Coordinates...................................................30

2.1.3. Situating My Family's Stories in the Research.............................................................. 32

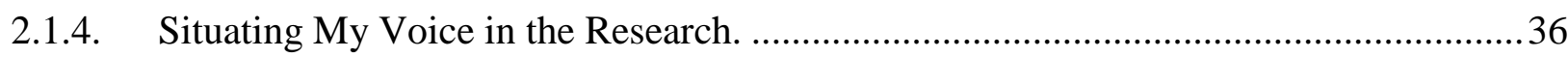




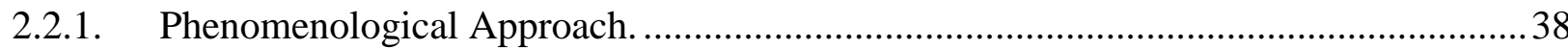

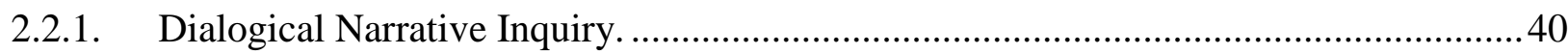

2.3. Employing 'Storytelling' as Data Collection Method...................................................... 40

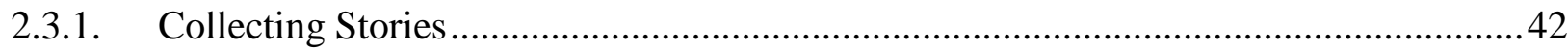

2.3.2. Transcribing, Translating, and Interpreting Stories. ............................................... 43

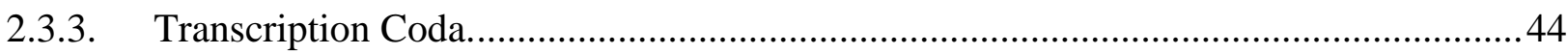

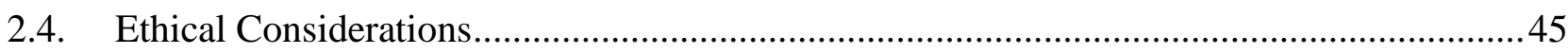

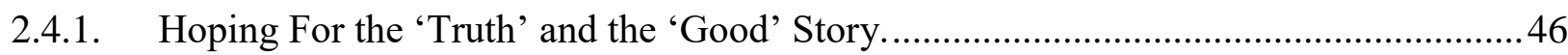

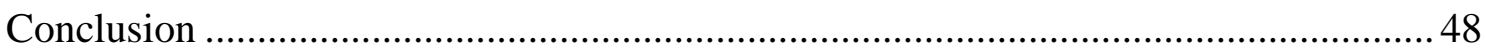

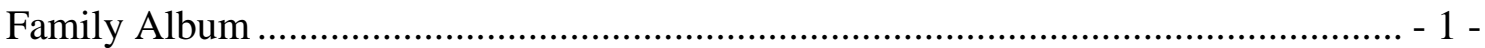

Chapter III. Telling Hegemonic Menstrual Tales ..................................................... 49

3.1. Menstruation as a Hegemonic Tale ............................................................................ 49

3.1.1. Historical Review of Hegemonic Menstrual Tales.........................................................51

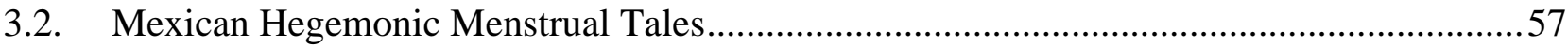

3.2.1. Sharing Family Hegemonic Menstrual Tales. ............................................................59

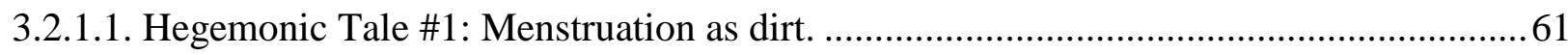

3.2.1.2. Hegemonic Tale \# 2: Vagina Horror and Virginity Loss. .........................................63

3.2.1.3. Hegemonic Tale \# 3: Menstrual Blood: Disgust, Odor and Shame. ..............................65

3.2.1.4. Hegemonic Tale \# 4: (Hetero) Sexualization of the Female Body................................68

3.2.1.5. Hegemonic Tale \#5: Menstruation as Mother - Daughter Disconnection and Blame .... 70

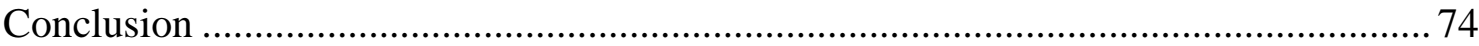

Chapter 4. Counter-storying Hegemonic Menstrual Tales ......................................... 75

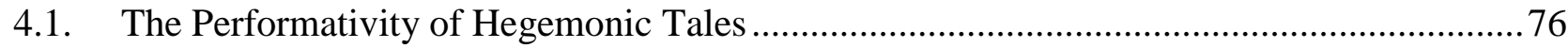

4.1.1. The Narrative Constitutive Instabilities of Hegemonic Tales. ....................................... 77

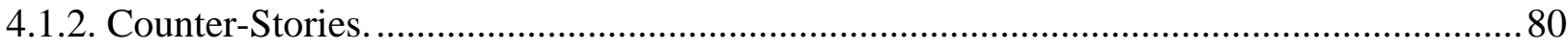

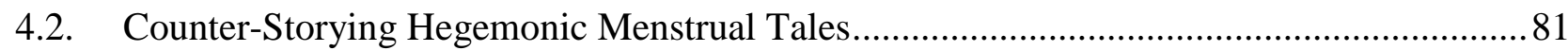


4.2.1. Counter-story \#1: Menstrual Blood and Odor as Awesome.......................................... 82

4.2.2. Counter-story \#2: Menstruation as a "Way Out". ............................................................ 85

4.2.3. Counter-story \#3: Menstruation as Women Bonding and Solidarity. ...............................87

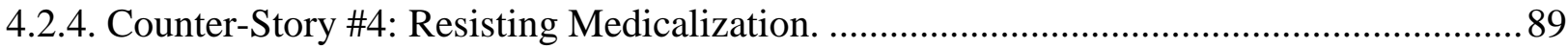

4.2.5. Counter-story \#5: Menstruation as Positive Re-appropiation. ........................................ 92

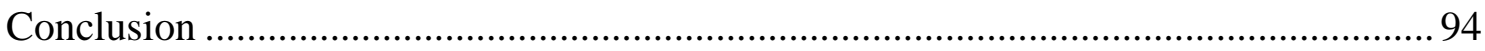

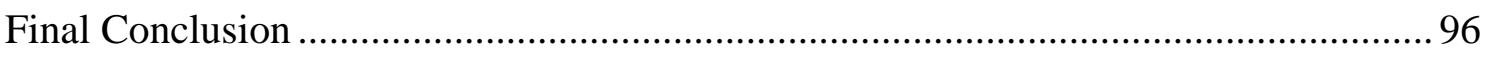

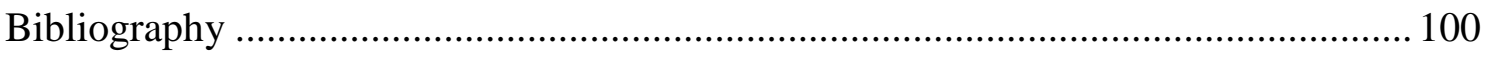




\section{Acknowledgements}

I would like to thank my advisors, Domitila Olivieri and Rosa Medina-Doménech, whose kind words and welcomed advice helped to keep my mind focused and my will strong. Thank you for understanding my way with this project. Thank you for believing in the power of small stories, the stories of the margins, the footnotes, and the corners. Thank you for believing in the power of women's voices, of women's resistance. As teachers, researchers, feminists, mentors, and friends, your guidance over the past months has been invaluable.

I also want to thank all the GEMMA Consortium and particularly prof. Adelina Sánchez Espinosa. GEMMA is a life-changing project. It is a magnificent opportunity for those who are committed to learn, understand, question, change, challenge and critique diverse systems of oppression. I am truly thankful to the University of Granada for giving me the best feminist academic ground to situate my body, my mind and soul. My deepest gratitude to the University of Utrecht for challenging me intellectually and personally. I am proud to be a GEMMA and I hope to make you feel proud of the feministqueer theorist you have cultivated these past two years.

I want to thank all the love, support and care from all my GEMMAS: Lore, Lau, Tere, Sheila, Shere, Ele, Clau, Melissa P., Marja, Magui, Judith, La Mani (Melissa Ch.), La Chabelita, y la Tan. This whole experience has been a gift but your friendship has been a blessing. Thank you sharing your lives and stories with me. Thank you for your love and support. Thank you for making friendship the most revolutionary affective-practice of all.

I owe a debt of gratitude to the women in my family who participated in this study. Their commitment to this project through their generosity in sharing their stories and experiences are most appreciated. I want to honor the strength and courage that being a woman in my family represents. In permitting me to use their narratives, these women allowed me to trace a genealogy of powerful women's voices in my family. Their stories have provided new ways of thinking about academic life and have made a difference in my own way of working. Thank you to my mom Emigdia. To my aunts Yolanda, Guadalupe and Martha. To my cousins Elka, Daniela and Susana, and my nieces Zabdi and Elissa. 
Your support and passion for this project is truly appreciated. This has been a life-changing experience.

With love and appreciation, I thank Abraham for seeing me through the happy moments and difficult paths of this incredible journey. As a partner and friend you provided steady encouragement and solid support for my work. Thank you for believing in me and having faith in moments where I did not. It is wonderful to be involved in a relationship where commitment and respect triumph.

As a last remark, I would like to address some words in Spanish.

Todo mi amor y admiración a mi madre. Honro tu fortaleza para sobrellevar las cargas que las estructuras de violencia patriarcal han impuesto sobre ti. Ojalá este trabajo pueda fortalecerte y hacerte ver que tu vida, tus historias y tus experiencias son la fuente de mi conocimiento. Sin ti, nada de esto sería posible. A mi padre por su incansable apoyo. Gracias por estar ser mi bastión y fortaleza. Eres una pieza fundamental en el cumplimiento de todos mis sueños. Por último, quiero agradecer a mis dos pequeñas sobrinas. Gracias por ser la energía para querer ser mejor.

Este trabajo quiere honrar todas las historias de las mujeres que se pierden en los ruidos de violencia. A todas las historias que se invisiblizan en los ojos del fuerte. A todas las voces que se escuchan como murmullos entre los ecos patriarcales. A todas las voces que en sus lugares resisten, gritan, tararean, y refunfuñan. Este trabajo es la suma de las historias dichas y no dichas por las mujeres en mi vida. A todas las voces de mujeres que resisten con fuerza, con cuerpo y con sangre, gracias. 


\section{Abstract}

This investigation focuses on the intergenerational (grandmother - mother - daughter) transmission of menstrual stories on three generations of women in my family, finding differences, over time, in how menstrual stories are acquired by each generation and how the event of menarche and menstruation is experienced, embodied and interpreted. As such, this thesis identifies and analyses hegemonic menstrual tales such as myths, rituals, taboos, secrets, routines, practices, and discourses that negatively shape the stories women in my family tell about menstruation. Through an examination of research literature about menstruation and the analysis of individual interviews, five dominant tales were found that, although not new, need to be examined as an important discursive approach in which women in my family construct their menstrual understandings and embodiments.

As an alternative, this thesis proposes intergenerational storytelling as a narrative strategy that offers discursive ways to challenge and subvert these hegemonic tales. Through an exploration of recent production of interdisciplinary feminist storytelling and performance and performativity theories, this investigation underlines the potential of stories' performativity to describe opportunities to challenge, resist and counter -story dominant discourses of menstruation. This resulted in five alternative stories that bring together broader questions related to menstrual experience, and how its embodiment and meanings are importantly constructed through male dominated expectations of women's bodies and behaviours.

Ultimately, this thesis contributes to the feminist sociolinguistic field by promoting women's intergenerational storytelling as a (re)generative narrative practice that challenges and subverts patriarchal discourses that harm women's relations with their bodies. But most importantly, intergenerational storytelling offers broader comprehension of the importance of hearing women's voices as a form of narrative resistance. In my family case, as a narrative strategy used to repair bodily stories, blood stories and blood relations.

KEYWORDS: menstruation, performativity, performance, intergenerational storytelling, hegemonic tales, counter-stories, phenomenology of the body. 


\section{RESUMEN}

Esta investigación se enfoca en la transmisión intergeneracional de historias menstruales en tres generaciones de mujeres en mi familia, encontrando diferencias, en la forma en que la menstruación es experimentada, vivida, encarnada e interpretada en cada generación. De esta forma, esta tesis identifica y analiza cuentos hegemónicos: mitos, ritos, tabúes, secretos, rutinas, prácticas y discursos sobre la menstruación que impactan de forma negativa la forma en que las mujeres de mi familia cuentan sus historias menstruales. A través de una examinación rigurosa de literatura sobre menstruación y el análisis de entrevistas personales, cinco cuentos dominantes fueron encontrados, que aunque no nuevos, necesitan ser examinados como formas discursivas que afectan los significados y la experiencia vivida de la menstruación en nuestra familia.

Como alternativa, esta tesis propone la trasmisión intergeneracional de historias como una estrategia narrativa que ofrece nuevas formas para retar y subvertir cuentos hegemónicos. A través de la exploración de teorías feministas interdisciplinarias sobre performatividad y performance; así como de la importancia narrativa de la trasmisión de historias, esta investigación destaca el potencial de la performatividad para describir estrategias y prácticas narrativas que desmantelan y ofrecen oportunidades de resistencia. Esto resulta en historias alternativas con respecto a la experiencia menstrual, cuestionando cómo ésta es encarnada y significada a través del lenguaje y discursos patriarcales. Finalmente, esta tesis contribuye al campo feminista de la sociolingüística al promover el intercambio generacional de historias de mujeres como una práctica poderosa y (re)generativa que reta y subvierte discursos que dañan las relaciones entre mujeres, y entre ellas y sus cuerpos; y que puede ser utilizada para reparar historias menstruales, historias familiares y lazos de sangre.

PALABRAS CLAVE: menstruación, performatividad, transmisión intergeneracional de historias, cuentos hegemónicos, contra-historias. 


\section{List of Illustrations}

Figure 1 (April 25 ${ }^{\text {th }}$ 1947) My grandmother Susana de la Brena and my grandfather Rolando Dartiz walking on the streets of Mexico City after getting married at the municipal hall. .34

Figure 2 (August $18^{\text {th }}, 1972$ ) Family Portrait in commemoration of my grandparents' silver anniversary. From left to right: Rolando, Helena, Martha, Oscar, Yolanda, Emigdia, Guadalupe, Ernesto, Erika, Rolando Sr., Oscar

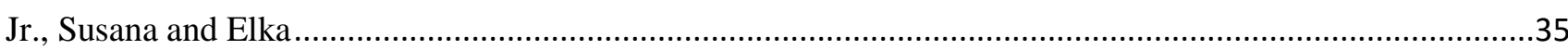

Figure 3 (2015) From left to right: Yolanda, Elissa and Elka .................................................................. - 2 -

Figure 4 (2016) From left to right. Zabdi, Susana and Guadalupe ............................................................. - 3 -

Figure 5 (2016) From left to right. Daniela and Martha................................................................................. - 4 -

Figure 6 (2013) From left to right: Emigdia and Dresda....................................................................... - 5 - 


\section{Introduction}

Let me begin with a story.

In March of 2015, I participated in the Vagina Monologues in Granada, Spain. It wasn't my first theater performance, but it was the first since I called myself feminist. It wasn't easy to digest all the contradictions and fights that this self-naming brought to my life. But feminism helped me to situate my body as my battleground. As the center from which I can resonate with injustice, violence, and oppression. My body, my Mexican, middle class, skinny, allergic, brown body was the center, the source and the gut of my feminism. However, my relation with my body hasn't been the most harmonious. I had hated my female body many times. I had had an on-going love-hate relationship with some parts of it. My vagina was one of these. Always moist, smelly, running. Menstruation was an additional bother. The pain, the inconvenience, the shame. I came to hate my body, and all the moist parts of it. Feminism offered me a place to situate my body, my smells, and my fluids. An opportunity of not renouncing and discarding a body that is intended to be erased by others. Feminism gave the words to denounce my own bodily exile. Participating in the Vagina Monologues was an impulse and a reaction. I wanted to tell stories of the body, and I wanted others to listen, to pay attention. The Monologues confronted me with performance and stories: I was performing with my body while I was performing bodily stories. Each show had different impacts. Even when I told the same lines, the audience had different engagements with them. Sometimes they laughed when they were not supposed to; other times they were shocked when it was supposed to be joke. But at the end of each show, people approached me to tell me how the stories had an impact on them. Something about the stories acted as a trigger to re-signify the vagina, its fluids, its smells, and its shapes. In performing the Vagina Monologues I understood the power of stories and I decided to start telling many of them.

This thesis is about bodily stories - women's bodily stories. ${ }^{1}$ But it is more than that. It is about stories and experiences embedded in the body. It is about how women's embodied experiences are part of the sociocultural and historical spaces they occupy. It is to recognize that the ways women narrate their experiences are not neutral; they are charged by a range of social attitudes and beliefs, cultural myths, symbols, and images that shape women's bodily experiences. It is to identify the body as the condition through which women narrate the world, and stories as instruments for giving meaning to women's bodily experiences.

This thesis is about menstruation. But it is more than that. It is to understand menstruation as more than the center of womanhood. It is about menstruation as estrangement. It is about menstruation

\footnotetext{
${ }^{1}$ This introduction was inspired by the powerful introductory paragraph by Suzanne McKenzie-Mohr and Michelle N. Lafrance (2014) in Women Voicing Resistance: Discursive and Narrative Explorations. I am paraphrasing, using some excerpts and narrative structures from this paragraph. I completely acknowledge the authors' words, and I hope that my use of theirs can bring about more meaning to and comprehension of the importance of hearing women's voices as a form of narrative resistance.
} 
as a biological process with cultural, social, and historical meanings. It is about menstruation as a material and discursive experience that shapes the specific circumstances of the bodies it occupies. Also, it is to reflect the ways bodies are socially, historically, and discursively mediated and positioned, and how some women's experiences constitute different forms of bodily engagement. But it is more than that. It is about questioning how gendered discourses affect the ways in which menstruation is experienced.

This thesis is about menstrual stories - women's menstrual stories. But it is more than that. It is about stories of women in my family. It is about what stories do in our lives and what we do with stories. It is about the social and cultural discourses that shape our stories and the consequences of these stories in our lives. It is about the stories we have been telling to each other over the years. It about how menstruation comes to matter as a story never told, and when told, discarded. It is about familial encounters: mother and daughter encounters. It is about knowing each other better. It is about menstrual stories circulating within our blood relations.

This thesis is about resistance - women's resistance. But it is more than that. It is about subverting dominant scripts about the body. It is about re-storying scripts differently. It is about repetition, reiteration, transformation, subversion. It is about never telling the same story twice. It is about intergenerational insubordination. It is about stories never performed in the same way. It is about breaking up, fissuring, destabilizing hegemonic tales. It is about creating narrative bridges, gaps, opportunities, new meanings to re-signify menstruation. But is more than that. It is to trigger new forms of engagement with corporeal flows. It is to smell, to touch, to see, and to listen to our bodies. At its core, this thesis is about my family's attempt to story, re-story, and counter-story their menstrual experiences when privileging discourses or hegemonic tales shape their lives, practices, and identities. As such, this thesis is an exploration of subversive stories. But it is more than that too. It is about stories of resistance, transgression, and agency of women in my family.

Ultimately, this thesis is about exploring how the repetition of stories can disrupt dominant discourses that rely upon women's bodies. Particularly, the main goal is to analyze how patriarchal myths, taboos, attitudes, and beliefs about menstruation are present in my family's menstrual stories, affecting how women in my family relate to their bodies. I have called these myths and taboos 'hegemonic tales' to denote the fictional elements of the narratives and normative discourses around women's bodies, and how, in their repetition, they become internalized and taken for granted. This is why hegemonic tales can be harmful to women, and this is why it is also important to explore they ways women can challenge and disrupt these tales.

To illustrate how hegemonic menstrual tales work and the powerful potential of stories to transgress them, in Chapter One I present intergenerational storytelling as a communicative act that 
entails the capacity of stories' performativity in a reiterative process that can destabilize the normative discourses of hegemonic tales. In this sense, I introduce mother-daughter storytelling performativity as a reiterative practice that can create "gaps and fissures" (Butler, 2011) that open doors for resignifications of those tales. In order to elucidate this process, in Chapter Two I present narrative excerpts of a total of 10 stories; 9 of them conversations sustained with 9 women of different generations (grandmother - mother - daughters) in my family. The story left is my own. Due to my position as a researcher/family member, in this chapter I describe the importance of finding a methodology that allows me to reflect upon not only my family's menstrual experiences but also my own experience, and how to find the most optimal form to capture and make sense of them throughout analyzing our stories. In this chapter, I situate my personal and theoretical coordinates, and the method I use to recollect my family's menstrual stories.

In Chapter Three, I explore the meanings women in my family attribute to menarche and menstruation, what they think and feel about it, and the significance of this event as represented in their stories. I focus on menstruation as a bodily experience discursively embedded in hegemonic menstrual tales. I analyze excerpts of my family's menstrual stories to reveal the dominant narratives in which they are inserted and how they shape our menstrual experience. Using intergenerational storytelling, I explore how menstrual stories are transmitted from mother to daughter, and how these stories carry on normative and negative menstrual meanings that are harmful for women's menstrual experience. Finally, in Chapter Four, I center my analysis on counter-stories as they are revealed in the transmission of menstrual stories from mothers to daughters. I show how counter-stories reveal gaps and fissures that open up possibilities for new menstrual meanings and signifiers. Importantly, this chapter aims to recuperate women's vinculations through their bodily stories, repairing family relations. This chapter is about returning to the importance of bodies, and bodily stories to family ties.

In between chapters, I present my family album. In it, me, my mom, aunts, and cousins introduce ourselves and our stories. This part was a family request. My family wanted to share their stories and share a little bit of themselves. They wanted that their voices were not just textual evidence of their menstrual stories but visual companions of their experiences. I decided to include this album, in the middle, at the core, on the heart of this thesis since their stories are the spine upon which this body of work is grounded. By presenting my family, the reader can put a face to each word, to each story and to each counter-story. In this sense, by exploring women's counter-storying, I am inserting myself in a long tradition of feminist scholarship (Cameron, 1990; Lakoff, 1975; Ehrlich \& King, 1994; Miller \& Swift; Spender, 1980) that aims to explore the intersection of discursive practices and material effects in women's lives, and the different forms women can use to subvert these discursive practices, even using their own bodies. By exploring mother and daughter resignifications of 
menstrual tales, I am situating their stories as discursive resistance practices that challenge and disrupt hegemonic framings of social realities.

Like any storyteller, I hope the readers can engage with the stories I am telling. However, I am aware of the fact that menstrual stories are perhaps not a suitable narrative for all. Then, I hope the reader can give me the benefit of the doubt. I hope the reader can understand that menstruation is just an excuse for writing about bodily stories, an excuse to talk about the power of telling stories intergenerationally, an excuse to tell stories about my family and the powerful potential of their stories to destabilize normative discourses. I also hope that the writing style of this research feels friendly, a little bit conversational, but also with literacy. I am not writing this thesis with fancy phrases or elaborate terminology. This thesis is directed to an audience that, like me, is more concerned with writing women's experiences as they are felt, lived, embodied, and told, than abstract conceptualizations. This thesis is an effort of hearing, feeling, and writing women's menstrual stories of resistance and situating them in conversation with feminist academic debates. But above all, this thesis is a personal effort to situate my mom's, my aunts', and my cousins' bodily stories as part of the academic body of knowledge. 


\section{Chapter I. Performance, Performativity, and Storytelling: A Frame of Analysis}

In this chapter, I present performativity and performance as interdisciplinary concepts applied in the study of storytelling. I argue that storytelling is a narrative form that encompasses both the telling of a story (performance) and the impact of the story told (performativity). Furthermore, I propose storytelling as a narrative-embodied-performance, and the stories as 'active doings' (McKenzie-Mohr \& Lafrance, 2014, p. 22) that evoke or transform reality (Berns, 2009). Through an exploration of performance and performativity theories, in this chapter I introduce storytelling as a reiterativecommunicative act with the power to either reproduce and/or subvert 'hegemonic tales.' Hegemonic tales $^{2}$ are dominant cultural narratives that are taken up as legitimate knowledge, yield power, and are regarded as truth. In most cases, they often are transmitted in imperceptible ways, which make difficult their identification and confrontation (McKenzie-Mohr \& Lafrance, 2014). Hegemonic tales are present in social institutions and proliferated by normative discourses, influencing how women story their own lives. Accordingly, in an attempt to provide a detailed examination of how, in the process of telling stories, there can be a counter-storying of hegemonic tales, I explore mother-daughter storytelling. I argue that the reiteration of their stories can lead toward a more subversive meaningmaking of their experiences.

Importantly, before introducing the term storytelling I would like to recall how I am using the concepts of 'story' and 'narrative' during this thesis. As Catherine K. Riessman suggests, it is important to pay considerable attention on how researchers employ the concept of 'personal narrative' or 'personal story', and the implication in the methodological suppositions, expectations and strategies

\footnotetext{
${ }^{2}$ By arguing the existence of hegemonic tales, I rely on two concepts -hegemonic and tales- that require further explication. The term 'hegemony' has traditionally signified domination of one sort or another (Bates, 1975). The origins of the theory of hegemony are founded in the ideas of Italian philosopher and politician Antonio Gramsci. Gramsci's ideas of hegemony were built upon the premise "that man is not ruled by force alone, but also by ideas" (Bates, 1975, p. 351). For Gramsci, without the ideological factor it would be difficult to explain the stabilization of class relations and the dynamics of structural change of whole classes. In the mid- 1980, the idea was transferred to the parallel problem about gender relations. The term 'hegemonic masculinity' was distinguished from other masculinities, especially subordinated masculinities. Hegemonic masculinity "embodied the currently most honored way of being a man, it required all other men to position themselves in relation to it, and it ideologically legitimated the global subordination of women to men" (Connell \& Messerschmidt, 1995, p. 832). In this sense and for the purpose of this thesis, I understand hegemonic as the result of the combination of both male-oriented ideological effects and dominant assumptions. In this sense, in narrative terms I refer to hegemonic tales as male-oriented storylines and dominant assumptions that need not necessarily be oppressive, but those that figure into the hegemonic category are supposed to be sexiest, classist, misogynist, and possible ethnocentric (Nelson, 2001). On the other hand, I am using the word 'tale' to denote the fictional attributes of stories. A tale can be defined as a story, especially one that might be invented or difficult to believe in a long term. As such, even when a tales carries a male-oriented storyline that presents itself as true and taken-for-granted, it also carries stories of consciousness, agency and resistance. As such, by referring to 'hegemonic tales' I address to the fictive features of male-oriented dominant narratives that can be subverted because even when they are presented as real, their fictional feature concedes spaces of resistance by questioning their veracity. In Chapter Three and Four, I will expand in further detail my definition of hegemonic tale, particularly in relation to menstrual discourses.
} 
of their analysis (Riessman, 2002). Consequently in certain sectors of the academia, the terms 'story' and 'narrative' hold different levels of interpretation. For instance, for authors such as Louise O' Brien (2010) stories are "personal accounts of experiences" whereas narratives are "structured and formal accounts containing research additions and omissions" (O'Brien, 2010, p. 18); that is, narratives are mostly used for researcher's inquiry analysis. In the same line of thought, F. Michael Connelly and D. Jean Clandini (1990) use "the reasonably well-established device of calling the 'phenomenon' story and the inquiry "narrative"" (Connelly \& Clandinin, 1990, p. 2). For Ian McGregor and John G. Holmes (1999) 'stories' and 'narratives' are absolutely the same in meaning and purpose. For Donald E. Polkinghorne (2004) 'narratives and stories' are either overlapping concepts or interchangeable in their meanings and utilization, making the distinction intrinsically difficult to sustain. Lastly, for Steven Cohan and Linda M. Shire (1988) stories, but not narratives, are events that evoke transformation.

In a different perspective, according to French philosopher Paul Ricoeur, stories function to articulate our experience of the world giving form to our experience (Ricoeur in Dauenhauer \& Pellauer, 2014). For this author a story is a structured sequence of events; that is, the content of particular arrangements of events that form a narrative. In a similar vein, American physiologist Jerome Bruner argues that humans organize their experiences and memories mainly in "the form of narrative-stories, excuses, myths, reasons for doing and not doing, and so on" (Bruner, 1991, p. 4). Accordingly for both authors, narrative is the communicative form people use to transmit stories. Thus, narratives refer to the structured sequence of events; that is, stories are the content form of a narrative. In an interesting move, Richard Menary (2008) and Daniel Punday (2003) propose that narratives are constituted by thoughts, feelings and perceptions which are anchored in the human body, affecting the way a story is told. For both authors, the human body and body experience need to have "a central role within narrative" (Punday, 2003, p. 2). As a result, the story and the experience of the body find their way out through the narrative. The authors named this entanglement 'embodied narratives', to address a narrative that "arises from a sequence of bodily experiences, perceptions, and actions" (Menary, 2008, p. 75). As such, narratives are the vehicle of communicating our embodied experiences.

Like the authors, I moved back and forth between 'narratives' and 'stories' during the theoretical framework of this research. For the purpose of this thesis, I understand on the one hand, story as the meaningful content of events; that is, a story is a fundamental form of communication that “conveys values and emotions" (O'Brien, 2010, p. 17) which brings meaning and transformation to the experience. On the other hand, I understand narratives beyond the customary idea that embrace them only as a structured and formal accounts in which events are related. In this sense, I build upon 
Menary and Punday's embodied narratives concept in order to understand women's storytelling as a narrative-embodied-performance; that is, to recognize women's bodies as the condition through which they experience the world and the narrative as an instrument to perform stories that link the body, the story, and the experience.

However, my working understanding of stories and narratives is not a definition. What I present here is a set of literature equipment to help in the understanding of how performance and performativity work together in the process of telling stories. Particularly, in a specific social dynamic: the family. In this context, it is important to pay detailed attention to how stories are embedded in a complex web of forces, power and significations, that will determinate how a story is told and the impact of this story on the family members.

\subsection{Introducing Storytelling}

Commonly, the term 'storytelling' refers to the oral communicative act of transferring stories to a determinate audience, and has been understood as an important communicative tool for understanding the complexity of human experience (Bruner, 1986). In a variety of academic areas, such as psychology, sociology, and anthropology but also in philosophy of language, literature, arts, and history, storytelling has been a relevant alternative approach for studying how values and beliefs contribute to the construction of self-identity, family, and community sense-making. Within these academic areas, storytelling has been employed as a form of understanding how humans construct and shape their lives based on their own memories. Therefore, stories became an important source of information and reveal particular values, emotions, and the uniqueness of human experiences (O'Brien, Storytelling: an approach that can help to develop resilience, 2010). Furthermore, stories reaffirm and validate the importance of personal meaning and perceptions against scientific knowledge validated as universal truth.

In outlining the position of storytelling within academia, authors such as Jerome Bruner (1991) explain that the triumph of postmodernism ${ }^{3}$ aided in storytelling being regarded as a source of

\footnotetext{
${ }^{3}$ The term postmodernism was first used in around 1970; however, its definition is not as simple to track, as it resists characterization. Postmodernism, as a philosophical movement, was a critical reaction against Western assumptions and values that situated scientific knowledge as having a universal claim to explaining the world. Jean Baudrillard, Jean-François Lyotard, Jacques Derrida, and Michel Foucault are considered the most influential early postmodern philosophers. Lyotard characterized "the Enlightenment (the narrative of progess and liberty) and science (the triumph of pure knowledge as the two master narrative of Modernity" (Herman, et al., 2005, p. 287). With the end of these grand-narratives, there is a fragmentation of history; consequently, there is no one, single story, but a multiplicity of small narratives. This fragmented perspective of history has opened up spaces for unregistered voices, exposing an estheatics of difference (Benhabib, 1995). According to feminist scholar Jane Flax, there are three constitutive elements of the postmodern idelogy: the "Death of Man," the "Death of History," and the "Death of Metaphysics" (Flax, 1990). These three elements emphasize the death of the primacy of the male subject, and with it, the claim of male history as universal. For Lyotard, the subject is replaced with a system of structures or meanings (the subject as a sign). Within feminist studies, postmodernism has been analyzed as
} 
legitimate knowledge, grounded in everyday life and social relations, within academic disciplines. Coming into use during the late 20th century, postmodernism permeated different disciplines, questioning scientific reason and logic, and the application of scientific empirical methods and technology (Bruner J. , 1991). Noticeably, the work of Jean-François Lyotard (1979), The Postmodern Condition: A Report on Knowledge, has been truly influential for questioning the scientific paradigm based on 'metanarratives. ${ }^{4}$ Lyotard calls for an incredulous, postmodern turn against universally valid narratives of historical events, knowledge, practices, and experiences based upon the appeal of general claims, giving preference to the multiplicity of "performed knowledge's that are competing with one another, changing the question from what is true to what knowledge is been used for" (Herman, Jahn, \& Ryan, 2005, p. 287). These small narratives (or petit récits in Lyotard's terms) can replace the hegemonic truths of the grand ones.

Given the importance of the 'postmodern turn,' many disciplines examine how narratives can be used as instruments for constructing and communicating meaning and knowledge. For instance, within anthropology and history, storytelling has proven to highlight the importance of introducing the voices, stories, and perspectives of disadvantaged and underrepresented people (Bauman, 1984; Clifford \& Marcus, 1986). In social psychology, storytelling has helped to understand how narratives aid in transferring knowledge, paying detailed attention to human intention within a temporal and social momentum (Bruner J. S., 1986); in narrative therapy, storytelling has shown how stories construct identity (Polkinghorne, 2004). In sociology and communication studies, storytelling is understood as a powerful source of human communication (Langellier, 1999; Menary, 2008), and within feminist studies, storytelling has revealed in what ways knowledge, truth, and reality are traditionally studied, constructed, and transmitted as if they were exclusively men's experiences (Rosaldo and Lamphere, 1974; Rubin, 1975; Personal Narrative Group, 1989).

Accordingly, storytelling is inherently interdisciplinary and is an extension of the "narrative turn $^{5}$ in the social sciences. In this sense, literary theorists have built upon linguistics, history,

an uneasy alliance (Benhabib, 1995). According to Jane Flax and Seyla Benhabib (1995), the alliance between postmodernim and feminism must be carefully read. If feminists go for the appeal of the "Death of Man" proposal, it would be difficult, according to Flax, to think on an emancipatory feminist project for women if the subject is no longer considered an agent, but a sign embedded in structures of meanings.

${ }^{4}$ The term metanarrative refers "to a pre-existent social-cultural forms of interpretation. They are meant to delineate and confine the local interpretation strategies and agency constellation in individual subjects as well as in social institutions" (Herman, et al., 2005, p. 287).

${ }^{5}$ As Matti Hyvärinen argues, the rhetoric of the concept 'turn' suggests some significant changes in the practice of a research field and its theorization. Specifically, the concept 'narrative turn' refers to the significance of language and story in the production of identities, communities, and histories (Hyvärinen, 2010). As previously stated, in the 1980's postmodernism was fundamental in the increasingly critical attitude towards metanarratives being the solely legitimite source of truth and knowledge. Relying on social constructionism, which understands the fundamental roles of language and communication in unfolding the ways in which individuals and groups construct and perceive their social reality, the 'narrative turn' has played an important role in situating stories as objects of study themselves. In her article (2010), "Revisiting the Narrative Turns," Matti Hyvärinen identifies and analyzes not one but four forms of narrative turn within academia (literary, historiography, social sciences, and cultural narrative turn), emphasizing how the concept of 
anthropology, philosophy, and sociology, emphasizing the importance of storytelling to capture the complexity of meaning within stories (Mitchell \& Egudo, 2003). Since storytelling focuses on how individuals or groups "make sense of events and actions in their lives through examining the story, and the linguistic and structural properties" (Riessman quoted in Mitchell \& Egudo, 2003, p. 5), literary theory has made the 'story' itself the object of its analysis.

In order to study a 'story' as a central narrative structure, literary theory has borrowed from the work of socio-linguistic scholars, such as J. L. Austin's (1979) performative speech act, Jacques Derrida's (1972) speech iterability, Michel Foucault's (1972, 1981) discourse formations, and Judith Butler's $(1997,2011)$ citationality and performativity, as these are narrative structures that help to situate and treat stories as 'active doings' (McKenzie-Mohr \& Lafrance, 2014); that is: stories that do things (Austin, 1979). With these interdisciplinary assemblages, literary theory studies storytelling as a communicative act that evoke or transform reality through performativity (Berns, 2009). It is precisely of particular relevance for this thesis to explore women's stories are capable of triggering new meanings and signifiers.

Feminist linguists, predominantly feminist sociolinguistics scholars have studied women's narratives, taking into account the dominant framings that constrain women's stories. In daily life, women and men routinely take up dominant stories that privilege normative forms, experiences, and meanings, thus reflecting gendered labor divisions and gendered expectations (McKenzie-Mohr \& Lafrance, 2014). Consequently, hegemonic tales of childbirth, marriage, menstruation, abortion, and menopause, among others, can work as naturalized and normalized stories, serving to maintain "existing ideologies and hegemonic relations of power and inequality" (Ewick \& Silbey, 1995, p. 212), thereby nourishing the status quo of dominant ideologies. Since the family is the first social and political organization of sexuality, reproduction, motherhood, and sexual division of labor, the family is a dominant frame that constrains women's stories. Consequently, the next section explores family storytelling as an important source for understanding how certain stories reproduce asymmetrical sex roles and gender norms that influence women's experiences.

\subsubsection{Family Storytelling.}

Storytelling is a communicative act by which people make sense of their experiences. Storytelling involves communication processes such as, "remembering and forgetting stories; interpreting, reinterpreting, and emphasizing what has been marginal or muted; sedimenting and innovating

\footnotetext{
'narrative' does not simply travel from discipline to discipline, but it is radically re-created and re-evaluated (Hyvärinen, 2010). For
} more detailed consultation, refer to this source. 
meanings; and aestheticizing and dramatizing 'bits' of [personal] experience” (Langellier \& Peterson, 2006a, p. 111). Generally, a storytelling carries a 'story content,' which is “formed in the struggles over meanings for particular events, acts, and identities, and such content is performed as it is told and retold" (p. 111) Therefore, stories are rooted in the social, marked by historical context, and shaped by the cultural discourses that are adapted to the person's own experiences. As a result, storytelling is embedded in peoples' daily lives, families, and communities. Predominantly within the family, ${ }^{6}$ storytelling is a communication act in which family members remember, transmit, enhance, and innovate stories through generations (Langellier \& Peterson, 2006a). Family storytelling is a way of making sense of experience as "a means to encode familial images and abstractions in stories, and as part of an ongoing struggle to create and maintain a coherent system of meanings through narrative" (Langallier \& Peterson, 2006b, p. 99). According to Leanne O. Wolff, family storytelling meets three essential needs: 1) persuading the members of the family that they are special; 2) teaching about ways of the world and the family's methods of coping with troubles and success; and 3) helping a person know their identity (Wolff, 1993). As a result, family stories shape the lives of its members.

Family stories become important vehicles in determining its members' lives by perpetuating "rituals, rites, customs and beliefs that give a pivotal sense of meaning and direction to a person... [stories] govern the way we see 'reality' and behave" (Keen, 1998, p. 42). The strongly formative power of the stories, and the specific ways in which they shape the family members' experiences, make each generation "unique and unmistakable" (Reulecke, 2008, p. 123). Therefore, family stories are intergenerational. With the term intergenerational, I describe not only the narrativized transmission of historical knowledge from one generation to the next (Svob \& Brown, 2012), but also the influence of parents' own practices and attitudes on the behavior of next generations.

Intergenerational storytelling implies at least three generations: grandparents, parents, and their children (Davies \& Fitchett, 2015). Each generation, according to Jürgen Reulecke, "makes its decisions based on the rich experience it is carrying forward and that which it has accumulated itself," provoking stimulating changes in how stories are told (Reulecke, 2008, p. 124). Intergenerational storytelling assures that stories and practices are transmitted across generations. Here, it is important to point out that I am addressing intergenerationality in line with Iris van der Tuin's (2015) conceptualization of the concept. For Van der Tuin, intergenerationality is often approached in a negative perspective (Van der Tuin explores the negative meanings of the term in Clare Hemmings'

\footnotetext{
${ }^{6}$ I am using the the concept of 'family' from a communication approach, which defines family, "as a small group culture created, expressed, and mantained in interaction" (Langellier \& Peterson, 2006a, p. 110). In this approach, families are the result of their own stories, rituals, convesations, and routines of daily life. Consequently, there cannot be a single definition that captures the complexity of meaning, construction, and identification of a family. Furthermore, the assumption of the monolithic family is contested when we recognize that families are not a natural phenomenon, but like stories, they are socially and culturally constructed.
} 
book, Why Stories Matter: The Political Grammar of Feminist Theory), and she pleads for a more positivistic approach that understands not only the 'generational features' (i.e. age, context), but the 'generative' results of them; that is, the active and thus transformative notion of intergenerationality.

Due to the importance of family storytelling as a vehicle for attitudes and beliefs, attention to its formative de-formative, and transformative powers upon family members is in order. According to Langellier and Peterson (1993), family stories can act as a form of "social control" that may "legitimate forms of reality and meanings" (p. 57) for family members. In this regard, family stories can create structures of subordination that situate women within a sex/gender system. Within feminist analyses, family sex/gender structures have been studied by different scholars: Adrianne Rich (1986) has analyzed family as a regulator of heterosexuality and marriage; Nancy Chodorow (1978), mothering as a continuum of reproduction; Margrit Eichler (1981), gender as a sexual division of labor; or Joyce Trebilcot (1983), family as an promoter of maternal instinct. Consequently, it is necessary to pay detailed attention to how women transmit their stories within a family-gendered context.

In this sense, it is particularly important to question what kinds of stories are transmitted, what these stories are, how they shape women's lives, and why they matter. In an effort to answer these questions, and drawing the introduction to a close, in the next section, I will critically engage with women's storytelling, particularly mother and daughter storytelling, in an attempt to provide a detailed examination of how, in the process of telling stories, mothers and daughters re-story ${ }^{7}$ and counterstory $^{8}$ dominant discourses, and move toward a more liberatory meaning-making of their stories.

\subsubsection{Women's Stories in a Family Context.}

Women's stories are part of specific social, cultural, and historical contexts. Their stories are those that shape their telling, their meaning and effects. Furthermore, stories are "constrained by rules of performance and norms of content” (Ewick \& Silbey, 1995, p. 2006); thus, stories' structures, content, and performances "are defined and regulated within social settings" (Ewick \& Silbey, 1995, p. 2006).

\footnotetext{
${ }^{7}$ I am using the word 'story' as a verb rather than to 'narrate' in order to make reference to the act and power of narratives to create and embody stories. When women's 'story' their lives, they are making meaning of their body experience. Thus, 'story' as a verb encompasses both the story and the embodiment in the process of telling a story. Following Donna Haraway's notion of worlding as acting in the world, not standing outside looking at it; storying involves acting in the story from within, wherein the practices and performances we are storying and the story itsefl comes into being. As Haraway describes: "It matters what matters we use to think other matters with; it matters what stories we tell to tell other stories with; it matters what knots knot knots, what thoughts think thoughts, what ties tie ties. It matters what stories make worlds, what worlds make stories" (Haraway D. J., 2013).

${ }^{8} \mathrm{I}$ am using the word 'counter-storying' as a verb to make reference to the act and power of narratives to recreate and subvert dominant narratives. When women's 'counter-story' their lives, they are making new re-signification and re-appropriation of meanings and practices.
} 
Normally, these norms have the hegemonic potential to contribute to the reproduction of existing structures of meaning and power.

As argued at the beginning of this chapter, stories are embedded in what I have described 'hegemonic tales' as culturally male-oriented narratives that articulate and reproduce "existing ideologies and hegemonic relations of power and inequality" (Ewick \& Silbey, 1995, p. 212). Because hegemonic tales are born in social and cultural contexts, they wield power and they "are often hard to see until you look under the covers - they are normally labelled as common sense and therefore become invisible in everyday life" (Harris, Carney, \& Fine, 2001, p. 8). As such, hegemonic tales are ubiquitous, they become unconsciously internalized and taken for granted. Consequently, by referring to hegemonic tales I address to dominant storylines and cultural assumptions that because they are male-oriented and power-unbalanced, they tend to be sexiest, classist, and misogynist (Nelson, 2001).

Particularly in a family context, hegemonic tales are dominant stories developed through conversations, shaping how family members construct and constitute what they see, feel, think, and do (Ewick \& Silbey, 1995). It is to take a particular discourse or practice as accepted within the family culture, which appears to represent reality, and never question it. In this sense, since mothers and daughters are part of a specific social, cultural, and historical context (the family), women's narratives are situated in concrete dominant discourses. As a result, taking into account mothers' and daughters' storytelling is especially helpful for understanding how women's practices are located within under normative hegemonic tales.

\subsubsection{Mother and Daughter Storytelling.}

Significantly, mother and daughter stories are embedded in "tensions between constructing canonical stories and deconstructing them" (Langellier \& Peterson, 2006a, p. 112). Mothers and daughters present family stories from different generational perspectives. On the one hand, mothers transmit to their daughters various types of canonical stories that provide a sense of the structures of sex/gender subordination. On the other, daughters internalize them as their own and often transfer them to their own daughters (Davies \& Fitchett, 2015). As such, daughters are frequently influenced by their mothers stories, "either mimicking or by actively resisting them" (Davies \& Fitchett, 2015, p. 729-30) within a generation system.

In this sense, mother-daughter storytelling makes evident how hegemonic tales are told and retold, privileging normative forms, experiences, and meanings (childbirth, marriage, menstruation, menopause), and muting marginalized or closeted "nontraditional experiences" (abortion, divorce, homosexuality) (Davies \& Fitchett, 2015, p. 112). As such, mother-daughter personal narratives are 
"stories of how women negotiate their "gender status both in their daily lives and over the course of a lifetime" (Personal Narrative Group, 1989, p. 4). Mother-daughter stories provide a setting in which it is possible to explore how families develop and endure myths and practices, how they become structured and enacted into everyday practices, and how mother-daughters negotiate gendered norms, values, and expectations.

To approach mother-daughter storytelling is to focus on how lived meanings are transmitted within and through generations. In this sense, it is important to pay attention to the forms in which women tell stories and how the story of the experience is told, in order to understand to what extent women reiterate norms and discursive conventions (Langellier \& Peterson, 2004). The combination of the process of telling (performance) and the impact of the stories told (performativity) opens up a pathway to approach women's storytelling as a two-step process: first, as an embodied act in which the storyteller is embedded in the experience of telling and performing the story; and second, as an reiterative act with the potential of disrupting discursive constraints in order to give rise to new possibilities of meaning and re-significations. Accordingly, the next section engages with both the performance and the performativity of women's storytelling. First I explore how women embody related experiences. Then, I explore how stories' performativity shows potential for creativity and resistance, with the capacity to subvert practices, norms, and conventions.

\subsection{Performing Women's Narratives}

In "Personal Narrative, Performance, Performativity: Two or Three Things I Know for Sure" (1999), Kristin M. Langellier opens up her essay suggesting a provocative question, what do performance and performativity contribute to doing and studying family storytelling? For Langellier, storytelling is a communicative act that requires 'the performative 'doing' of storytelling with what is 'done' in the performance of a story" (2004, p. 2). Implicit across this idea is the assumption that stories matter, because they $d o$ things. Stories are more than a reflective experience; they are constitutive and performative since stories produce what they name (Butler, 2011). In the author's words,

Performing narrative constitutes the event and conditions to communication, not as a singular or intentional act but as a reiterative practice by which discourse produces the effects it names. Performing narrative focuses on doing things with words and asking what difference(s) it makes to do it. (Langellier \& Peterson, 2004, p. 3) 
In performing a narrative, the story is an event (an occurrence happening at a determinable time and place) that acts in a two-way process. On the one hand, narrative performance is how the story is told, that is, how this speaking is embodied in the experience of someone. On the other hand, the performativity of the story relies on "doing things with words" (Austin, 1979), wherein the story transforms the person's experience. That is, "stories do something as a discourse in the social world" (Langellier, 1989, p. 265). In order to analyze how women's storytelling is performed within a family context, Langellier and Peterson develop a two-fold approach for analyzing the performance of narrative: 1) as embodied narrative; and 2) as discursively regulated. (2004, p. 8). Analyzing these aspects will help to understand how bodily performance affects the narratives women tell, how women use their bodies, and/or how women are constrained by them.

\subsubsection{Narrative Embodied Perfomance.}

Women undoubtedly live with their bodies, and these bodies inevitably shape their lives and the stories they tell about those lives (Heavey, 2015, p. 432). Women's storytelling takes place in the context of "bodily participation" (Langellier \& Peterson, 2004). In this sense, "when the body is the source and topic of stories, even if it is presented as only a tangential topic, it is crucial to acknowledge that that body is more than those stories" (Heavey, 2015, p. 432). Consequently, the body is more than just the object of the story; the body becomes the condition that molds women's perceptions of the world, shaping the stories women tell.

Within narrative theory, bodily participation has been studied predominantly from a phenomenological perspective. ${ }^{9}$ In this approach, the body is in constant relation with others and with the world. This body represents a 'lived-body'; that is, a body that "is not just one thing in the world, but a way in which the world comes to be" (Leder, 1998, p. 123). Thus, the 'lived-body' presents itself as a site of knowledge, experience, action and intention (Leder, 1998). In other words, experience is embodied. Particularly within feminist phenomenology, women's embodied experiences require a specific "horizon of speaking, listening, and feeling -a lived unity of bodily participation" (Langellier \& Peterson, 2004, p. 11). For instance, to Iris Marion Young (1990), women's bodily experiences need to be understood as different kinds of engagements with the world. In her account, the modalities of feminine ${ }^{10}$ bodily comportment and motility are fundamental to understanding not only women's

\footnotetext{
${ }^{9}$ In Chapter II, I will explore in further detail the main philosophical concepts and notions in phenomenology. Particularly, I will consider phenomenology as an approach for conducting research. That is, I will expand the craft of conducting phenomenological research, both as approach and methodology.

${ }^{10}$ Iris Marion Young refers to the 'feminine' not as the mysterious quality or essence that all women have by virtue of their being what is considered as biologically female. But rather, as "a set of structures and conditions that delimit the typical situation of being a woman in a particular society, as well as the typical way in which this situation is lived by the women themselves (Young, Throwing like a Girl
} 
lived experiences, but also women's oppression. Consequently, feminist phenomenology describes the modalities of feminine bodily existence for women in society.

In effect, women's narratives occur within feminine bodily practices, and it is precisely this particular embodiment that makes possible the representation of the body in the narrative. Thus, feminine bodily experiences and the bodily participation are the context upon which the narrative is performed. Therefore, women's narratives are shaped by both: the women's bodies and their circumstances. Furthermore, because telling a story is not a bodiless act, the body becomes the instrument with which the narrative is performed (Heavey, 2015). Thus, "[t]he body of the storyteller takes up some part of bodily activity (such as the perception of the event) and moves it to another activity of the body (such as the performance of the story)" (Langellier \& Peterson, 2004, p. 9). In other words, in performing women's narratives, experiences and stories meet in an embodied entanglement.

As noted at the beginning of this chapter, Punday (2003) and Menary (2008) denote as 'embodied narratives', the narratives that arise directly from the lived experience of the narrator. The authors argue that a story cannot escape from the bodily experience (Menary, 2008). As a result, narratives are the primarily form in which the body becomes what of the story rather than the how (Punday, 2003). In reflecting upon this idea, Emily Heavey describes women's embodied narratives as a "process of constructing, performing, and making meaningful [women's] own body in the narrative one tells about it" (Heavey, 2015, p. 430). The author focuses on how storytelling "constructs women's embodied experiences, and their bodies themselves in the narratives they tell" (Heavey, 2015, p. 430). Heavey calls this process "narrative embodiedness" to point out that when women tell stories, they are talking "explicitly or implicitly about their bodies, [and] they are also constructing and performing versions of those bodies" (p. 434). The strength of this argument resides in its subversive potential. As it will be explained in detail in the following sections, if stories do something in the world, they can also undo it through the same narrative they are telling. That is, if embodied narratives "constitute identities and experiences, producing and reproducing that to which it refers" (Langellier, 1999, p. 128), they can also enact and perform other meaningful significations of their experiences.

Understanding women's stories as a narrative-embodied-performance, is to recognize women's bodies as the condition through which they experience the world. It is to comprehend that when women talk about their stories, they are inevitably and inescapably talking about the body as "site of the possibility of reconfiguring the hegemonic symbolic, imagining a future horizon that 
values the body differently" (Bordo, 1998, p. 85). Thus, embodied narratives open up the possibility to question to what extent dominant discourses affect how women's story their embodied experiences, and the ways women's can change the meanings of their experience.

\subsubsection{Narratives as Discursively Constricted.}

Stories are also constricted by immaterial circumstances that locate the narratives within particular contexts and temporalities. Conditions such as history, time, language, family, and culture impact the way a story is understood and related. Langellier and Peterson (2004) define "constraint" as the "boundary that defines the condition of what is possible. A constraint is not merely a constriction or and obstruction... constraint both facilitates and restricts possibilities for expression and perception" (p. 14). Here it could be questioned, until what point do immaterial constraints limit or enable the process of an embodied narrative?

Michel Foucault's notion of regulatory discourses serves to frame the immaterial circumstances that constrain or enable how a story is told. In The Order of Discourse (1981), Foucault argues,

in every society the production of discourse is at once controlled, selected, organised and redistributed by a certain number of procedures whose role is to ward off its powers and dangers, to gain mastery over its chance events, to evade its ponderous, formidable materiality. (Foucault, 1981, p. 52)

In this sense, discourse reveals power and desire acting together. Since discourse is not simply that which manifests desire, but also is the object of that desire, discourse manifests itself as a "system of domination" (Foucault, 1981, pp. 52-3). Discourse is what exercises power, therefore discourse is the power that needs to be regulated.

For Foucault, any speech is embedded with discursive practices and discursive formation (Foucault, 1981), that is, particular institutions that establish orders of truth to regulate and validate the veracity of discourse within society. Foucault distinguishes two systems that control and limit discourse, acting upon the interior and the exterior of society: in the exterior, there is a 'principle of exclusion,' (Foucault, 1981, p. 56) not strictly as a prohibition but more as a rejection of discourses considered null and void, not fitting into what it is considered the truth. In the interior, discourses exercise control over themselves through interior procedures, which function as systems of classification, ordering, and distribution, locating discourse's regularities (repetition and sameness). Foucault calls this series. Both internal and external systems work to limit discourse acting as a regulatory power that produces normative means, by which discourse is produced. 
Foucault identifies a third discursive system of control. Yet, this time, this regulatory system does not control discourse, but the individuals who hold it. Foucault calls these regulatory limits rituals. A ritual "defines the qualification which must be possessed by individuals who speak...; it defines the gestures, behaviors, circumstances, and the whole set of signs which must accompany discourse" (Foucault, 1981, p. 62). All these systems give rise or limit discourse, offering the "possibilities of its existence" (Foucault, 1981, p. 63); that is, the fact that discourse has the power to enact what it names not only gives discourse the capacity to create reality, but also to legitimate the individual who has the power to enunciate discourse.

The importance of taking into account the immaterial constraints in storytelling relies on taking “context as seriously as [a] text ... social relations of power as seriously as... individual reflexivity, and... therefore examin[ing] the cultural production and reproduction of identities and experiences" (Langellier, 1999, p. 128). Family storytelling takes part within constricted discourses, meaning that power works as the regulatory and normative means by which stories are enacted. Particularly, women's personal stories within a family context are embedded within a dominant ideology that conditions their existence. Consequently, women's storytelling within the family is "situated not just within locally occasioned talk- a conversation, public speech, ritual, but also within the forces of discourse that shape language, identity and experience" (Langellier, 1999, p. 127).

Accordingly, family stories transmit and produce power by "intervening in the ways culture produces, maintains, and transforms relations of identity and difference" (Langellier \& Peterson, 2004, p. 3). However, intergenerational storytelling is not only the reiteration of constricted practices and discourses. As Foucault asserts, discourse "also undermines and exposes it [power], renders it fragile and makes it possible to thwart it" (quoted in Langellier \& Peterson, 2004, p. 25). Bringing in Iris van der Tuin's (2015) notion of "generativity," this allows to understand how, within intergenerational storytelling, new discourses "come into being" (Tuin, 2015, p. xvii). This translates into a more progressive narrative that, even when shaped by social constraints, its transformative possibilities are not limited by its meanings. Consequently, intergenerational storytelling has a "generative force" (Tuin, 2015, p. xx) while performing that undoes the dominant stories it is embedded. In order to fully understand the generative force of performativity, the next section introduces the genealogy of performativity and its disrupting potential.

\subsection{Performativity Of Women's Stories}

At the beginning of this chapter, I referred to stories as "active doings" (McKenzie-Mohr \& Lafrance, 2014) to denote the performativity of stories. The concept of performativity is used here to suggest 
stories' capacity of performative utterances; that is, in saying a story, the story does something in the world (Austin, 1979). Consequently, telling a story is a performative act in which a story becomes an active force, an active doing. As such, in this section I draw on the work of the linguistic philosopher J. L. Austin (1979) and Arthur W. Frank (2010) to present how language is used performatively, meaning that language consists of performative doings: in saying something we perform the action (Austin, 1979). Then I explore feminist philosopher Judith Butler's concept of performativity, emphasizing how language consists of performative utterances when discourse becomes social practice, or, in other words, stories become actions. I rely on Butler's (2011) idea of 'gender' as a reiterative and citational practice to suggest stories' capacity for subversion.

\subsubsection{Stories as Active Doings.}

The performativity of words has its origins in the 'speech act theory' of British philosopher of language J. L. Austin in his perhaps most influential work, "How to Do Things with Words" (1979). Here, Austin differentiates between a "statement" that describes and one that commands. The first is called a "constative statement" (words that just say something), and the latter is "performative" (words that incite action). Austin exemplifies the differences with words such as 'good' or 'all,' in contrast to 'I do' or 'I name,' wherein the first ones "describe my doing," and the second, "the state that I am doing it: it is to do it" (Austin, 1979, p. 6). In other words, a constative act of speech is an utterance that just $i s$, whereas a performative speech is an utterance that does, acting directly upon the world.

In addition, Austin cautions that it is not always easy to distinguish a performative utterance from a constative one. There is a difference in "how many senses there are in which to say something is to do something, or in saying something we do something, and even by saying something we do something" (Austin, 1979, p. 94). For Austin, the act of 'saying something' is a locutionary act, that is, saying something with a certain meaning in a customary fashion. In performing a locutionary act, we are doing an illocutionary act, that is, the performance of an act in saying something. In other words, in saying something, we are doing something. Furthermore, the way we use the meanings and effects of the speech act are an illocutionary force, that is, the speaker's intent of the act of speech (Austin, 1979). Lastly, Austin names perlocutionary acts as those acts that "bring about or achieve by saying something, such as convincing, persuading, deterring, and even, saying, surprising or misleading" (Austin, 1979, p. 109). Perlocutionary acts have a direct influence on the actions and meanings affecting either the speaker or the listener. That is, they influence on a psychological level, provoking consequences (i.e. convincing, scaring, inspiring). 
Following Austin's work, within narratology, a story is a speech act that sets actions: stories do things as well as have meaning. Since stories do something in the world (Langellier, 1989), the performativity of stories is emphasized in their capacity of materialization. In his book Letting Stories Breathe. A Socio-Narratology, Arthur W. Frank (2010), builds upon the work of Sharon Traweek and Donna Haraway to situate stories as material semiotic companions. The author explains his statement by quoting Law's work. He underlines:

Donna Haraway and Sharon Traweek teach us that when we tell stories these are performative. This is because they also make a difference, or at any rate might make a difference, or hope to make a difference [...] To put differently: stories, effective stories, perform themselves into the material world -yes, in the form of social relations, but also in the form of machines, architectural arrangements, bodies, and all the rest. This means that one way of imagining the world is that it is a set of (pretty disorderly) stories that intersect and interfere with one another. It means also that these are, however, not simply narration in the standard linguistic sense of the term (quoted in Frank, 2010, p. 42).

What Frank is proposing is a shape-shifting capacity of stories. Stories are not only words, they do something in the word because they take the form of objects, which are known as "materialized stories" (Frank, 2010, p. 43). He argues that stories are 'material semiotic companions' (p. 42); semiotic beings that not only do something in the world but they can actually take material forms. Frank beautifully writes: "[s]tories are made of air but leave their mark" (p. 43).

As such, stories can shape and legitimate dominant forms of reality. As a result, stories as active doings participate in discursive fields, producing, maintaining, and reproducing power structures. Stories can be material companions in "a wider network of power relations" (Langellier, 1989, p. 267), leaving their mark as "ideological device[s] to legitimate the meanings of dominant groups and the status quo of habitual and established practices" (Langellier, 1989, p. 267). However, as shape-shifters, stories can also take different and unique forms in every narrative performance, creating new continuities and transformations of their meanings. In this frame, storytelling's performativity presents itself as a reiterative practice that creates fissures or constitutive instabilities (Butler, 2011, p. xix) in the stories, which transgress, delegitimize or contest dominant discourses. 


\subsubsection{Stories' Performativity.}

To focus on performativity is to build upon the work of Butler's (2011) Bodies That Matter: On the Discursive Limits of "Sex", in which Butler develops a new paradigm within performative and speech act theory, suggesting that sex/gender is constructed through a repetitive performance of discourse. In this frame, 'sex' is constructed through regulated practices or norms (e.g., discourse regimes) that materialize "'sex" and achieve this materialization through a forcible reiteration of those norms. That this reiteration is necessary is a sign that materialization is never quite complete, that bodies never quite comply with the norms, by which materialization is impelled" (Butler, 2011, p. xii).

The relation between performativity and materialization relies on understanding performativity "not as a single or deliberate 'act', but, rather, as the reiterative and citational practice by which discourse produces the effects that it names" (Butler, 2011, p. xii). Consequently, gender performativity can be read as a repetition of acts or an imitation of the dominant conventions of gender discourse that materialize sexual difference (Butler, 2011). For Butler, gender identities are constructed and constituted by discourse; this suggests that there is no gender identity that precedes language. Butler argues, "[f]or if gender is constructed, it is not necessarily constructed by 'I' or a 'we' who has not been submitted, subjected to gender, where gendering is, among other things, the differentiating relations by which speaking subjects come into being" (Butler, 2011, p. xvi). There is no subject outside language since identity, sex, and gender are reiterative practices caused by the power of discourse. Since language and discourse "do" gender, gender identity is performative.

Important to consider in Bodies That Matter, is Butler's potential for subversion. Butler assigns the title, "the contentious practices of "queerness'," to specific reiterative practices that work "not only as an example of citational politics, but as a specific reworking of abjection into political agency that might explain why 'citationality' has contemporary political promise” (Butler, 2011, p. xxviii). To constitute this argument, Butler builds upon Derrida's characterizations of the "iterability" 11 in speech

\footnotetext{
${ }^{11}$ In the opening essay, "Signature Event Context," in Limited Inc (1977), Jacques Derrida offers an interesting critique to Austin's performative act of speech. According to Derrida, "Austin's notions of illocution and perlocution do not designate the transference or passage of a thought-content, but, in some way, the communication of an original movement (to be defined within a general theory of action), an operation and the production of an effect" (Derrida, 1972, p. 13). In other words, Austin does not take into account the 'context' in which the act of speech performs. For Derrida, context can never be determinable, since speech acts work through a potential of never-ending 'iterability' (Derrida, 1972), that is, the endless repetition of speech acts within a discursive history that has lost its original context (Hall, 2000), if ever even was one. Derrida points out that in order to understand written communication, the signs (words) must be repeatable and repeated in different contexts and different circumstances. In this sense, the very act of citing and reiterating a sign brings about its performative utterance, which is the primary function of language. Consequently, the importance of Derrida's 'iterability' resides in emphasizing its alterative faculty within discursive practices, which can fracture, fissure, and subvert the dominant forces that exert the most control over a discourse. With this linguistic move, borrowing the words of Kira Hall, we are entering what might be called, "the second generation of the performative linguistic studies" (Hall, 2000) with Judith Butler's notion of "performativity" as a form of gender citationality.
} 
acts, and moves her own theory from performativity to "citationality." Here, Butler refers to subversive practices whereby gender performatives are 'cited,' and by revealing the citationality of discourse, Butler presents a failure in the materialization of bodies, provocatively suggesting that gender can be subverted.

Butler argues that the repetition of discourse in the same conventional forms produces stable, hegemonic discourses as the norm. However, the 'citationality' (a reiteration of) of discourse also involves 'iteration,' producing the possibility of change. Butler describes these changes as gaps and fissures, that is, "the constitutive instabilities in [the] constructions, as that which escapes or exceeds the norm, as that which cannot be wholly defined or fixed by the repetitive labor of the norm" (Butler, 2011, p. xix). In other words, performativity as citationality produces fractures that help to identify the means through which discourse produces its effects.

Within feminist storytelling, Butler's account of performativity recognizes the power of performativity as a citational practice. Butler argues: "Within speech act theory, a performative is that discursive practice that enacts or produces that which it names" (Butler, 2011, p. xxi). In this sense, performativity situates, on the one hand, stories within social relations of gender, sexuality, class, race, age. On the other hand, it contextualizes stories within the politics of discourse, that is, "institutionalized networks of power relations" (Langellier, 2001, p. 51), such as: the law, religion, or the family. By adding performativity to personal stories, Langellier and Peterson (2004) highlight "the way speech acts have been extended and broadened to understand the constitutiveness of performance. Through performativity, storytelling can rupture or reaffirm the sedimentation of discourse in lived experience" (p. 26).

The potential of Butler's linguistic performativity in storytelling relies on understanding the potentiality of stories. If stories can transmit, reproduce, and legitimate hegemonic discourses, they can also expose, reveal, revise, and disrupt them. In this sense, if women's stories do something in the world, they can undo it too (Langellier, 1989). Paraphrasing Butler, women's stories not only take place in time, but are temporal processes that operate through the reiteration of discursive norms. Stories are both produced and destabilized in the course of their reiteration (Butler, 2011, p. 10). At some point, women's experiences create gaps and fissures that create new meanings in contingent and destabilizing ways. Given the reiterative or subsequent retelling practices in the process of telling their stories, women's storytelling opens up a pathway through which it is possible to understand stories within a different framework "of embodiment, or social relations, or ideological interpellations, of emotional, and political effects" (Langellier, 1999, p. 130). Furthermore, analyzing storytelling's performativity situates women's narratives as "a site for understanding and intervening in the ways culture produces, maintains, and transforms relations of identity and difference" (Langellier \& 
Peterson, 2004, p. 3). Consequently, approaching mother-daughter storytelling as a performative process helps to understand how their stories are shaped by hegemonic tales, but not limited in reshaping their meanings.

\subsection{Disrupting Hegemonic Tales}

As previously discussed, stories' performativity can destabilize discourses in the course of this reiteration. The reiterative practice of stories creates gaps and fissures that allow for questioning the idea that discourses are transparent and fixed in meaning. Furthermore, the performative faculty of stories can subvert the dominant forces that exert control over them. In this sense, the repetition of stories brings about its performative capacity of transgression. As such, in this section I propose that intergenerational storytelling can function as a form of repetition that highlights the different and conflicting views each generation has of certain family stories, practice, or ritual. This implies that stories' performativity enables mother-daughter intergenerational storytelling to subvert hegemonic tales. But how do they do it? In the following section, I discuss how intergenerational storytelling helps to trigger "new signifiers and meanings beyond the present act itself" (Saloul, 2009, p. 143), and through this, a possible change of the meanings of women's stories.

\subsubsection{Retelling and Retold the 'Same Stories'.}

In his book Conversational Narrative (2000), English linguistic Neal Norrick explores the extent to which it is possible to retell the 'same story,' and what can be learned from such retellings. Following Polayni's (1981) ideas, Norrick asks whether it is possible "retelling the same story twice," (Norrick, 2000 , p. 68) and what is gained or lost at the moment of retelling. In this sense, Norrick, along with Polayni, sets out to understand the existence of an underlying semantic structures and script (Norrick, 2000): a core structure that is repeated.

In narrative terms, repetition refers to the process of 'restarting' and 'rephrasing' in conversational narratives (Norrick, 2000, p. 58). Repetition plays an important role in "establishing patterns and rendering structure recognizable" (Norrick, 2000, p. 57). Repetition helps to find a current word or phrase in the story highlighting how they perform in different environments; that is, how a story repeats and reformulate itself within different contexts, purposes, tellers and audiences. In the same line of thought, in On Stories, Richard Kearney (2002) argues that since stories never end, for there is always someone telling a story, stories are always recreating themselves. He retakes Aristotle's 
mimesis concept ${ }^{12}$, that is, "mimesis re-enacts the real world of action by magnifying its essential traits. It remakes the world, so to speak, in the light of its potential truths" (Kearney, 2002, p. 131) to the storytelling. Kearney takes mimesis as a form 'retelling', that is, the power of re-creating stories as possible words (Kearney, 2002).

According to him, the act of mimesis "involves a circular movement from action to text and back again - passing from prefigured experience through narrative recounting back to a refigured lifeworld" (p. 133). In the act of mimesis the story is retelling, and in doing so, a certain 'gap' appears "demarcating the narrated word from the lived one, opened up the fact that every narrative is told from a certain point of view and in a certain style and genre" (p. 133-134). Retelling thus, is never literal as it is figurative since retelling involves "certain selection, sequencing, emplotment and perspective" (p. 136). Consequently, telling and retelling always contain gaps presupposing the performativity of the narrative act.

Intergenerational storytelling fulfills an important feature in stories' performativity. As generations tell their experiences, they are rewriting the past, and openly contradicting the indisputable practical realities of present discourses. As Norrick (2000) argues,

retelling and retold stories have special heuristic value for our understanding of narrative processes. Correlating multiple performances of the same story will reveal which elements of the basic narrative remain stable and which vary with the particular narrative context, thereby providing empirical support for recognizng a range of strategies by which the tellers shape memory into contextually appropriate storytelling performances (Norrick, 2000, p. 67).

Intergenerational storytelling shows that telling stories through generations implies that "the retold story is, firstly, likely to differ from the initial telling because of differences in the audience's understanding and interests which requires that the talk is tailored for the occasion" (Lambrou, 2014, p. 36). As a result, in intergeneration storytelling the same story cannot be repeated twice, which create fissures on the story and the beginning of a new one. By examining intergenerational storytelling, it

\footnotetext{
12 The term mimesis is derived from the Greek word mimesis which means to imitate. Plato and Aristotles positioned within the sphere of aesthetics, the notion of mimetic as an illusion produced in the representation of art, literature, and music. Imitation, for Aristotle, involves not merely physical resemblance or the imitative process, but also "what one might call generally the relations between things or the 'mechanisms' of things" (Hagberg, 1984, p. 366); that is, Aristotle views mimesis as something that nature and humans have in common: not only mimesis is "embedded in the creative process, but also in the constitution of the human species" (Puetz, 2002). In most recent years, the term mimesis has returned to social and human sciences particularly in the works of Walter Benjamin, Theodor Adorno, Rene Girard, and Jacques Derrida to situate mimesis as a human faculty defined by representation and expression. Particularly, Jacques Derrida foused on the concept of mimesis in relation to texts. According to Derrida in words of Michelle Puetz, "the mimetic text lacks an original model and its inherent intertextuality demands deconstruction" (Puetz, 2002). Consequenly, for Derrida Differénce "is the principle of mimesis, a productive freedom, not the elimination of ambiguity; mimesis contributes to the profusion of images, words, thoughts, theories, and action, without itself becoming tangible" (Kelly, Michael quoted in Puetz, 2002). As a result, mimesis in not only the repetion of a word or an action in a text, is the difference that results in the repetion process.
} 
is possible to observe a manifestation of the generative force since it allows us to question how stories are transmitted and retold within a family context. It also helps to render questions regarding the power, knowledge, ideology, and identity established in the stories that are narrated. In this sense, intergenerational storytelling can be counter-hegemonic since in its performative nature, the retelling of a story can reveal details that hegemonic tales have suppressed. If the retelling is successful, intergenerational storytelling can provide a significant form of resistance. Consequently, when stories are intergenerationally told, they defy hegemonic tales, and at times, politically transform them.

\section{Conclusion}

In this chapter, I have presented performativity and performance as interdisciplinary concepts applied in the study of storytelling. I propose that storytelling is a narrative-embodied-performance, and stories are 'active doings' that can evoke or transform discourses. My main goal has been to situate storytelling within family dynamics; particularly focusing on mother and daughter stories. I argue that family constitutes the primary site where myths, ritual, taboos, secrets, routines, and language are constituted and transmitted. In this scenario, women's stories are embedded within "normative and normalizing context that regulates what kind of stories, types of storytelling, and possibilities for identity and agency" (Langallier \& Peterson, 2006, p. 100).

By situating women's personal stories within a family context, my aim is to present how hegemonic tales (childbirth, marriage, menstruation, abortion, and menopause) can be harmful to women. I describe hegemonic tales as dominant narratives located in the social that legitimize certain ideological discourses; carrying with them the relative power of the interests they serve (McKenzieMohr \& Lafrance, 2014). Since hegemonic tales exist as internalized and taken for granted discourses, mother and daughter storytelling reveals how hegemonic tales are transmitted across generations influencing how women story their own lives. Importantly, by introducing mothers' and daughters' intergenerational storytelling, I have shown how the reiterative practice of telling stories across generations creates fissures or constitutive instabilities in the stories, which can transgress hegemonic tales.

These gaps and fissures recount particular constitutive instabilities in the stories that can trigger "new signifiers and meanings beyond the present act itself" (Saloul, 2009, p. 143), and through this, a possible change of the meanings of women's stories. Therefore, intergenerational storytelling is counter-hegemonic, to the extent that it can reveal the oppressive nature of hegemonic tales. As 
such, the general aim of this chapter is to set a theoretical framework that helps to situate mothers' and daughters' storytelling as a reiterative narrative practice capable of undermining hegemonic tales.

In this framework, in the following chapters I present mother and daughter menstrual stories within my own family. In order to situate menstruation in my family stories, I rely on a phenomenological and narrative inquiry approach as my methodologies in order to explore the meaning that women in my family assign to their menstrual experiences; what they think and feel, and how their stories travel through generations (Lee \& Sasser-Coen, Blood Stories: Menarche and the Politics of Female Body in the Contemporary U.S. Society, 1996). Consequently, in Chapter Two I present phenomenology and narrative inquiry as a qualitative methodologies that have allowed me to collect my family stories. I also present a profile of the women in my family whom I interviewed, and a description of my data collection and analysis practices. 


\section{Chapter II. Writing Family Menstrual Stories: Methodology}

In this chapter, I introduce the methodological approach used for the collection of my family's menstrual stories. The main purpose of this chapter is to explore in detail the methodology applied to address my research questions: What kind of menstrual taboos and myths have been created, storied, retrieved, experienced, and signified in my family? And, how do we either corroborate or subvert these myths in transmitting menstrual stories throughout generations? Because these questions are focused on menstrual stories and the ways my family gives meaning to them, I have needed to find a methodology that allows me to reflect upon the menstrual experience, trying to make sense of it throughout telling and retelling stories.

Accordingly, this chapter introduces two qualitative methodologies (narrative inquiry/analysis and phenomenology) selected to study the connections between menstrual experiences and stories. On the one hand, I rely on feminist phenomenological research to attend to women's bodily and menstrual experiences. Phenomenology argues that reality can be only comprehended through the experience. Therefore, we perceive the world irredeemably through the body, which represents the primary dimension of experience. On the other hand, dialogical narrative inquiry allows me to study the ways women have storied ${ }^{13}$ those experiences. Stories are a way of understanding lived experiences and they offer a powerful transformation in their retelling (Connelly \& Clandinin, 1990). Stories make our experiences present. Phenomenology and dialogical narrative inquiry are each considered both the phenomenon and the method, in that central to both methodologies are the beliefs that experiences and stories give meaning to people's lives, and, as such, both (experiences and stories) are treated as data. Writing family menstrual stories using both methodological approaches has helped me to gain insight not solely into "how stories work - what they consist of - but [also] into how stories do their work for people and on people" (Frank, 2010, p. 28). That is, understanding the ways women in my family enact and give meaning to their menstrual experiences through stories.

As elaborated in more detail in the following sections, I have needed to find a method for data collection that provides different nuances in capturing the entanglement of the body, the experience, and the stories. In order to show these differences, I have used storytelling as a qualitative method to provide more comprehensive insight into my family's menstrual stories. In storytelling more than in doing interviews, the aim is to enact conversations that allow the construction of mutual meanings and

\footnotetext{
${ }^{13}$ Here, the word 'storied' is used in a verb form that describes the process for "seeking meaning in the stories themselves and encouraging the listener/reader's active engagement with the material” (Berger \& Quinney, 2005, p. 9). 'Storied' narratives give to the teller control over the story's meaning and bring "interpretative and emotional sensibilities to bear on the tale being told" (Berger \& Quinney, 2005, p. 9).
} 
understandings of experience. As such, in this research I present narrative excerpts of a total of 10 stories; 9 of them conversations sustained with 9 women of different generations (grandmother mother - daughters) in my family. The story left is my own.

Before exploring how I got to the chosen methodologies (phenomenology and dialogical narrative inquiry) and my data collection method (storytelling), I first want to situate my research within my personal/theoretical position. Also I want to situate my family within my research, and describe why menstruation has been chosen as the experience to be told. Subsequently, I will develop my process of collecting data and the challenges for its analysis. Lastly, I will engage with ethical considerations regarding my personal involvement with my research topic.

\subsection{Personal Theoretical Situatedness}

In this section, I want to address my 'personal theoretical situatedness' in engaging with my family's menstrual stories. The use of the swung dash $(\sim)$ between the personal and the theoretical is not by chance. The swung dash denotes the impossibility to separate my personal motivations of sharing my family's stories and my feminist theoretical commitment to conferring value to women's stories within academy's standards of knowledge production and academic writing. In "Trans $\sim$ Waters $\sim$ Coalitional Thinking on Art + Environment," Eva S. Hayward argues that the swung dash $(\sim)$ represents a coalition of what she calls Trans knowledge. For Hayward, the swung dash,

promises movements across, but never without holding tightly to the locations that it is moving from.[...] it is a crossing of spacetime, a movement within relationship. As such, trans materializes the process of movements; trans marks the where-ness of with-ness. (Hayward, 2014, para. 1)

As such, I embrace trans $\sim$ knowledge as a coalition across the personal and the theoretical because it offers a figuration of movement across lines and possibilities. It gives a glimpse into a continual positional flux; a moving location that dissolves the 'here' and 'there,' recognizing “coalitional modes of emergence as possibilities" (Hayward, 2014, para. 2). My understanding of coalitional knowledge allows me to recognize the limitations and partialities of personal and theoretical locations. The mark bounds each word from its own specificities, differences, and limitations, making possible an exchange and habitation of different positions: positions from there or no-where, positions in the movement, liquids, dynamics, and unstable; and from that where-ness, embracing and naming my personal, theoretical, and embodied 'situatedness.'

The word 'situatedness' follows Donna Haraway's (1988) premise that “only partial perspective promises objective vision" (p. 583), developed in her well-known article "Situated 
Knowledges: The Science Question in Feminism and the Privilege of Partial Perspective.” Here, the author draws upon the importance of knowledge location; that is, situated knowledge questions the traditional myths of scientific objectivity. Through situated knowledges, feminist scientists can obtain "embodied objectivity" (Haraway, 1998, p. 581) against the scientific gaze considered the only form of objective knowledge-gathering. The author writes,

I am arguing for politics and epistemologies of location, positioning, and situating, where partiality and not universality is the condition of being heard to make rational knowledge claims. These are claims on people's lives. I am arguing for the view from a body, always a complex, contradictory, structuring, and structured body, versus the view from above, from nowhere, from simplicity. Only the god trick is forbidden. (Haraway, 1998, p. 589)

Haraway offers a powerful image of the embodied, complicated, actively seeing eye "to reclaim that sense to find our way through all the visualizing tricks and powers of modem sciences and technologies that have transformed the objectivity debates" (1998, p. 582). Haraway offers a possibility, or better said, an opportunity for using a different gaze, one that is based on particular and specific embodiments full of contradictions between embedded positions. Both Hayward and Haraway, reject strong positionalities, and rather plead for ambiguities, fluxes, and movements across porous, multi-layered, and complexly situated perspectives. Taking this opportunity for positional movement, my intention is to locate this research within complex, porous, limited, and specific theoretical personal locations, upon which I build this research. In what follows, I present the locations from where I am writing.

\subsubsection{Situating My Research.}

This research is a theoret[h]ical bet. It is a project that aims to position menstruation from what I understand as 'women's experience.' Here, I am already naming three terms that have been widely contested within feminist scholarship. In naming 'women,' 'menstruation,' and 'experience,' the necessity of facing the monstrous endeavor of crafting definitions shows it academic appeal. In a risky decision, I do not attempt to offer eternal nor universal definitions, neither lineal scripts nor determinant categories to frame my research. Instead, what I offer are coalitions, associations, assemblages of feminist theories that move from different positionalities. My research is situated on trans coalitions of academic disciples, knowledges, corporealities, and materialities. As such, 'women,' 'menstruation,' and 'experience' as described in this research need to be read not as 
transparent, innocent, unique, or determinate appeals to what these words must signify. Instead, I am presenting them as guides that allow me to navigate my family knowledges, experiences, and stories.

\subsubsection{Women's experience.}

Opening the threshold of analyzing women's experience can be a contested battlefield. Primarily, because there is no unanimity about the term 'women' as a category within contemporary feminist academia. It appears that the category of 'women' carries the stigmatization of being essentialist in feminist discussions, to the point of becoming an invalid or unearthly word. The main argument resides in the problems of locating women as a category of analysis without assuming "that all women, across classes and cultures, are somehow socially constituted as a homogeneous group" (Gunnarsson, 2011, p. 27); that is, in engaging with the false idea that all women experience the same problematic for the simple fact of being women. In this debate, intersectionality as a theoretical perspective, method, and concept has challenged this monolithic assumption. Without entering into a complete analysis of intersectionality within feminist theory, it is important to underline how non-Western feminist scholars (see, for example, Mohanty, 1988, 2003; Anzaldúa, 1987) have offered analytic lenses emphasizing that "women are not only women, but also black, white, rich, poor, heterosexual, homosexual, etc." (Gunnarsson, 2011, p. 25).

The scrutiny of assumptions about women's experiences has led to epistemological struggles regarding how to acknowledge women's differences and experiences in social science. For instance, in "The Evidence of Experience," Joan W. Scott (1991) describes the risks of using experience as evidence. She argues that within feminism, to claim women's experience as a source of knowledge is "to universalize the identity of women and thus to ground claims for the legitimacy of women's history in the shared experience of historians of women and those women whose stories they tell" (1991, $p$. 787). Experience jeopardizes the "identities of those whose experience is being documented" (Scott, 1991, p. 777) because when experience is located as the source of knowledge, it becomes incontestable evidence of some histories, thus naturalizing the differences. In order to avoid this bias, Scott calls for a historicity of experience that does not "reproduc[e] and transm[it] knowledge said to be arrived at through experience, but the analysis of the production of that knowledge itself" (1991, p. 797). As such, for Scott, historicity allows going beyond the experience itself; it allows for explaining how the experience is produced. Therefore, the potential of historicity is that it problematizes the foundations of the experience, giving space to difference.

In another theoretical landscape, queer-oriented feminists such as Judith Butler have argued that the category of women is a fiction. Women as a category presents fictive elements on the grounds 
that it is not "a stable signifier that commands the assent of those whom it purports to describe and present" (Butler, 1999, p. 6). In this sense, women as a category is unstable because it is a historical/social product constructed perversely for structuring a world that applies a regulatory force upon them. Here, I agree with Bulter's idea that women and men are constructed categories demarcated by discourses, norms, and practices that produce bodies; however, I argue that there is still something real, concrete, and specific in the materiality of the body. There is a concrete embodiment and experience from which a reality can be measured, observed, and felt.

In this research, I offer an entrance into particular meanings and embodiments of 'women's menstrual experiences.' Here, I build upon the work of Iris Marion Young $(1980 ; 1990 ; 2005)$ and Elizabeth Grosz (1991), which gives an account of particular structures and conditions in which women's experiences are generated, affecting women's subjectivities. For Young, pregnancy, breastfeeding, and menstruation are corporeal, real, and tangible experiences that need to be understood beyond their biological concreteness in their multi-layered historicity. To situate my research in the concrete real of women's experiences allows me to take 'women' in my family as the subject-position for this research. My ambition is not to claim any kind of women's experience as a universal entitlement for knowledge, but to recognize the indisputable, practical realities expressed in different "types, modalities, styles of existence" (Young, 2005, p. 17), around which women in my family have negotiated, resisted, embraced, rejected, and loved their womanhood. In my specific theoretical personal location, I have chosen 'woman' as a "strategic, all-encompassing embrace and dedication to their particular women experiences" (Hedva, 2015, para. 34). This research aims to honor their on-going life-struggles as 'women' and to honor the feminist political project that considers the category of women still indispensable for feminist politics and knowledge production.

\subsubsection{Situating Menstruation within Theoretical Coordinates.}

Within women's movements and feminism, menstruation has become a site for reflection, confrontation, and activism. Menstruation has been approached from different perspectives that have exhibited a wide range of misogynist discourses, attitudes, and reactions to women's secondary social position due to certain body specificities. As Grosz describes, "patriarchal oppression, in other words, justifies itself, at least in part, by connecting women much more closely than men to the body, and through this identification, restricting women's social and economic roles to (pseudo) biological terms" (Grosz, 1994, p. 14). By creating a fixed notion of women's bodies, women's bodily cycles, such as menstruation, pregnancy, maternity, and breastfeeding, have been used to justify women's biological, psychological, and emotional limitations by men. 
To face these misogynist perspectives, feminists have re-explored and re-examined forms to understand women's body specificities outside patriarchal categories. Depending on the approach, feminists have re-theorized women's bodily cycles according to particular conceptual frameworks. In this sense, borrowing from Grosz's classification, menstruation has been re-conceptualized within egalitarian, socio-constructivist, and sexual difference feminisms (Grosz, 1994). According to Grosz, egalitarian feminism tends to understand menstruation as a social and biological limitation. Feminists sharing this view have tried to "move beyond the constraints the body" (1994, p. 15) to eliminate the effect of women's biology in social, economic, and cultural contexts. This perspective attends to situating the body as natural versus the cultural system that constrains it; creating a binary contraposition to determine women's oppression.

In the social constructionist perspective, particularly psychoanalytic feminists, such as Julia Kristeva or Nancy Chodorow, among others, are more focused on the social system that organizes and gives meaning to bodies. To this group, the notion of body is still "biologically determined, fixed and ahistorical" (Grosz, 1994, p. 16-7); however, they recognize that "it is no biology per se but the ways in which the social system organizes and gives meaning to biology that is oppressive to women" (Grosz, 1994, p. 17). The theoretical project of this group has worked toward the neutralization of the sexually specific body (Grosz, 1994); that is, working against the attitudes, beliefs, and values that sexualize the bodies.

In another account, feminist theorists such as Judith Butler, Vicky Kirby, Elizabeth Wilson, Susan Bordo, and Elizabeth Grosz focus on bringing back the body into theory in order to understand women's "physical and social existence[,] but the body is no longer understood as ahistorical, biologically given, a cultural object. They are concerned with the lived body, the body insofar as it is represented and used in specific ways in particular cultures" (Grosz, 1994, p. 18). This group recognizes difference neither as an essentialist project nor as a cultural marker. Instead, they approach a body as part of natureculture (Haraway, 1991); that is, the body as an entanglement of the natural and the cultural, the body and the mind, the material and the semiotic. In this approach, menstruation is situated and understood within a hierarchical "order of desire, signification, and power" (Haraway, 1991, p. 19). Finally, third-wave feminism and queer theory have contributed to queer menstruation. According to Chris Bobel, this project aims to dessentialize women valorizing the body. "Radically, these bodies are neither necessarily female nor necessarily woman identified” (Bobel, 2010, p. xiii). For instance, by using the word "menstruators," these groups aim to acknowledge other types of bodies that "bleed periodically rather than equating menstruation with womanhood" (Bobel, 2010, p. xiii). As such, this perspective tries to offer a more comprehensive account of menstruant bodies.

After providing these positionings, I would like to recall how I am using the concept of 
menstruation during this thesis. I understand menstruation as a biological process with cultural, social, and historical meanings. These processes create "menstrual experiences which are neither fixed nor universal, but rather adaptable and transformable not only between cultures, but from within cultures as well" (Armeni, 1996, p. ii). Furthermore, I recognize that saying that menstruation is an exclusive feature of the female anatomy is reductive, and certain bodies that experience social prejudices for not fulfilling the requirements of heterosexual and heteronormative bodies might been erased. As a result, I situate myself among those voices that recognize that 'to be a woman' does not necessarily imply to be a menstruator; that is, I recognize that some men menstruate and some women do not (intersex men, post-menopausal women, trans* women, trans* men). Consequently, I am aware of the importance of paying attention to how menstruation is gendered and how it affects certain identities and bodies.

For the purpose of this thesis, I situate menstruation as a shared biological feature of women in my family. By doing so, I am in line with feminist psychologist Elizabeth A. Wilson's idea "that biology [is] a site of important political and conceptual argumentation for feminism, and — in particular - that detailed understanding of biological processes [is] crucial to [...] feminist analysis" (2015, p. 3). Consequently, I am not positing an essentialist approach based only on a certain kind of body, nor assuming that menstruation is necessarily a feature of all women's experiences and thus a political and practical concern for every woman (Bobel, 2010). The menstrual stories I am presenting here are situated (Haraway, 1988); that is, they respond to the particularities of my family's experiences of menarche and menstruation. Furthermore, their stories raise questions regarding the ways dominant socio-cultural constructions of gendered biological processes affect women's experiences, attitudes, and beliefs about menarche and menstruation. In this sense, I hope that my family's menstrual stories contribute to a further dialogue that problematizes sex/gender differences generally associated with what is considered the female body and, with this, start reshaping and transforming the socio-cultural discourses that shape women's bodily experiences. This research, therefore, recognizes the vital dimension of biology and the materiality of the body as the concrete location of women's experiences, and the cultural dimension of living in a gendered body as the subjective preconditions of inhabiting a society.

\subsubsection{Situating My Family's Stories in the Research.}

Storytelling in Mexican households is part of a strong oral tradition, in which knowledge is passed down through generations via storytelling from the older generation to the younger. These stories may 
convey information "about roles within the family, concepts of masculinity and femininity, and values and expectations, all through sharing stories [...] that have a moral or central message of their culture on a daily basis" (Gleaves, 2008, para. 2). This practice comes from indigenous oral traditions before the conquest of Mexico by the Spanish. Storytelling includes poetry, prayers, and discourses through which cultural content is transmitted from generation to generation (Reese, 2012). With the imposition of Spanish language and writing, storytelling became a form of oral resistance. Since then, storytelling has been a form of communication that connects oral traditions with contemporary practices in Mexican homes. From this perspective, "dichos, narratives, legends, stories and consejos that make up the lived experiences of many Mexican[s ...] represent a resource for communities and individuals" (Reese, 2012, p. 278).

As part of a Mexican household, I grew up in a house filled with family stories. I grew up with stories women in my family have been telling to each other all over the years. Family storytelling constitutes the primary site where cultural myths and metaphors, ritual and routines, language and secrets are constituted and transmitted (Langellier \& Peterson, 2006). Some stories have embraced and reinforced normative experiences that have marked and defined our bodies (childbirth, marriage, menstruation, menopause, and breastfeeding). Other stories have contributed to our genealogical memory. Others have been discarded and neglected. Stories have been forgotten, erased, and minimized. However, not all Mexican families tell and/or are influenced by the same stories. Stories get told and listened to in different contexts. For this reason, it is important to locate stories in the sociocultural and historical contexts in which they are unfolded, as well as the particular familial circumstances that shape them. To this end, it is important to briefly describe the family I am addressing in this thesis; that is, my family.

In this research, I focus particularly on my mother's side of the family, which consists of seven siblings (five females and two males). In order of birth, their names are: Yolanda de la Brena Dartiz (68), Guadalupe de la Brena Dartiz (67), Martha de la Brena Dartiz (65), Elena de la Brena Dartiz (†), Rolando de la Brena Dartiz, Rosa María Emigdia de la Brena Dartiz (61) and Ernesto de la Brena Dartiz (58). My mother (Emigdia), aunts, and uncles are part of the emergence of middle-class families in urban contexts in the 1950s in Mexico. Between 1940 and 1970, Mexican populations in urban areas increased by 296 percent, basically because of rural-to-urban migration in search of jobs and 


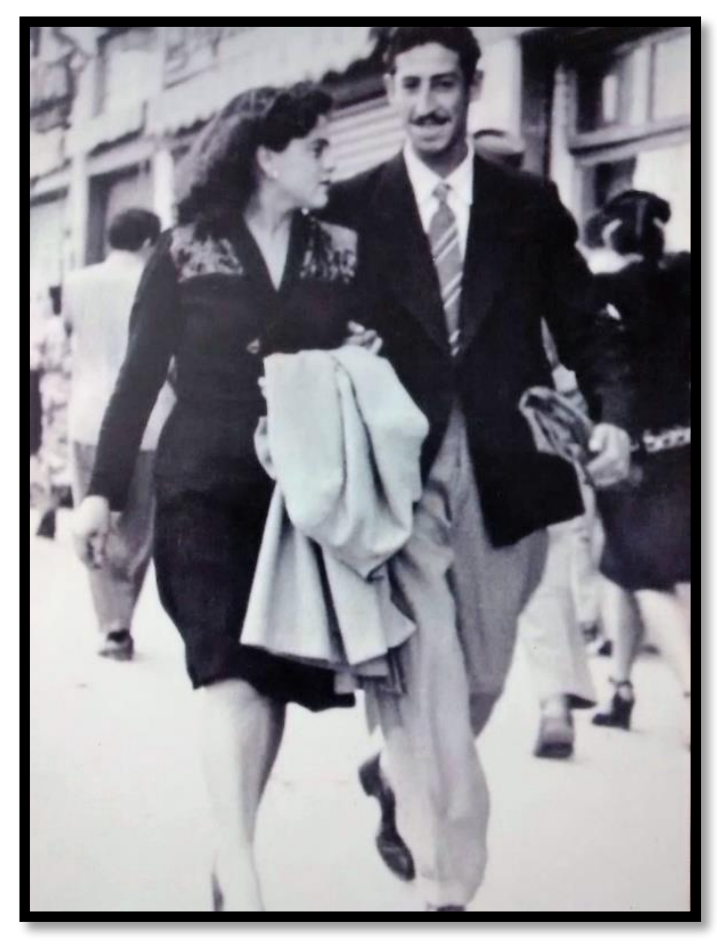

Figure 1 (April 25th 1947 ) My grandmother Susana de la Brena and my grandfather Rolando Dartiz walking on the streets of Mexico City after getting married at the municipal hall. education (Russell, 2011). Particularly in Mexico City, the population increased 1.8 million due to migration and high birth rate of its residents. My family is the result of this internal migration. My grandmother migrated from Guadalajara to Mexico City to find a job. She was received by her family network in the city: her cousin's family. My grandmother's cousin was an electrician and he introduced my grandfather to her. As my mother and aunts tells me, it was love at first sight, and since then, they have never been apart. That is the beginning of my family's story.

According to Maria Aysa-Lastra (2016), the 1950s decade marked the consolidation of the patriarchal family structure, with clearly defined roles for mothers, fathers, brothers, and sisters. The author argues, "the ideal and traditional Mexican family is based on hierarchies of power that are arranged according to the age and gender of family members, as well as trust in kinship ties" (Aysa-Lastra, 2016, p. 1). Mexican middle class families have been formed under a traditional value-system (influenced by the Catholic Church) that has had a strong impact on the ways in which its members behave and view the world around them.

Kim Ann Zimmermann (2015) argues that the Catholic Church (which represents 98 percent of Mexican religious beliefs) contributes to the concept of family and inclusiveness. She states, "[f]amily units [were] usually large, with traditional gender roles and extensive family involvement from the external members who assist[ed] one another in day to day life" (Zimmermann, 2010, p. 5). Within this traditional structure, my grandmother's duties have been solely domestic while my grandfather, the sole economic supporter of the household. My grandfather had a full-time job as an electrician, and with his income, built the house in which my mother and aunts grew up. 
My family's house was situated in Mexico City. It was a two-story house sufficient for the needs of a household full of children. My grandfather's income was not highly-waged, therefore, when the time was right, my aunts and uncles contributed to the family income. All my aunts and uncles (including my mother) had access to education; although, only my aunts Yolanda, Guadalupe, Helena, and Martha completed undergraduate studies. The first one to get married was my aunt Yolanda. She got married to my uncle Oscar and had three children: Erika Méndez de la Brena, Elka Méndez de la Brena, and Oscar Méndez de la Brena. In a curious turn of events, two of my aunts (Martha and Emigdia), married two of my uncle (Ernesto and Gilberto) respectively. This situation brought a singular familial relationality that kept the two families close for many years. With time, stories of divorce, infidelity, and violence broke some of these ties, undermining the relationships between some couples and between siblings. As a consequence, conflicts and misunderstandings fractured the communication between sisters; affecting also the communication among cousins.

It was not until five years ago, strengthened by my aunt Elena's death in June of 2015, that an opportunity to heal the old wounds emerged. Stories appeared as a form of familial reminiscing about

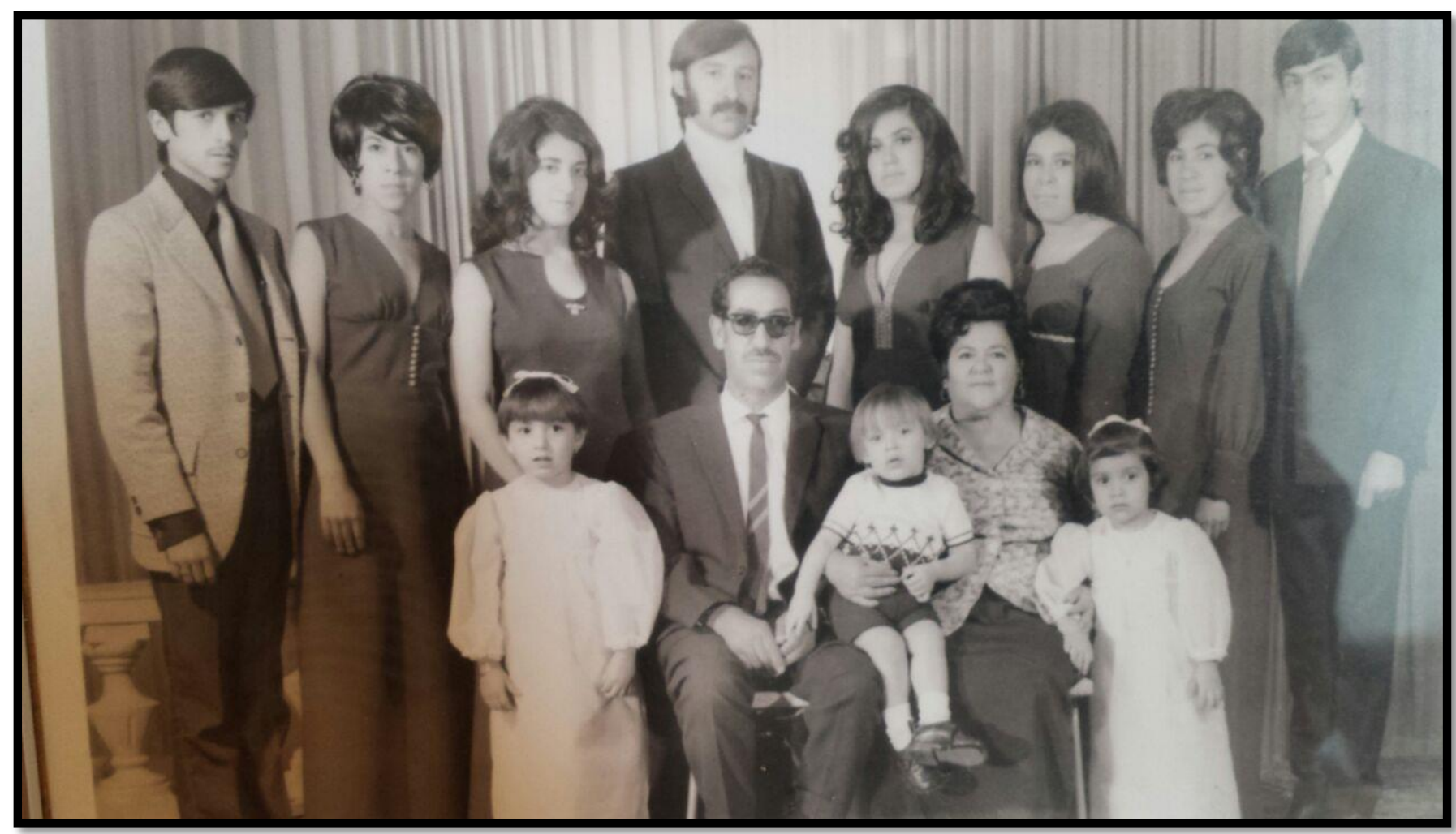

Figure 2 (August $18^{\text {th }}, 1972$ ) Family Portrait in commemoration of my grandparents's silver anniversary. From left to right: Rolando, Helena, Martha, Oscar, Yolanda, Emigdia, Guadalupe, Ernesto, Erika, Rolando Sr., Oscar Jr., Susana and Elka

events they experienced together, stories about the family's past: childhood, adolescence, and adulthood. Stories of highly emotional events have provided a more casual understanding and resolution to past conflicts. With this new familial willingness to talk, new possibilities of family 
storytelling have begun. As a member of this family and as a researcher, I could not resist the occasion to motivate these new encounters. I saw an opportunity to hear stories I have never listened to and get in contact with family members to which I have barely spoken. This research gave me the excuse of telling and hearing stories while getting to know my family (Langallier \& Peterson, 2006).

Nonetheless, finding the 'right' story to tell has not been the easiest endeavor. I have needed to choose the most appropriate story that motivates the process of family storytelling. Particularly, I have needed to find a story we were willing to share without opening new or old wounds, or bringing about delicate topics. I have needed a story that connects all the women in my family; an event we all have experienced and which has/had signified something important in our lives. As such, menarche and menstruation represent the point of entrance to my family's stories. However, in my family, stories of menarche and menstruation are rarely told.

In a family of five sisters, seven female cousins and four female nieces, stories about menarche and menstruation are surprisingly scarce. Mothers and daughters rarely tell menstrual stories, and when they do, these stories stick to cultural taboos around menstruation. These stories influence all conversations around our relationships to our blood, to our bodies, and to our bodily experiences. But how? This is precisely the focus of this research, to explore the effects that menstrual stories have on women in my family when they talk about menstruation, and the impact that these stories have when transmitted through generations. Consequently, as a researcher, I have decided to analyze the particularities of my family's menstrual stories. In situating my family's stories as the focus of this research, I am also attentive that their stories fit into the larger picture of menstrual literature and scholarship. However, I believe that despite the situatedness of my family -class, race, age, and nationality of my family- our stories - as particular and specific as they are-can resonate with other menstrual experiences and other stories of other menstruant bodies.

\subsubsection{Situating My Voice in the Research.}

In her beautiful and powerful article "My Mother's Story as a Narrative of Contradictions," Mary Ann Loewen (2010) shares the difficulties of situatedness in studying family stories for academic purposes. She recounts how, as the daughter of the interviewee, she was more likely to be accused of limited objectivity, or even worse, of scholarly bias (Loewen, 2010). As I was recollecting my family stories, it was getting clear that, as Loewen did, I needed to evaluate my particular situatedness in relation to both my personal interests and my 'particularly' chosen interviewees. I found that by incorporating my own menstrual story, I could be more be attentive to the relationship between telling my family's 
stories and my own involvement in the process. I needed to situate my voice within my family's stories.

In "Personal Writing is Social Research: Issues of Production and Interpretation," Marjorie L. Vault (1997) engages in the debate of incorporating personal writing into empirical studies. She defines personal writing as, "sections of text that present autobiographical or introspective material" in the service of research (Vault, 1997, p. 218). She argues that personal writing has been traditionally seen as biased, and as a weakness in claiming for "the truth, the whole truth, and nothing like the truth at all" (Vault, 1997, p. 220). However, incorporating personal-reflective material can offer different types of revelations, doing more for the research than simply reporting the facts. In situating my voice within the stories, as Ken Plummer (1995) argues, I am writing "personal narratives of the intimate" (Plummer, 1995, p. 19), revealing that, as researchers, we are not writing from the outside, but we are always writing from what it is happening in one's life.

Thus, I am describing the experience from the inside: of my body and my family. I am writing sections of me as part of my 'corporal self-itinerary'; that is, "the pertinence of self-experience in order to understand the others and vice versa, particularly when similar experiences have been felt" (Esteban, 2004, p. 1). I am using my voice to make explicit the interconnections that exist between my corporal self-experience and my researcher body. Using my voice in the research process is to narrate myself, as an individual and as a researcher in the tissue; as a "biological, historical, and social being whose experiences and actions are also ready for narration” (Menary, 2008, p. 64). In this sense, I am offering a more complex view of the researcher, investigating from the "conflictual incarnation" (Esteban, 2004, p. 1) of the bodily experience and the language. That is, in using my voice, I can hear the resonance of my mother's, aunt's, cousins' and niece's sexual, corporeal, and emotional experiences in my body, and I can write and tell our stories, situating these experiences in tension with the contexts where they take place.

But how to find an analytical approach that allows me to approach our bodies as "both a biological being and a conscious, experiencing, acting, interpreting entity” (Esteban, 2004, p. 3)? In this specific pursuit, phenomenological and narrative inquiry appear as qualitative research approaches that facilitate the understanding of menstruation as an experience through the recollection stories. In the next section, I describe the features of both approaches upon which I have relied to gather my family's menstrual stories. 


\subsection{Methodological Approaches}

As explained at the beginning of this chapter, this research is grounded at the crossroads of phenomenological and dialogical narrative inquiry. The reason to combine these methodological approaches is to obtain a more comprehensive, descriptive approach to my family's menstrual stories. In this sense, I have found that each methodological approach on its own does not fully integrate all my methodological needs for understanding how cultural narratives shape my family's menstrual experiences and how to get the most comprehensive descriptions of these experiences. In other words, I have needed a methodological approach that could, on the one hand, conceptualize the experience of menstruation not merely as a bodily capacity, but as an embodied process (that is, menstruation as a process through which women experience their bodies), and, on the other hand, I have needed to capture the way women give meaning to those experiences in daily communicative acts, focusing on how women story their menstrual experiences.

In a daring move, I have decided to distinguish two methodological approaches to attend to menstrual experience as an important dimension in women's lives, and stories as a form to understand the meanings of those experiences. The next section engages with phenomenological and dialogical narrative inquiry. The relationship between both methodologies is that they focus on the details of the experience; however, while phenomenological inquiry explores the experiences as they are lived, dialogical narrative inquiry focuses on "how and why a particular event is storied" with "particulars and context" coming to the fore (Riessman, 2008, pp. 12-13). This combination is what makes narrative and phenomenological inquiry both exciting and challenging. Let me give a flavor of these threads here.

\subsubsection{Phenomenological Approach.}

Phenomenologically oriented inquiry allows focusing on the body (the lived body) as a coherent framework for understanding the meaning of experience. For phenomenologists, particularly those following Merleau-Ponty's phenomenology, our bodily presence in the world is delivered by the "lived-body," which is a subjective body that forms our personal experiences as important as any physical body or bodily function we may have; that is, as a form of embodied subjectivity. Crafting phenomenological research is to agree that the lived-body "discloses the world just as the world discloses itself through the body" (Finlay, 2006, p. 3). Phenomenological research as an empirical method 1) gathers experiential material through the lived body, and 2) uses reflective methods to interpret the meanings embedded in the experiential material (Manen, 2014). 
In attending to the body and the embodied experience, phenomenological research offers opportunities at the level of methodological practice to go beyond the body as an object -"as observed and scientifically investigated"- to understand the body and its experiences as-they-are-lived (Finlay, 2006, p. 20). In this sense, phenomenological inquiry, in contrast with other methodological approaches, aims to gather "lived experiences, especially in the form of anecdotes, narratives, stories, and other lived experiences accounts" (Manen, 2014, pp. 312-313). In phenomenological research, the data is the human experience. Thus phenomenological research involves the return of experience to determine what an event means "for the person who have had the experience and are able to provide a comprehensive description of it" (Moustakadas, 1994, p. 13).

In focusing on the lived body, phenomenological research allows me to be aware of how the experience is lived in different forms by different bodies. In this sense, Young (2005) argues, researching the specificities of women's experiences can “describe subjectivity and women's experience as lived and felt in the flesh" (pp. 6-7). The author focuses on menstruation as a particular experience, and with phenomenological research, she approaches the processes and meanings of menstruation. Because it is through the body (tasting, touching, seeing, hearing, and smelling) (McCormick, 2010, p. 67) that we experience the world. Phenomenological research offers a framework for exploring the meaning of menstrual experience as it is lived by women's bodies.

In order to study the experience, phenomenological research requires that "the researcher immerses herself in the lifeworld of the other" (McCormick, 2010, p. 71). In this sense, Linda Finlay (2006), in “The Body's Disclosure in Phenomenological Research," proposes three perspectives to help the researcher to investigate other's bodies: bodily empathy - to be "attentive to our participants' bodies and their existential embodied experiences"; embodied self-awareness, in which the researcher reflects on her own body as a researcher in a participant observation and when analyzing an interview transcription, and describes how this can help her/him to gain insight into the participants' embodied experiences; and embodied intersubjectivity, which "focuses on how in the process of research, the bodies of participant and research may intertwine in empathic connection" (Finlay, 2006, p. 20). These three perspectives have helped me to approach my family's menstrual experiences.

Because I was exploring my family's menstrual experiences, I did not want to simply observe, describe, and objectify their bodily experiences. Since menstruation is a shared event amongst my family, I have wanted to be aware of and be accountable to their experiences since, by exploring theirs, I was exploring mine as well. Because these were personal stories to me, I wanted to engage in a reflexive bodily analysis, where I was developing a mutual relationship with my family's menstrual stories; they are my own. Consequently, in crafting phenomenological research, I was investigating menstruation as we live it rather than as we conceptualize it. However, the limitation I have found on 
phenomenological research for my thesis is that it focuses more on the concrete ways experience is lived rather that how it is told. As such, I have needed a complementary methodological approach that helps me to unpack the experience. Therefore, I have found in dialogical narrative inquiry an approach that allows me to focus on women's stories as the meanings of their experiences.

\subsubsection{Dialogical Narrative Inquiry.}

Dialogical narrative inquiry can be described as follows: "what is told in the story -the story's content - and what happens as a result of telling that story-its effects" (Frank, 2010, p. 72). In the strict sense of the word, dialogical narrative inquiry is not a methodology. Authors such as Arthur Frank or Catherine Riessman argue that there should be no method of narrative analysis, "if method is understood as a prescribed set of steps that the analysis should follow" (Frank, 2010, p. 72). What they offer instead is a 'movement of thought': an "[a]nalytic or interpretative though that is moving more likely to allow and recognize movement in thought being interpreted. Thought moves in dialogue, as those participating in research are given scope to upset the presupposition of the researchers" (Frank, 2010, p. 73). Thus, dialogical narrative inquiry is an analysis practice that helps to pose questions, letting those who do analyses, including the storyteller and the protagonist of the story, decide which of these questions are the most useful to emphasize. In this sense, to use dialogical narrative analysis is "to take care of yourself" (Frank, 2010, p. 74) and the others.

In this process of care, dialogical narrative inquiry makes sure not to pressure the researcher to find only one methodology. Dialogical narrative inquiry lets the researcher to be creative and discover its own "form to represent the story in a most appropriate manner to the research interests but also true to the stories themselves" (Frank, 2010, p. 112). However, dialogical narrative inquiry puts emphasis on the fact that stories are always told within conversational dialogues. In this regard, dialogical narrative analysis' (DNA) main concern is "how to speak with a research participant rather than about him or her" (Frank, 2010, p. 112). Consequently, for dialogical narrative inquiry, storytelling appears as the more comprehensive method for data collection because it recognizes the importance of the dialogue in order to obtain a deeper understanding of the teller's story. As such, in the next section I describe the process of using storytelling and the advantages of using such a narrative method.

\subsection{Employing 'Storytelling' as Data Collection Method}

Louise O' Brien (2010) argues that storytelling, "is a powerful process that extends beyond research" (p. 23). Storytelling is a narrative method of inquiry that offers a great insight for "conduct[ing] 
retrospective research of past experiences, and generat[ing] — due to the interaction with other stories - different interpretative perspectives and new meaning configurations" (Gherardi \& Poggio, 2009 , p. 53). In this sense, storytelling as a method of data collection recognizes that both the stories and the experiences are fundamental parts of the process of creating meaning.

Within narrative research, storytelling has proven to be a powerful tool for addressing the concerns on privileging certain narratives over others that do not appear or are not considered to enrich the traditional narrative inquiry. In this regard, storytelling has been seen to contribute to what has been recently coined the 'big' and 'small' stories research debate (Bamberg, 2006; Georgakopoulou, 2015; Squire, Andrews, \& Tamboukou, 2013). This narrative research divergence is grounded in the notion that traditional or dominant narrative studies: 1) define "narrative restrictively and on the basis of textual criteria"; and 2) privilege "a specific type of narrative, in particular the long, relatively interrupted, teller-led accounts of past events or of one's life story, typically elicited in research interview situations" (Georgakopoulou, 2015, p. 256). Consequently, a recent articulation of storytelling as a data collection method has "made a difference" (Squire, Andrews, \& Tamboukou, 2013 , p. 8) theoretically and methodologically in re-positioning small stories within conventional narrative analysis.

Thus the term 'small stories' applies to "small narratives phenomena that occur naturally between people" (Squire, Andrews, \& Tamboukou, 2013, p. 8); that is, stories of the everyday. Small stories tend to prioritize the experience, "the unconscious realities and material causalities" (Squire, Andrews, \& Tamboukou, 2013, p. 12) of disenfranchised voices that have been discredited from having conversational-analytic validity. In these terms, storytelling -and by extension small storiesare considered as a counter-narrative movement that "bring[s] to the fore silenced, neglected, and marginalized voices in an array of contexts" (Georgakopoulou, 2015, p. 256). Storytelling offers a mode of communication that makes visible the "unseen and unheard moments of diversity within prevailing mega-narratives" (Olson and Craig in Georgakopoulou, 2015, p. 263). Thus, such as narrative and discourse analyst Alexandra Georgakopoulou (2015) argues in "Small Stories Research," "small stories then frequently emerge as counter-stories, the stories that are not encouraged or allowed in specific environments, that do not fit expectations of who the tellers should be and that stories they tell” (p. 263). This is why storytelling is a central standpoint for data collection in my research, since small stories make marginalized voices audible.

For example, in recollecting menstrual stories, this research is putting on the map stories of social oppression of women as menstruators. In doing storytelling, this research is bringing into the spotlight women's bodily experiences "covered by patriarchal biases and interest" (Young, 2005, p. 97). Particularly, by using storytelling, I am providing important insights into my familial menstrual 
event, giving importance to women's voices in particular historical and cultural contexts, and how their voices open opportunities for women's bonding (particularly in my research, mother and daughter bonding). Even more, storytelling not only is a fitting tool for gaining knowledge about women's lives, but also it serves as a helpful method for integrating women's experiences into scholarship (Leavy, 2007). In this regard, according to Ronald J. Berger and Richard Quinney (2005), storytelling "encourages writing that experiments with different forms of representation and that seeks engagement with the world beyond academe" (p. 10). They argue,

We need to cultivate a writing that reaches a broader audience, not just a writing that impresses our colleagues with our ability to master theoretical abstraction or mathematical technique. We need a writing that avoids esoteric language, that informs and enlightens without being pedantic, that appeals to both the intellect and emotions, seeking to inform and inspire and joining the 'endeavors of documentation, interpretation, and intervention.' (Berger \& Quinney, 2005, p. 10)

Taking the above into consideration, this research is thought not only for academia. This thesis is aimed at a particular audience: my family. Each word is chosen so women in my family can recognize their own voices. It was written to inspire them, and to encourage their stories. It was written to put their small stories into the bigger picture of stories told.

\subsubsection{Collecting Stories}

In dialectic narrative inquiry, storytelling is mostly done using unstructured or informal conversational dialogues in which "the interviewer, although guided by the purpose of the study, asks questions in the course of a naturally occurring conversation" (Wells, 2011, p. 24). In order to begin with my family dialogues, I built a typology of narrative questions. In my initial document, 35 questions covered the parameters I wanted to explore. However, during the conversational dialogues, my interviewees recount their stories in no sequential order. In total, I have recollected nine stories, each around one to one and a half hours. Given the fact that I was not able to sustain presential conversations, I have relied on the utilization of media. Therefore, the conversations were done through Skype and Facebook calls. These mediums have brought several challenges, such as: 1) Older women in my family were not familiar with the use of these communication systems, thus the conversations needed to be planned with anticipation and depended on the help of some younger member in the family. This was in my Aunt Yolanda's case, in which her niece (Elisa) helped her to connect the call; 2) One of the interviewees (my aunt Martha) did not have Facebook nor a Skype call account, which led me to ask 
for my mother's help in gathering my aunt on a specific day; 3) Internet quality connection was a determinate factor that did not make the conversations run smoothly.

\subsubsection{Transcribing, Translating, and Interpreting Stories.}

In narrative inquiry, the production of verbatim transcription is considered crucial for a full analysis of people's stories. This means that "every ungrammatical or colloquial speech is not 'tidied up' to make it sound better" (Wells, 2011, p. 38). However, dialogical narrative analysis involves interpretation. To this end, Max Van Manen (2014) writes, "[a]ll recollections of experiences, reflections on experiences, descriptions of experiences, taped interviews about experiences, or transcribed conversations about experiences are already transformations of those experiences" ( $p$. 313). As such, interpretation influences how the stories are analyzed and presented.

For instance, once the transcription is realized, units of meanings are listed. Taking a phenomenological approach into account, stories have been carefully listened to in the search of meanings within the experiences, without yet ascribing significance or connotations, in order to let the full array of themes emerge for themselves. Then, I have separated similar stories into common categories when overlapping themes or meaning-clusters begin to suggest themselves. Through this associative process, from the 10 stories recollected, narrative excerpts were taken, becoming the basis for a rich, textual description of the phenomenon (menstruation) (McCormick, 2010). The discussion following these excerpts describes a wide range of literature read, through which stories gain their own meaning structures and propose insights into the experiences that elucidate different layers and levels of complexity.

Importantly, in doing the transcription and interpretation of my family's stories, I have faced certain challenges. One of them is the language. Given the fact that my family's native language is Spanish, and because I am not an English translator, finding accurate words for capturing their narratives has been difficult. As a researcher, I have needed to situate myself between two languages and to make strategic choices of translation from one to the other. One of these choices is to be aware of the "translator-effect"; that is, the mark that I could leave on the work (Flotow, 2001, p. 35). In acting as a translator, it is important to recognize that the researcher is "an active participant involved in distinctive ways with the shaping of a personal narrative" (Personal Narrative Group, 1989, p. 201). It is important to have "awareness of the contingency of meaning in both tongues, as well as their different modes of signifying" (Gonzalez, 2006, p. 4). This awareness, as Samia Mehrez (2007) implies, recognizes, on the one hand, how the translator is "always conditioned and shaped by 
histories, ideologies, values, beliefs, and representations that pre-exist the very act of translation in the target language" (p. 108); and, on the other hand, how the relationship between a foreign narrative and a target language culture points to "the violence that resides in the very purpose and activity of translation" (p. 108).

Clearly, my interview material cannot be seen as an unmediated account of their stories, and I recognize that an exercise of "translation violence" has happened as I decided to translate my family's stories into English. However, more than the translation itself, I am interested in how the experiences could extend the boundaries of a given language. In this sense, my aim has been not to depend on technical accounts, but is in translating the meaning of the stories collaboratively. As Arthur Frank (2012) beautifully writes, “[s]tories are non-specialized. If technical accounts depend on expertise, stories, on my observation, depend on imagination" (p. 41). He continues: "[s]tories are representations not so much of life as it is, but of life as it is imagined, with that imagination shaped by previous stories. Storytelling is a dialogue of imaginations" (Frank, 2012, p. 50). As such, translating is also a dialogue of imaginations.

\subsubsection{Transcription Coda.}

For this research, I am using Katheleen Wells (2011) instructions for transcribers that suited my narrative analysis purposes. The author obtained this transcription guideline from B. Poland (2002) in “Transcription quality”. In dialogical narrative analysis, every word that is spoken need to be recorded, and it is prohibited to summarize or paraphrasing what you hear. The next box summarizes some of the transcription features used for analyzing my family stories.

\begin{tabular}{|l|l|}
\hline Pauses: & $\begin{array}{l}\text { Insert symbol [...] for long pauses of four or more seconds, and insert } \\
\text { symbol [..] for short of less than four seconds. }\end{array}$ \\
\hline Expressive sounds: & $\begin{array}{l}\text { Insert en parentheses the relevant word for a non-verbal communication } \\
\text { such as (laughing), (crying), (sighing), for example. }\end{array}$ \\
\hline Interruptions: & $\begin{array}{l}\text { Insert a hypen (-) in parentheses where interruption in speech occurs (She } \\
\text { said that was impo-). }\end{array}$ \\
\hline Overlapping Speech: & $\begin{array}{l}\text { Insert a hyphen where interruption occurs and the insert a parentheses } \\
\text { where overlapping speech occurs: R: She said that was impossible-; } \\
\text { (overlapping) I: Who said that? R: Ana. }\end{array}$ \\
\hline Garbled Speech: & $\begin{array}{l}\text { Enclose in brackets a word that has been transcribed for one that was } \\
\text { difficult to hear clearly [resigned] and use the letter, x, to indicate each } \\
\text { word that cannot be understood at all (xxxx). }\end{array}$ \\
\hline Emphasis: & $\begin{array}{l}\text { Use capital letters to denote emphasis through volume or pitch of speech, } \\
\text { for example (WHAT?) }\end{array}$ \\
\hline Held Sounds: & Repeat sounds that are held, separated by hyphens (No-o-o-o). \\
\hline
\end{tabular}




\begin{tabular}{|l|l|}
\hline Paraphrasing others: & $\begin{array}{l}\text { Use quotation marks to indicate when the speakers is parodying what } \\
\text { someone else said or expressing inner voice (I though "I am in control } \\
\text { now") }\end{array}$ \\
\hline
\end{tabular}

Source: Poland, B. (2002). Transcription quality. In J. Gubrium \& J. Holstein (Eds), Handbook of interviews research: Context and method (pp. 629-650). Thousand Oaks, CA: Sage.

\subsection{Ethical Considerations}

In investigating my own family, questions regarding the ethics of whether being a member of the population studied or not arise. This question has been debated within qualitative research in social science, trying to analyze the implications of the researcher membership status in relation to those participating in the research. Accordingly, there is a debate on whether the direct and intimate role of the researcher in both data collection and analysis is an essential aspect of the investigation. In the article "The Space Between: On Being an Insider-Outsider in Qualitative Research," Sonya Corbin Dwyer and Jennifer L. Buckle (2009) engage with this dichotomous perspective. Here, the authors explore the notion of the "space between" that allows researchers to occupy "the position of both insider and outsider rather than insider or outsider" (Dwyer \& Buckle, 2009, p. 54).

The authors describe insider research as the process in which "researchers conduct research with populations of which they are also members so that the researcher shares an identity, language, and experiential base with the study participants" (Dwyer \& Buckle, 2009, p. 58). According to them, among the benefits of being a member of the group one is studying are "access, entry, and a common ground from which to begin the research" (Dwyer \& Buckle, 2009, p. 58). However, the researcher's closeness can lead to "mak[ing] assumptions of similarity and therefore fail[ing] to explain their individual experience fully" (Dwyer \& Buckle, 2009, p. 58), impeding the research process as it progresses. On the contrary, outside research offers space for objectivity in order to gain a full understanding of the phenomena by not influencing the research process.

The authors' proposal is to stop positioning insider and outsider research as binaries or two separate entities. Instead they try to create a bridge, a third space, wherein "paradox, ambiguity, and ambivalence, as well as conjunction and disjunction exist" (Dwyer \& Buckle, 2009, p. 60), can be negotiated. They argue,

The stories of participants are immediate and real to us; individual voices are not lost in a pool of numbers. We carry these individuals with us as we work with the transcripts. The words, representing experiences, are clear and lasting. We cannot retreat to a distant 'researcher' role. Just as our personhood affects the analysis, so, too, the analysis affects our personhood. Within 
this circle of impact is the space between. The intimacy of qualitative research no longer allows us to remain true outsiders to the experience under study and, because of our role as researchers, it does not qualify us as complete insiders. We now occupy the space between, with the costs and benefits this status affords. (Dwyer \& Buckle, 2009, p. 61)

It is precisely from this space between, a space for shared questions, knowledge, and experience, that reflections upon power, privilege, hierarchical, and manipulative relations can be thought. From here, questions of authorship, authority, and entitlement can be discussed collaboratively, constructing creatively new forms of doing research. In this space, ethical considerations can be negotiated, and can also reveal new opportunities for doing more interactive and dynamic research. To illustrate one possibility of doing research, taking into account ethical considerations and trying to work with them, in what follows, I want to share an ethical reflection my mother has helped me to take into account in this research.

\subsubsection{Hoping For the 'Truth' and the 'Good' Story.}

Mili: We (my family) sent with Susana (my friend) a nice cup for Domi and Rosa.

Dresda: Thank you mom. But what for?

Mili: Well, they are reading our stories and they are going to grade them. What if our stories are not good enough?

Dresda: (laugh). What do you mean, Mom?

Mili: Well (silence), that maybe they are hoping for something more [...], I don't know, interesting, or maybe they do not believe us or just do not like our stories.

This conversation between my mother and me is part of several conversations resulting from the interview process. In this Skype call conversation, my mother expresses two legitimate concerns: the reliability and the importance of their stories. This conversation reflects, following the ideas of Berger and Quinney (2005), how women's stories are expected to be judged by scientific standards of authenticity. In this context, 'authenticity' reclaims a degree of coherence and a concept of truth in order to prove stories' narrative plausibility, "a story that makes sense; narrative fidelity- a story consistent with past experiences or other stories; and aesthetic finality - a story with satisfactory closure and representational appeal"' (Sandelowski, 1991, p. 164). In this sense, my mother's concerns are grounded in the assumption that a 'good story' is one that appeals to intelligibility, validity, and narrative truth. However, it is precisely these concerns that I want to dispute with their stories. 
My mother is expecting to be judged by a criteria of logical arguments as adequate or correct. For my mother, the idea that our menstrual stories can become a source of academic knowledge is unthinkable. She is expecting to be graded according to an academic validity system that seeks to separate the expert/non-expert knowledge from people's lived experiences. For my mother, the content of their stories is small compared to the gigantic claims of academic and scientific knowledge; that is, our menstrual stories do not have any formal sense of being 'good stories.' In these terms, my mother is considering women's knowledge and experience as deficient in relation to the truth and reality of scientific knowledge production.

To address this concern, I have found in the article "'Who Were the Experts?' The Science of Love vs. Women's Knowledge of Love during the Spanish Dictatorship,” by Rosa Ma MedinaDoménech (2014), a way to contrast marginalized knowledges with the scientific standards of knowledge production. In the article, the author analyzes women's knowledge, particularly emotional knowledge in Spanish culture during the early years of National-Catholicism (1940s and 1950s). She argues that the "science of (heterosexual) love became a privileged location for the production of a gendered and patriarchal normativity enmeshed with wider Francoist ideology and violence" (MedinaDoménech, 2014, p.179), leaving outside non-traditional forms of emotional expertise, authorized by “"centers' of scientific knowledge production” (Medina-Doménech, 2014, p. 181). In her proposal, the author highlights the importance of "excavating and discovering subaltern knowledges," arguing that “women's past are not only valuable as history, they also become a repository, or 'yacimiento,' of innovative ideas" (Medina-Doménech, 2014, p. 181).

'Yacimiento' refers both to the act of locating a site from which to extract a resource, and to the site in which raw material must be processed, distilled or worked to be made useful. In this sense, 'yacimiento' emphasizes the recovery of past knowledge relevant to the present. To understand past women's emotional knowledge as 'yacimientos' entails extracting this knowledge as an alternative to mainstream, scientific knowledge during particular historical periods. (Medina-Doménech, 2014, p. 181)

Building upon the author's ideas, it could be argued that women's stories are 'yacimientos': narratives and emotional sites from which it is possible to extract the meaning of marginalized experiences; particularly, excavating and discovering bodily stories that remain hidden. Stories as yacimientos challenge mainstream discourses about women's bodily experiences because they inform different and offer diverse voices in the ongoing process of constructing and transforming scientific 'truth' and 'reality.' This implies that women's stores cannot be measured by “conventional scientific standards 
of validity and reliability but the power of stories to evoke the vividness of lived experience" (Berger \& Quinney, 2005, p. 9).

In this frame, when my mother says "what if they do not believe us or just do not like our stories," she questions the veracity and the truth of her lived experience. However, as the Personal Narrative Group (1989) argues, "when talking about their lives, people lie sometimes, forget a lot, exaggerate, become confused, and get things wrong. Yet they are revealing truths" (p. 261). Women's stories are fragmented, ambiguous, and contradictory. This does not mean that women's stories are any less coherent or transparent. What it does mean is that women's stories do not give a truth that seeks an objectivity standard, but instead stories come from the truths of women's experiences:

Unlike the reassuring Truth of the scientific ideal, the truths of personal narratives are neither open to proof nor self-evident. We come to understand them only through interpretation, paying careful attention to the context that shape their creation and to the world views that inform them. (Personal Narrative Group, 1989, p. 261)

My mother's concern invites a rethinking of what is ethically expected of women's stories in academia. To stop forcing them to stand the examination of scientific standards. We cannot expect a narrative truth because there is not one; but perhaps this can be the beginning for encouraging new forms to approach women's experience as a real positioning in the scientific world.

\section{Conclusion}

Stories are the primary source for the content of women's experiences; therefore, I wanted to find a methodology that allows me to approach my research objectives in these two dimensions: a phenomenological approach has facilitated me to situate menstruation in the realm of experience, whereas dialogical narrative inquiry has helped me to narrate my family's menstrual stories. Working collaboratively, both methodologies offer me pathways for making sense of my family's menstrual experiences and at the same time position them within the powerful field of academic knowledge.

Using both methodologies, my aim has been to approach, in a more flexible, caring, and responsible manner, my subjects of study. As a researcher, both methodologies allow me to enter into a self-reflexive process, being able to become sensitive to the storytelling process and to be affected by the creation of knowledge through women's stories. Importantly, through this reflexive process, as a researcher, I have become aware of the importance of my own values, attitudes, and affections 
towards this research, and the biases I can bring to the process of knowledge building. In this vein, I am aware that in positioning my family as a subject of study, a plethora of ethical questions regarding authority, privilege, representation, and power differences are be opened. However, I have come to the conclusion that inner involvement, even if it poses methodological problems, also provides new opportunities for the researcher. In my case as a researcher and as a participant, both methodologies have helped me to understand that my family's stories are not separate from who I am, and that I inevitably need to negotiate my relationships with them and my research. The only thing I have been sure of is that I want to take care of my family during this process, I want to let their stories breathe (Frank, 2010) as they animate me with their meanings. Taking these methodologies into account, the next chapter presents the narrative excerpts I have gathered in the storytelling process. The process of storytelling has helped to reveal stories of hierarchy, inequality, domination, and bodily control, but they also reveal flows of resistance and subversion. Therefore, the next chapter reveals conversational dialogues, and I pay attention as carefully as I can to what my family tells in their stories, and then, in an imaginative act, I interpret them. 


\section{Family Album}

This part is an intermission. It is a parenthesis, a break, a pause, a stop. It is a moment for breathing, for making a cup of coffee. It is a relaxing escape of academic wordiness.

It is a moment for introductions. For personal encounters. It is a moment for getting to know each other. For letting you get familiar with us.

We wanted to tell you about us. We wanted to have a moment for talking to you directly. Maybe by looking at our photos, our bodies and stories can resonate with yours.

In this intermission we narrate ourselves. This is our family album, a family gathering.

This is us. 
You asked me to introduce myself and the first thing that comes to my mind is the word WOMAN (in English). Yes, that word defines me. I like the song Woman by John Lennon. It moves my emotions. Defining myself is quite an existential endeavor to me, but I will try to introduce myself, I do not know if for you or for myself. I am a woman that has lived many years with a lot of vicissitudes, but at this point in my life, I am happy and satisfied with the things that God, life and myself have built, although I am not exempt from contradictions. Now that you ask about menstruation, I think that I lived in a rush, I wanted to grow up, and menstruation made me an adult, so much and fast that I married too soon. With respect to the women around me, I was not very closed. Sisterhood was not something that flourished in me. Just until recently, as adults, that we re encountered and new relations have started to get strong. When I talked about my daughter's menstruation, I felt ashamed of not having been there for her or being more affective, or perhaps giving more significance to that event, but my life limited my decisions many times. Now that I have reached menopause, I realized that I am happy to be a WOMAN close to other women and for other women. Thank you Dresda for inviting me to take part in your research and to narrate this blood circle.

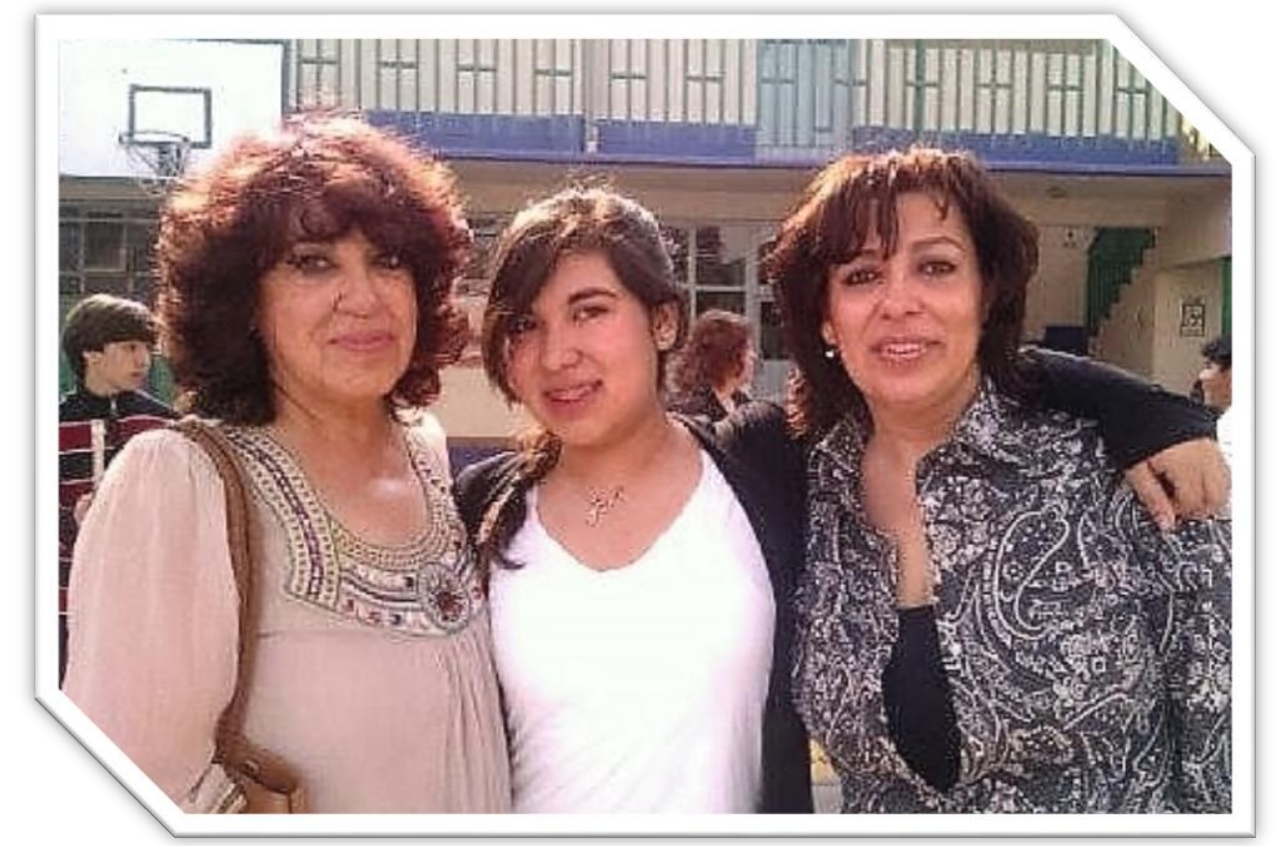

Figure 3 (2015) From left to right: Yolanda, Elissa and Elka

Hi! I am Elissa Fernanda Navarro Méndez and I am 18 years old. I love to sing, going to the movies, musical theater, TV shows, to read and getting to know new places I live with my mom Elka, my dad Julián and my brother Fausto. I have just finished high school and I am about to go to college. The experience of menstruation was not weird for me, because my friends and I always tell stories. But when my cousin asked me about a positive stores I had about menstruation I could not remember! Maybe I hadn't have one. That made me think on how I experience and perceive my menses.
Hello! I am Elka Méndez de la Brena. I am Elissa's and Fausto's mother. Elissa is my oldest and she is about to go to college. She loves singing and going to the theater. My youngest is in high school and he is addicted to video games. My husband Julián Works an audiovisual producer. Another important person in my live is my mother, because I have the opportunity to share with here he most important thing for me: my children. Talking about menstruation made me remember comfortable and disagreeable situations. I think it is super interesting that Dresda is working on this subject because it allowed me to think about menstruation from a different point of view and to find an important tie between the women in my family; particularly a mother and daughter bonding. 
Hello! My name is Susana del Pilar Tapia de la Brena. I am 43 years old. I am a mother of three adolescents. I am a housewife and I sell make up and body creams and lotions. Anyway, I am really sociable and I like being with my friends. I love listening to music and have a nice time. I also enjoy being with my family, watching movies, and have family time. As for the 'menstruation' thing, I think it is really important in puberty. It is the physical sign that you stop being a child and start being a women. It is a moment that can be confusing, and because we do not talk about this, it can create anxiety or fear. We need to tell more menstrual stories. We need to share more. Stories are good for women.

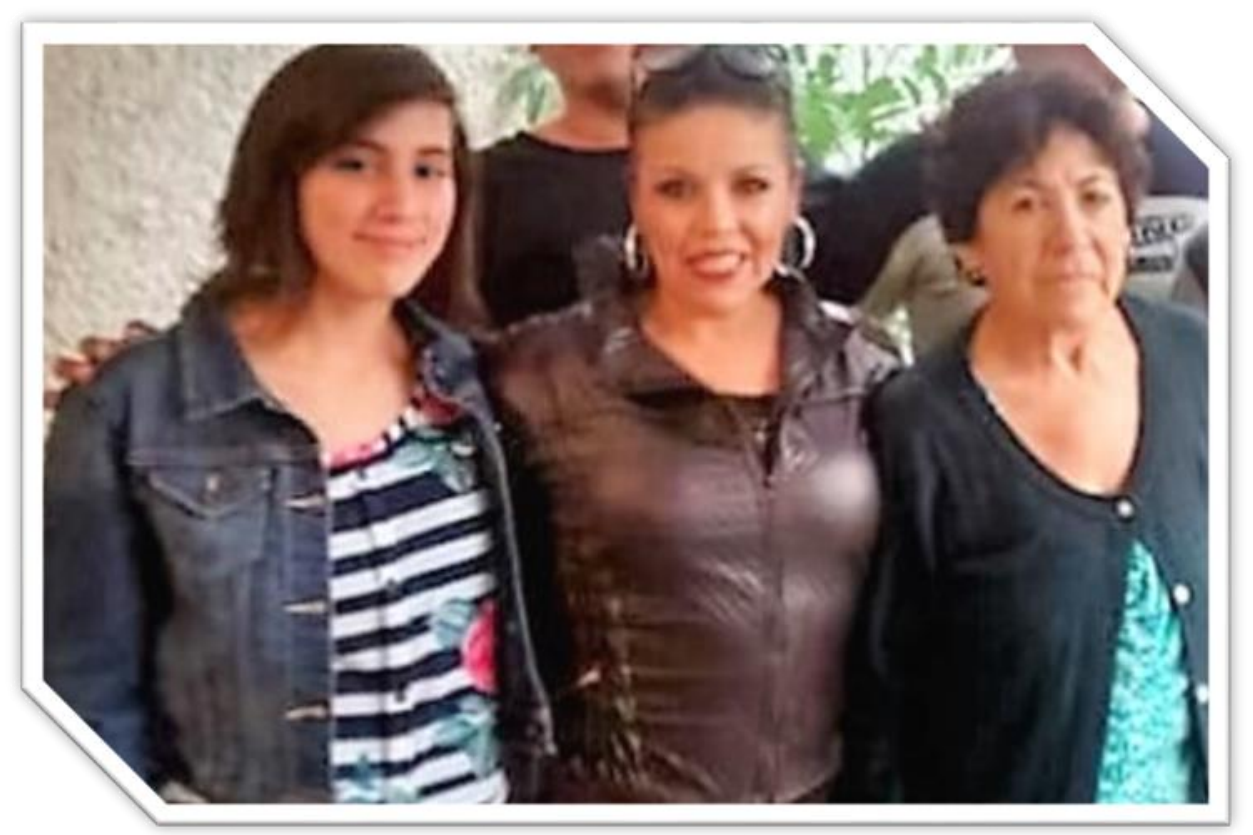

Hi all! My name is Zabdi Susana Anaya Tapia. I am 16 years old. I live with my dad José, my mom Susana, and my two brothers, Carlos and Christian. I love watching animé, going out with my friends, eating ice-cream and climbing rocks. My experience of telling my menstrual stories was uncomfortable because I do not talk about this topic, just with my friends or my mom. But after a while, it got easier to share how I felt. I have had different menstrual experiences. Sometimes they have been really painful; others have made me think I am growing up, and in really few of them, I have actually felt embarrassed or ashamed. It is something I am used to live with. Anyway, I am happy that I had the chance to tell my experiences that brought into light weird memories.

Figure 4 (2016) From left to right. Zabdi, Susana and Guadalupe

My name is Maria Guadalupe de la Brena Dartiz What I felt when talking about menstruation was the lack of sufficient information to express the experience. I did not receive enough information from my mother so I wasn't able to transmit accurate menstrual stories to my daughter. 


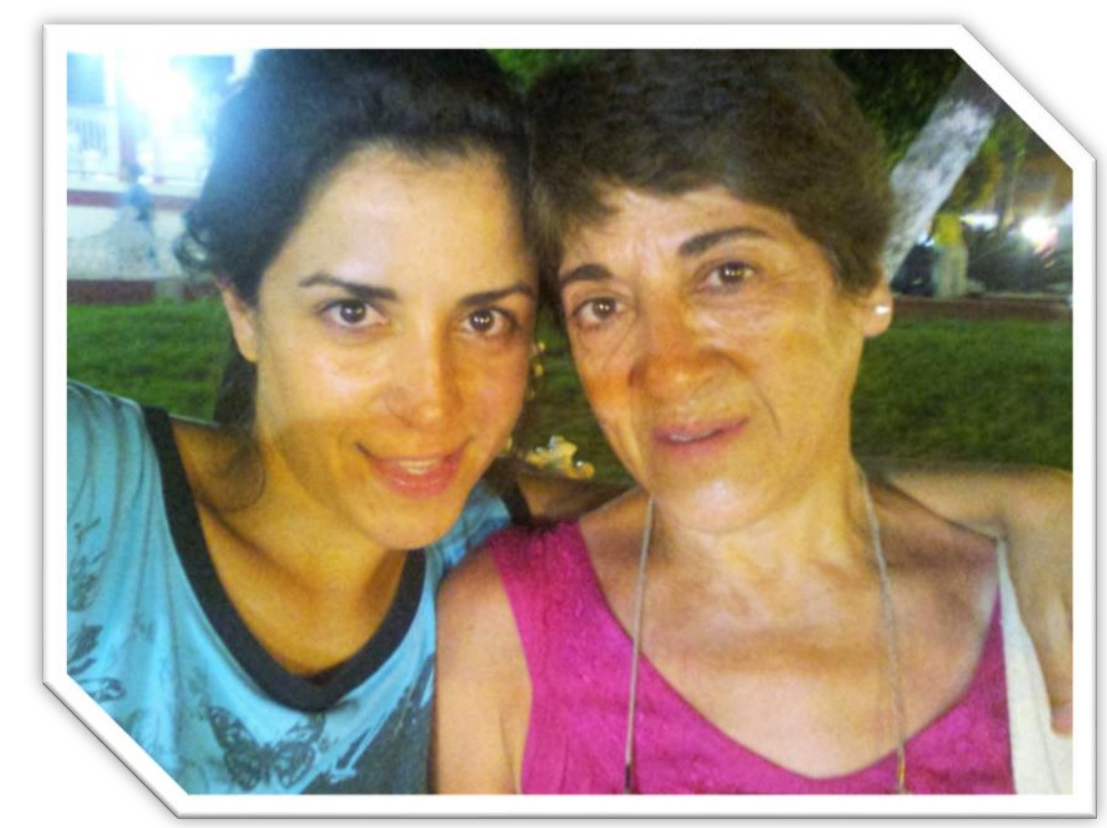

My name is Martha de la Brena Dartiz. I am 65 years old, I am married and I am the mother of two Young adults: Daniela and Didier. I live in Mexico City. I studied to be a Certified Public Accountant at the National Autonomous University of Mexico. I work as a federal employee. Talking about menstruation signified shame and anger to remember all the physical changes (the augmentation of breast, the bleeding) imposed by this new bodily status. Menstruation in my life meant a restricted experience both at school and at home. Due to the lack of information, as a consequence of our shame of asking questions in order to clarify myths and rumors, I relied on magazines, newsletters, and gossiping among friends. Another problem at that time, was getting menstrual pads because we were 5 sisters. Telling stories about menstrual experiences made me think about all these years in which I was not aware of the magnitude of this experience. It is something that happens every month ad I have never stopped thinking about it.

Figure 5 (2016) From left to right. Daniela and Martha.

My name is Daniela and I am 36 years old. I am a nutritionist and I give medical consultations while I finish a second degree in sociolinguistics. I was really gland in helping with memories, stories and feelings about menstruation. A moment really worth remembering. Menstruation in general seems to me as an automatic bodily act, and sometimes imperceptible, as long as the PMS does not appear! I really think that we could have a biological break and have the period every two or three months. It could be an ecological act. Telling my story made me think about the process and to appreciate it as part of my life. Telling my story was to pull a memory puzzle together. I was really excited and it gave me a great satisfaction that our family stories could help my cousin's research. 


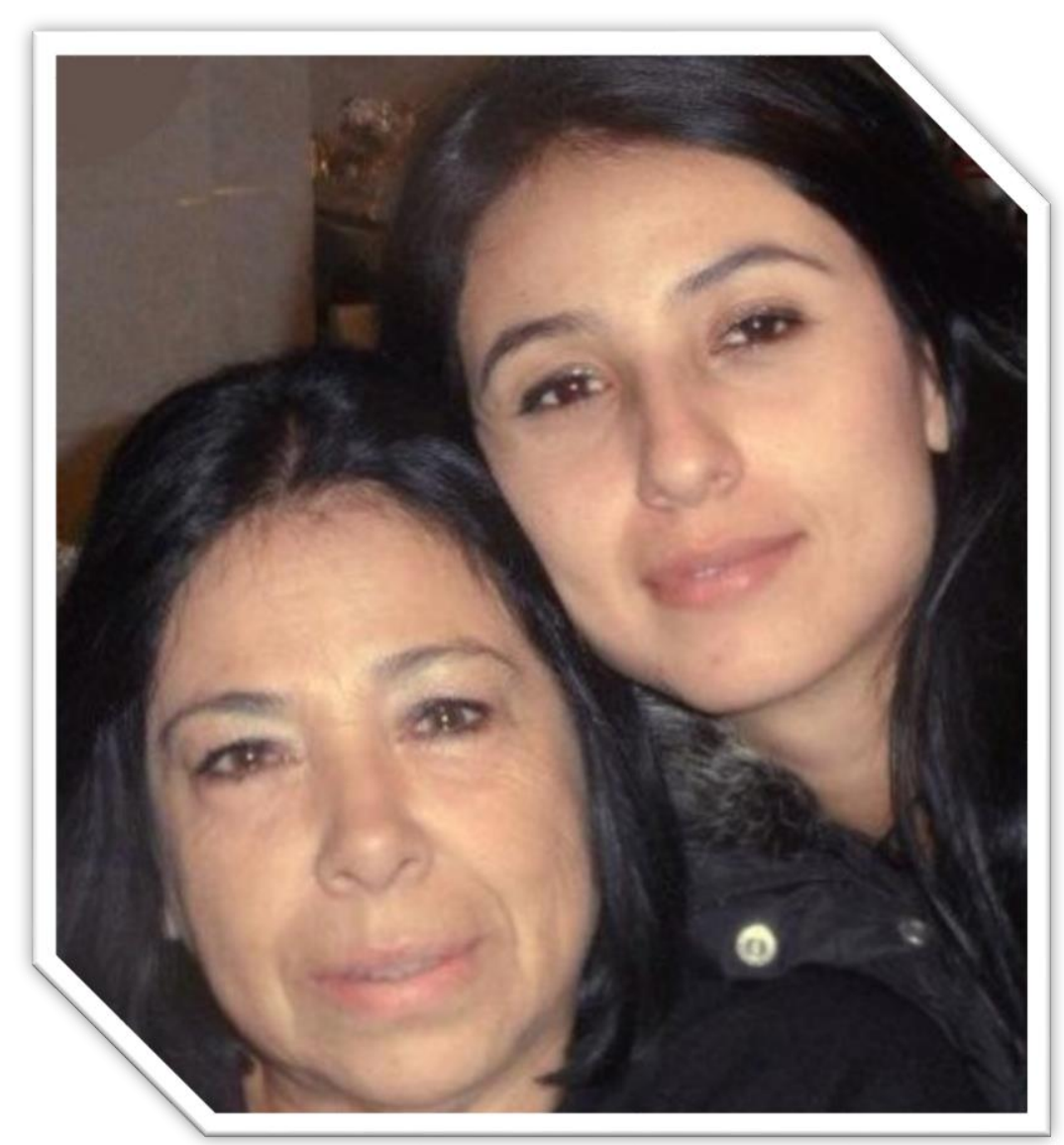

Figure 6 (2013) From left to right Emigdia and Dresda.
My name is Dresda Méndez de la Brena. I am 32 years old and I have been menstruating for 20 years. I love words and stories. Words have been my semiotic companions all my life. I believe they can breathe, they can move, they can dance, they can repair and they can hurt. I have always been suspicious about how words and stories have been used against women; against our bodies. My love for stories makes me believe that they can disrupt, explode, turn over, shake, and transform the perverse use that patriarchy, it all its shapes and forms, has made of them. Every part of our body has a story to tell. Menstruation is a bodily story that has been waiting to be told for a long a time. But it did not want to be told alone. It needed to be told with other stories. Stories that share de the same blood: family stories. I love stories. I love bodies. And I love what stories can do when they dance together.

My name is Emigdia de la Brena Dartiz. I am Dresda's mother. I am also a full-time grandmother. I enjoy taking care of my two granddaughters: Fernanda and Maria José. Telling stories about menstruation brought into light pleasant experiences, and I think I know and understand now my sisters and my mother better 


\section{Chapter III. Telling Hegemonic Menstrual Tales}

In this chapter, I introduce intergenerational storytelling. I explore different hegemonic menstrual tales shared by three generations of women in my family. Bringing chapter one to a close, I have introduced the term "hegemonic tales" to refer to dominant social narratives that reproduce "existing ideologies and hegemonic relations of power and inequality" (Ewick \& Silbey, 1995, p. 212), which become internalized and taken for granted. In this chapter, I expand its meaning by referring to "hegemonic menstrual tales" as the hegemonic dominant narratives - taboos, attitudes, and beliefs - of menstruation that are proliferated by social institutions and dominant discourses, and thus come to be taken for granted, having a determinant influence on how women experience menstruation during their lives. Consequently, the main focus of this chapter is to present what kinds of menstrual discourses hegemonic tales create, and how that translates into the ways we give meaning to our menstrual stories through generations.

Accordingly, the first part of this chapter concerns general information about the history of hegemonic menstrual tales in cultural narratives and a discussion of the most influential texts on the subject. Following, there is a presentation of how menstruation has been studied in different social contexts, and then I focus on the particularities of the Mexican context. Finally, by using excerpts from oral narratives, I explore my own family's menstrual stories, particularly focusing on stories capacity to be performative, meaning not only that storytelling is a performance, but also that stories enact whatever truth they claim. Particularly, I argue that my family menstrual stories are a form of narrative-embodied-performance ${ }^{14}$ that reveals how women can perform their stories, in a particular embodiment that makes possible the representation of the experience in the narrative.

\subsection{Menstruation as a Hegemonic Tale}

In Chapter One, I argued that stories are embedded in culturally dominant narratives that are taken up as legitimate knowledge, yield power, and are regarded as truth. I have called these narratives 'hegemonic tales,' and they often are transmitted in imperceptible ways, which make difficult their identification and confrontation (McKenzie-Mohr \& Lafrance, 2014). I presented the family as a social institution in which stories can create, reinforce, and reproduce cultural structures of subordination

\footnotetext{
${ }^{14}$ In chapter One, I situate women's narratives within feminine bodily practices. I argued that it is precisely this particular embodiment that makes possible the representation of the body in the narrative. Thus, feminine bodily experiences and the bodily participation are the context upon which the narrative is performed. When women's tell stories, the body becomes the instrument with which the narrative is performed (Heavey, 2015); as a result women's stories are narrative-embodied-performances wherein the body is both an instrument and content of the narrative itself.
} 
that privilege normative forms, experiences, and meanings (childbirth, marriage, menstruation, menopause), and mute marginalized or closeted "nontraditional experiences" (abortion, divorce, homosexuality) (Davies \& Fitchett, 2015, p. 112), articulating and reproducing "existing ideologies and hegemonic relations of power and inequality" (Ewick \& Silbey, 1995, p. 212). Ultimately, the oppressive power of hegemonic tales influences how women story their bodily experiences.

Particularly, menarche and menstruation are significant milestones in a woman's life. Both biological processes have deep cultural implications that "produce the body and the women as cultural entities" (Lee, 1994, p. 343). In this sense, women's bodies are trapped within ambivalent discourses that, on the one hand, celebrate the journey of puberty into womanhood and, on the other, devalue women "through cultural scripts associated with the body" (Lee, 1994, p. 344). Predominantly in Western societies, menarche and menstruation tend to be situated in the intersection of dominant narratives that construct women's understandings of menstruation as a hygienic crisis that needs to be controlled and managed (menstruation as a shameful and disgusting moment that must be concealed, menstruation as a biological and medical process where the purpose of menstruation is restricted to pregnancy or considered as an illness or disability that needs to be treated), and menstruation as constitutive of womanhood in terms of motherhood and femininity (Agnew, 2012). As such, these tales of menstruation encompass the power of ideas, discourses, practices, and images that situate women and women's bodies in the subordinate position of a sex/gender structure.

Understanding how meaning and knowledge about menstruation is constructed through language and discourse, it is vital to realize how the normalizing powers of language impact issues of gender and sexuality. Consequently, by situating menstruation as a hegemonic tale, I am underlying the complex dynamics "between the body, the self, and family as well as the interplay of power, agency, and social control in society" (Lee, 2008, p. 1326). Menstruation as a hegemonic tale emphasizes the ways in which ideas and ideologies have the power to discipline women's bodies.

This ideologies function in a system is called patriarchy, and this system promotes tales of women's menstrual bodies as failed, embarrassing, dirty, crazy, ill, unbalanced, fearful, shameful, humiliating, preoccupied, and messy; it is part of normal, everyday thought and speech. The next section deals with the emergence of these tales and their influences on social attitudes and beliefs toward menstruation. Here, it is worth remarking that the history I am tracing does not reflect the complete emergence of these tales, instead, the historical review I am presenting is my own mapping of it. 


\subsubsection{Historical Review of Hegemonic Menstrual Tales.}

Hegemonic tales regarding menstruation have been studied for several decades. Within the research literature I have found, some of the most recognized texts on the subject are mostly anthropological studies, such as the 1976 work of Janice Delaney, Mary Jane Lupton, and Emily Toth, The Curse: A Cultural History of Menstruation, Emily Martin's (1987) The Woman in the Body: A Cultural Analysis of Reproduction, and Thomas Buckley and Alma Gottlieb's (1990) Blood Magic: The Anthropology of Menstruation. These texts introduce different taboos, myths, rituals, and symbolisms of menstruation in non-Western and the so-called 'traditional' societies. Throughout their pages, these books explore how the perception of taboo is a powerful source for constructing experiences, including women's experiences of menstruation.

Like taboos, there are several forms of knowledge, experience, dominant discourses, and ideologies that influence perceptions about menstruation. Particularly, medical discourses have been keystones in shaping women's ideas and perceptions regarding menstruation. For instance, Deborah Lupton (2003), in Medicine as Culture: Illness, Disease and the Body in Western Societies, has explored the use of medicine as an agent of social control, and the social construction of gender in medical discourse. The author presents concerns about the ways in which women's bodies have historically been defined by patriarchy, and how this has led to reduce women's embodiment to being purely social constructions constituted by medical and scientific discourses.

Another example within socio-cultural discourses about menstruation is the study presented by Umme Busra \& Fateha Sultana (2011) in "The Imageries of Menstruation in Sanitary Napkin Ads: Representation and the Practice of Discourse as a Marketing Strategy" where they analyze how dominant discourses surrounding menstruation have consistently been used as a product promotion strategy in ads for sanitary napkins. They have captured how the mainstream media, as well as media targeted towards women, uses discourses such as dirt, shame, and concealment that establish specific rules, attitudes, ideas, and beliefs, which shape women's behavior and serve to control their bodies and sexuality.

All of these examples aim to elucidate how social and cultural narratives regarding menstruation can become so embedded in general narratives; accepted as if they were a commonsense reality, taken for granted, remaining unchallenged. Next I present a more detailed review of the emergence of these dominant discourses in cultural narratives. However, I am aware that plenty has been written regarding this topic, and that by excluding some works I am limiting not only the scope of my research, but the reader's ability to engage with the full scope of menstrual aspects. I take full 
responsibility for these important omissions. Nevertheless, for the purpose of this research, the material that I present gives an elaborate framework for analysis.

\subsubsection{Hegemonic Menstrual Tales in Cultural Narratives.}

As aforementioned, one of the most influential and cited books regarding menstrual taboos is Delaney, Lupton, \& Toth's work. The authors explore how menstrual taboos have been yielded in order to protect men from women's “threatening supernatural power" (Delaney et al., 1974, p. 5). In this sense, menstrual taboos are, "practices that help others to avoid [woman] and her dangerous influence and that enable her to get through the menstrual period without succumbing to her own daily power" (Delaney et al., 1974, p. 5). Throughout the book, Delaney et. al. describe a variety of ways in which taboos around menstruation have worked, including exclusion from social spaces, religious ritual, and sexual practices. The authors present how in some cultures menstruating women have been considered capable of, for example, damaging the crops, injuring cider, bread, or mayonnaise fermentation, or how even musicians have blamed women for breaking guitars or violin strings. The authors also point out how sex taboos against menstruation have helped to situate menstruating women as "messy, sloppy, and possibly frightening; it is also a subtle reinforcement of [,] the message that women is the "unclean sex"” (Delaney et al., 1974, p. 19). Particularly, the authors explore menstrual taboos in Jewish and Christian religious practices that codify and organize discrimination against menstruating women.

In Blood Magic, Buckley and Gottlieb compile different essays that contribute to the understanding of anthropological perceptions of menstruation in different societies (i.e. the Ivory Coast, Turkey, Borneo, Sierra Leone). By exploring these menstrual attitudes and beliefs, the authors challenge the idea of a universal menstrual taboo that operates in the same way in all societies. They argue: “The menstrual taboo' as such does not exist. Rather, what is found in close cross-cultural study is a wide range of distinct rules for conduct regarding menstruation that bespeak quite different, even opposite, purposes and meanings" (Buckley \& Gottlieb, 1989, p. 7). Interestingly, the authors offer a more positive image of menstruation as a powerful tool for women, in contrast to the alwayssubordinated female menstrual position. They write: "Thus the desirability and benefits of some menstrual taboos for women, the possibility that these taboos enhance rather than suppress women's influence and power, have generally been ignored by investigators" (Buckley \& Gottlieb, 1989, p. 14). Furthermore, with meticulous case studies, the authors demonstrate that menstrual blood is used and understood in rituals also as potentially positive and powerful (i.e. Yurok women use menstrual 
blood in rituals as a route to knowledge and heath) (Buckley \& Gottlieb, 1989), challenging the negative beliefs and attitudes regarding menstruators and menstrual blood.

As a symbolic element, menstrual blood has been seen as dirty and menstruation as something needing careful management. In the well-read text Purity and Danger: An Analysis of Concepts of Pollution and Taboo, Mary Douglas (1966) explores how ideas of pollution have worked in instrumental and oppressive ways within different societies. She observes that certain beliefs reinforce social pressures; in this sense, ideas of pollution work as, "analogies for expressing a general view of the social order" (Douglas, 1966, p. 3). In her view, pollution beliefs express symmetrical or hierarchal structures that are imposed upon the sexes (particularly females) regarding ideas of sex contagion and sexual purification. Thus, menstruation is coded as 'dirty' and placed antagonistically against the sacred, the pure, the rational, and bodily control and management.

Interestingly, Douglas argues that women's bodies represent a challenge to the margins of the human body. According to Douglas, a body's orifices produce social anxiety because they traverse the boundaries of the body. She argues that the dangers that a body's orifices evoke are related to 1) the danger of pressing on external boundaries; 2) the danger of transgressing the internal lines of the system; and 3) the danger of internal contradiction (Douglas, 1966). In particular, women's bodies' orifices construct the idea that women spill over, that they have volume and thus have "an outside surface and an inner space, in particular the inner space with a reproductive purpose" (Jeffries, 2007, p. 158). Women's orifices break out of the idea of a controlled body, or the body as a liminal space.

Pondering in the same line of thought, Jean Comaroff (1985), in "Bodily Reform as Historical Practice," explores how the perception of the 'orifice' has been understood as a "universal marker of the threshold between 'inside' and 'outside,' 'self' and 'other' and controlled (and, hence cultural) process against unbounded, asocial flux" (p. 546). Comaroff suggests that bodily orifices generate social anxiety because they represent the uncontrolled, the unmediated, and the "less than optimal containment of the person within his/her bodily margins" (1985, p. 547). Women's bodily orifices, particularly the unmediated orifice of menstrual blood flow, are considered as social dangers because they threaten to act freely upon the world by "spilling over into it and breaching the distinction between inside and outside" (Comaroff, 1985, p. 547). In a male dominated system, the menstrual flow represents a "lacking closure in relation to the external world" (Comaroff, 1985, p. 547), in which women's orifices blur the line between inner and outer bodily space, and consequently evoke restrictions upon women's participation in the social world.

From a different perspective, Martin (1987) uses a Marxist way of thinking to examine the reproductive politics of the female body. For Martin, menstruation is considered as a kind of a failure that describes a body of production gone out of control. Martin argues that menstruation proposes 
another kind of reproductive horror, which is "the lack of production: the disused factory, the failed business, the idle machine" (1987, p. 45). Thus, women's bodies are located in a 'General Factory' (Martin, 1987) in which humanity's great role is to produce. She states,

Menstruation not only carries with it the connotation of a production system that has failed to produce, it also carries the idea of production gone awry, making products of no use, not to specification, unsalable, wasted, scrap. (Martin, 1987, p. 46)

In a system of capitalism, women's bodies are trapped in metaphors of mass production that value the quantity and efficiency, and cast female bodily processes as failed production (Bobel, 2010). In Martin's view, medical texts applaud the male body for being a continuous producer and supplier of sperm while the female body and its biological processes are contemplated as inefficient suppliers, and therefore easily degraded. Even more, Martin's exploration of premenstrual syndrome (PMS) ${ }^{15}$ highlights the dominant model (psychological/medical) that catalogues PMS as "a malfunction in the production of hormones during the menstrual cycle," which causes a variety of physical, emotional, and behavioral symptoms (Martin, 1991, p. 113). As a result, PMS is considered a "genuine female illness," giving faculty to medical experts (males) to offer different 'treatments.'

The medicalization of menstruation and the medical model of chronic illness is perhaps one of the most challenging dominant narratives that women face nowadays about menstruation. Medical tactics have been based on treating women's bodies with drugs to calm women's symptoms and thus relieve men from irregular, unpredictable, and discomforting changes in women's mood and bodies. This is why hegemonic tales can be harmful to women - , and this is why it is also important to explore the ways hegemonic menstrual tales influence the perception of the female body in social sciences and politics, as well as in scientific and medical discourses.

\subsubsection{Hegemonic Menstrual Tales in Medical Narratives.}

Perhaps the most influential work regarding the western history of menstruation is Chris Bobel's (2010) book New Blood: Third-Wave Feminism and the Politics of Menstruation. This book has added new dimensions to prior debates by focusing on contemporary menstrual activists who reject the construction of menstruation as a problem in need of a solution. Bobel comments, "at the core of menstrual activism [are the] efforts to confront negative representations of menstruation, which

\footnotetext{
${ }^{15}$ Premenstrual Syndrome (PMS) refers to "the cyclic recurrence of certain physical, physiological, and behavioral changes that begin during the week prior to menstruation and disappear soon after menstruation has begun" (Chrisler \& Gorman, 2015, p. 78).
} 
impede the development of safe products, the distribution of comprehensive information, and honest, informed dialogue about this bodily process" (2010, p. 7).

Contemporary menstrual approaches resist the idea of a medicalized and commodified body, advocate against pathologizing and shaming the natural menstrual experience, and, most recently, menstrual suppression (Bobel, 2010). Nowadays, the female body and its reproductive functions are medicalized in a culture that aims to silence women's bodily experiences. The medicalization of menstruation "generally means that menstruation is defined as an illness with physical and psychological symptoms" (Fingerson, 2006, p. 57). Negative medical discourses often describe menstruation as a "loss" or a "failure" in reproduction, focusing on the dysfunctional states of the menstrual cycle such as amenorrhea.

In fact, Martin (1991) describes how medical texts and scientific discourses have constructed a 'scientific fairy tale' in which menstruation is viewed in this way. Consequently, menstruation is reduced to terms of pain and illness, needing to be socially controlled by medical 'expertise.' Menstruation, or more precisely, the menstrual cycle, needs to be regulated in order to adjust the reproductive system. In Martin's view, the 'scientific fairy tale' has created the understanding of menstruation as a failed production, opening to male control over women's reproductive bodies and a negative perspective of menstrual blood as waste and scrap.

Importantly, this view of menstrual blood as a waste has led to literature that establishes the remarkable health advantages of suppressing menstruation. For instance, Elsimar M. Coutinho and Sheldon J. Segal's (1999) book Is Menstruation Obsolete? argue that regular menstrual bleeding is unnatural, and that it actually produces several medical conditions. They state,

Over the years, little attention has been given to the possibility that repeated menstruation, a relatively recent experience for women, could be harmful to their health. The era of menstruation began when human social structure and cultural changes broke the relentless pattern of repetitive pregnancies and prolonged periods of lactation. As women reproduced less, they menstruated more often. Presently, fertilization of an egg during a woman's lifetime is a rare event. (Coutinho \& Segal, 1999, p. 5)

The authors maintain that while menstruation is a modern development that may be culturally significant, it is not medically meaningful (Coutinho \& Segal, 1999). Moreover, they propose that "substantial health benefits can be derived from adopting menstruation suppression as standard practice" (Coutinho \& Segal, 1999, p. 117), such as the elimination of menstrual related illness: anemia, endometriosis, and PMS, just to name a few. In this sense, women can now have menstruation 
'treated' or 'cured' as if it were a medical disease. As a result, many women have come to question the purpose and necessity of their monthly bleeding, shaping many women's relationships with their menstruation, and moreover, with their own bodies.

Besides the failure of menstruation, the menstrual cycle is connected to another pathological malfunction, the premenstrual woman. The study of premenstrual symptoms (PMS) has predominantly originated within medicine and psychoanalysis, both in fields concerned with anomalies and diseases (Walker, 1997). In these fields, moods and emotions are considered "symptoms" of a disordered body that needs to be regulated. According to Chrisler and Gorman (2015), PMS is typically framed biomedically, in a way which tends to approach premenstrual women as "ranging" or "unbalanced" (Chrisler \& Gorman, 2015). Consequently, mood regulation becomes one more step in the continuing medicalization of women's lives and emotions. These authors argue that, even when physiological and biochemical factors may explain some changes in women's endocrinological systems, they are not the only thing that do.

Cultural beliefs and social interactions are important reasons why women might expect PMS or attribute symptoms to it that could be the result of some other problem (e.g. depression, lack of social support) or circumstances (e.g., financial or relationship stress). (Chrisler \& Gorman, 2015, p. 84)

By labeling PMS as an illness, there is an absence of critical thinking about the societal rules, gender roles and gendered division of labor that contribute to women's menstrual experiences. As Esther Rome comments, "calling these times of rage symptoms of disease is a handy way of not looking at what women are upset about and why. It is a way of 'keeping us in place'" (Rome, 1986, p. 145). In this sense, menstruation is a cultural experience.

What all this body of literature shows is that even when menstruation may appear as a natural, physiological process experienced by most people who menstruate, its meaning and symbolic potency is derived from particular cultural, historical, and social contexts that are impossible to ignore. Studies (Marván \& Trujillo, 2010; Uskul, 2004; Montgomery, 1974; Castañeda, García \& Langer, 1996) have shown how women in different countries differ in their preparation for menarche, their beliefs and attitudes toward menstruation, and, as a consequence, in their experiences of menses (Marván \& Trujillo, 2010). These studies shed light on how even when the experience of menarche and menstruation are significantly shared, the particular meaning of these events varies considerably in different contexts, having an impact on how menstruation and menarche is experienced. Consequently, cultural, social, and familial backgrounds in which women grow up influence their 
beliefs about and attitudes toward menstruation. For the purposes of this research, it is important to situate hegemonic menstrual tales within the socio-cultural contexts which they coexist. As such, in the next section I present some literature regarding menstrual attitudes and beliefs in Mexico, and its implications on menstrual experiences in the lives of my family.

\subsection{Mexican Hegemonic Menstrual Tales}

Depending on the social context in which menstruation is experienced, it will be accompanied by specific hegemonic tales of menstrual shame, silence, and taboo. Cultural repercussions of social and cultural attitudes towards menstruation have been studied by different scholars. For example, in Rita E. Montgomery's (1974) anthropological research "A Cross-Cultural Study of Menstruation, Menstrual Taboos, and Related Social Variables," she studies 44 societies (including the Mexican indigenous group the Tarahumaras) regarding the numbers and kinds of menstrual taboos present. Montgomery found six basic social codes based on taboos shared by these social groups: 1) A generalized belief that menstrual fluid is unpleasant, contaminating or dangerous; 2) Menstruants may not have sexual intercourse; 3) Personal restrictions are imposed upon menstruants, such as food intake; 4) Restrictions are imposed upon contact by menstruants with men's things; 5) Menstruants may not cook for men; and 6) Menstruants are confined to menstrual huts for the duration of their periods (Montgomery, 1974, p. 152). Her results prove how certain taboos are transcultural in nature, though not all restrictions are universal.

More recently, in "Women's Menarche Stories from a Multicultural Sample," Ayse K. Uskul (2004) presents a study composed of 450 participants from 115 different countries ranging between 23-52 years old. Her findings show that there are more similarities than differences, despite women's cultural backgrounds. However, Uskul has found important differences that need to be taken into account while studying menarche and menstruation with a multicultural approach. She notes that the existence of formal education about menstruation, regulation surrounding menstruation, the power of religion and traditional rules, and the presence of ceremonies for menarche (Uskul, 2004) have different impacts on women's cultural, social, and familial environments. She observes that women from Western-Europe and North and South America generally have formal education about menstruation at some point of their lives. She also has found that women who come from traditional and religious countries often have more difficulty adjusting to menarche and socialization about menstruation.

Particularly in Mexico, a body of scholarship that studies menstrual attitudes and beliefs exists, but it is limited. Significantly, Mexican scholar María Luisa Marván has been the lead researcher in 
the study of menstrual attitudes and beliefs in Mexico, particularly in urban areas. In her several research projects with different scholars, the author has analyzed Mexican adolescents' experiences and attitudes toward menstruation (Marván \& Molina-Abolnik, 2012), including emotional reactions to menarche among Mexican women of different generations (Marván, Morales, \& Cortés-Riestra, 2006), premenarcheal Mexican girls’ expectations (Marván, Espinoza-hernández, \& Vacio, 2002), menstrual beliefs and attitudes in middle-aged Mexicans (Marván, Cortés-Iniestra, \& González, 2005), body appreciation toward menstruation (Chrisler J. C., Marván, Gorman, \& Rossini, 2015), and menstrual socialization concerning menstruation in rural and urban Mexican women (Marván \& Trujillo, 2010).

Interestingly, Marván and Paulina Trujillo (2010) have found considerable cultural similarities and differences between Mexico and developed Western countries. For example, according to both authors, Mexican and American women share cultural attitudes, especially negative ones, toward menstruation. Cultural discourses such as shame and concealment, secrecy, and menstruation as an illness or disability perpetuate women's alienation with menstruation in both countries (Marván \& Trujillo, 2010). However, the relevance of Marván's and Trujillo's work resides in understanding how the particularities of Mexican women's attitudes and beliefs toward menstruation depend on their immediate familial environment and the cultural background in which they grow up.

Consequently, Mexican women's attitudes and beliefs toward menstruation need to be explored taking into account the particular segment of the population in question (Marván \& Trujillo, 2010). Therefore, Mexican menstrual attitudes and beliefs need to be approached including a differentiation of women living in rural and urban areas of the country. Also, it is important to be aware of the fact that contemporary Mexican society "is the product of a mixture of cultures, in which pre-Colombian elements are still very important" (Castañeda, et al., 1996, p. 133). Thus, Mexican women will experience menstruation according to a complex system of beliefs that depend on the sociocultural context they inhabit.

Unfortunately, academic studies that offer a comparative framework regarding women's rural and urban menstrual attitudes and beliefs in Mexico are still quite scarce. Mostly these studies focus on women's attitudes and beliefs toward menstruation in industrial cities such as Puebla (Marván, et al., 2005), Hermosillo (García-Pérez, et al., 2010), and Mexico City (Marván, et al., 2002; Marván \& Alcalá-Herrera, 2014). In contrast, there is only one study regarding beliefs about menstruation in two rural communities, Tlaltizapan and Yecapixtla, located in the State of Morelos (Castañeda, et al., 1996). Despite the abundant bibliography of sources, these studies reveal that the specificities of the menarche and menstrual experience depend on the sociocultural contexts in which they occur and, 
consequently, menstruation is framed by the discourses of a determinate time and place (Marván, et al., 2005).

In this context, I situate the influence of dominant menstrual discourses in a specific social institution: my family. My family's attitudes and beliefs toward menstruation have been influenced by the socio-cultural context in which we have taken part. My family has always been located in an urban area (Mexico City), particularly residing in the suburbs. My family exemplifies the typical middle class household in Mexico, which consists of a nuclear family (father, mother and maximum three children) with stable income (either one or the two parents work), a sizable house (either owned or rented), a few cars and family vacations. Coming from a middle-class sector, almost all of the members of my family have had the opportunity to access education (mainly until graduate level). Importantly, even when Mexican society is predominantly mestiza ${ }^{16}$, my family does not belong to or identify with any particular indigenous group. However, the indigenous cosmovision and traditions are present in my family as part of the Mexican culture with which we identify, so we are not completely alienated from Pre-Colombian elements. Consequently, our beliefs and attitude regarding menstruation are influenced by the dynamics of an urban middle-class and a series of our particularly cultural traditions.

\subsubsection{Sharing Family Hegemonic Menstrual Tales.}

Dresda (32): Aunt, do you remember what you said to Susana when she had her menarche?

Lupe (68): Back at that time we had female dogs, and there was one that was having her bleeding, and she was cleaning her leg. I told her (Susana), 'look how that dog is cleaning herself, she is really clean' and then I told her: 'you need to be smart because the male dogs leave and then the female dogs have to stay with their babies.' Now, Susana laughs and makes fun of me for telling her that story. I do not know how she took it. Maybe she took it as a joke or as a really superficial story. But back at that time, for me, it was the most concrete thing that I could have ever possibly taught her.

Menstrual tales are not innocent; they do something in the world. This is why menstrual stories matter. Menstrual stories are "active doings" (McKenzie-Mohr \& Lafrance, 2014) embedded in a larger web of meaning and signification that is often concealed in secrecy, taboo, and negativity. Take for example my aunt's dog story. It might be seen as an innocent, mother's story, even a sweet one. However, her 'simple' story speaks about menstrual cleanliness, bodily (hetero) sexualization, and an

\footnotetext{
${ }^{16}$ Mestizo/a refers to a population with mixed racial ancestry, especially of mixed European and Indigenous ancestry.
} 
ambivalence about changing bodies. It also brings about the changing relationship between mothers and daughters, and mothers' preparation for giving their daughters information about menstruation before and after their menarche. Most importantly, it actively speaks to how an innocent, naïve story can go through generations, shaping mothers' and daughters' reactions and expectations to menstruation.

As such, my aunt's story is embedded in hegemonic cultural scripts (taboos, attitudes, and beliefs) of menstruation that are proliferated by social institutions and dominant discourses, thus taken for granted and never challenged, a determinant influence on how women experience menstruation during their lifespans. These hegemonic menstrual tales are grounded in social practices and norms that shape the ways women construct themselves in relation to menstruation. As stated in prior sections, Mexican mothers are the primary source of information about menstruation for menstruators (Marván \& Molina-Abolnik, 2012). Therefore, mothers' menstrual stories will have an impact on girls' initial attitudes, beliefs, and practices toward menstruation, and, moreover, they will have an influence on those of any of the daughters' future offspring.

In Mexico, Marván and Molina-Abolnik (2012) have explored the kind of information Mexican mothers give to their daughters about menstruation before their menarche. They have studied 1) the kind of messages Mexican mothers give their daughters about menstruation before their menarche, as well as how prepared the daughters feel when they experience their first blood, and 2) the influence of menarcheal experience on adolescents' current attitudes toward menstruation (Marván \& Molina-Abolnik, 2012). As a result, they have found that Mexican girls often receive mixed messages about menstruation. They argue, menstruation

is presented as being [a] natural, normal, and important biological event, but at the same time information is included on the importance of concealing and denying menstruation. Messages congratulate girls on their entry into womanhood while at the same time suggesting that menses should be kept secret. (Marván \& Molina-Abolnik, 2012, p. 358)

In what follows, I analyze my aunt's and others' stories that elucidate what kinds of hegemonic menstrual tales have been transmitted in my family and how each generation has adapted those tales to make sense of their own menstrual experiences. There are many of these accounts and for the purpose of this chapter, I have grouped them into broad stories: menstruation as dirt, menstrual blood as disgust and shame, (hetero)sexualization of the female body, mother and daughter disconnection and shame, and vagina horror and virginity loss. I take full responsibility for having chosen these stories and not others that might also have been important to present. However, I consider the 
hegemonic menstrual tales I have chosen to illustrate how menstrual stories are shaped by the context in which they take place, and to the ways in which a hegemonic tale impacts menstrual history, body image, and gender development.

\subsubsection{Hegemonic Tale \#1: Menstruation as dirt.}

Douglas (1996) mentions that the idea of 'dirt' consists of two things: care for hygiene and respect for conventions. The first one speaks of the need to control mess, the second, of putting things in order. Douglas argues, "Dirt is the by-product of a systematic ordering and classification of matter, in so far as ordering involves rejecting inappropriate elements" (1966, p. 35). Since being dirt implies being not clean and mise-en-place, dirt can be understood as 'the avoidance of hygiene or aesthetics' (Douglas, 1966), and it is dominated by the idea of bacterial transmission, pollution, or impurity.

In this context, menstrual blood, according to Douglas is an offense against purity and order; particularly within a system that expresses male superiority. In this sense, "society does not exist in a neutral, uncharged vacuum" (Douglas, 1966, p. 4), and men will invent taboos in order to protect themselves from danger and to control the wildness and unpredictability of women's bodies. Consequently, the proliferation of taboos about menstrual blood as something unclean will permeate passively into women's discourses about menstruation as part of a male-dominated society that codes itself as seeking "the safety of the entire society" (Douglas, 1966, p. 5).

Let's consider my aunt's story about the dog. When she told my cousin Susana "look how that dog is cleaning herself, she is really clean," my aunt expresses the dominant discourse claiming menstrual blood as something dirty that needs to be washed out ${ }^{17}$. In her attempt to explain in a simple way, my aunt transmits a powerful story of menstruation as dirt that remains in her daughter's memory, and marks how she experiences her menarche. The influence of my aunt's story is expressed in my cousin's story remembering her first period.

Susana (43): I went to the bathroom and there it was; all dirty. I told my mom (Lupe): 'Mom, something happened to me!' And my mother told me to wear a pad. She told me that that was my period, and that would it be my destiny for all my life. She told me that now I will need to be as our dog, really clean. Otherwise, dogs would follow me anywhere, and I felt that I needed to take a shower every day while menstruating or dogs would sniff my tail (laughs).

\footnotetext{
${ }^{17}$ In 'Mexican Adolescents' Experience of Menarche and Attitudes toward Menstruation: Role of Communication between Mothers and Daughters," Marván \& Molina-Abolnik (2012) perform an in-depth study on the most common topics discussed in Mexican households regarding menstruation. These results shed light on how menstruation is still perpetuated as "dirty" (within a sample of 405 post-menarcheal adolescents, $89 \%$ indicated it as having to do with "hygiene" and $82 \%$ "body function").
} 
Susana's reminiscence of her first menarche serves as evidence of the hygiene and care discourses that mark the disciplinary regimes of feminine bodily care. The subordination of women, through these practices of hygiene/care, is part of the male-dominated system that aims at managing and controlling female bodily processes. Such practices and forms of women's menstrual regulation, according to Lee \& Sassen-Coen (1996), are part of a male-dominated culture that wants girls not to understand menarche, and thus be "more likely to believe negative messages about the whole process, and [be] more easily controlled to menstrual practices" (p. 65). The importance of these menstrual hygiene/care practices resides in that they easily become normalized in the menstruation routine, promoting menstruation cleanliness as part of a "normal body." In the conversation with Susana's daughter, she highlights the importance of feeling normal during her menstruation:

Dresda (32): Do you remember when you had your first period? What did you mom (Susana) tell you? Zabdi (17): Let's see, my first time? I went to the bathroom and I saw all the blood and I got scared. My mom had already told me that something like this would happen. It was really weird and I almost cried because I was in pain, but not that much. My mother told me to clean myself and take a shower. For her, having me clean was really important. Since then, I always take one or two showers when I am menstruating. It makes me feel clean and normal.

Dresda (32): Can you describe what do you mean by normal?

Zabdi (17): M-m-m-m, don't know. Maybe that I do not feel my body is dirty; I do not feel mucky. Mm-m-m, I feel like the others.

Zabdi's story connotes how menstruation makes her feel unclean, but even more surprisingly, her story reveals how the 'normal body' is the body of 'the other,' the body that does not menstruate, the body which is not one (Irigaray, 1985), the male body ${ }^{18}$. Such expression elucidates how menstrual cleanliness affects her senses of self and bodily worth, and helps to set up the idea that the female body, particularly, the menstruating body, is not normal, is out of order. As a result, hegemonic menstrual tales about dirt and pollution position the menstruating body within a hygiene/cleanliness regime that fragments the self from the body, locating menstruation as something that women have to

\footnotetext{
${ }^{18}$ It is particularly interesting how the story of the 'dog' becomes a 'figuration' of the female body. Donna Haraway (2008) in When Species Meet defines 'figures' as a form to "collect the people through their invitation to inhabit the corporeal story told in their lineaments. Figures are not representations or didactic illustrations, but rather material-semiotic nodes or knots in which diverse bodies and meanings coshape one another". (Haraway D. , 2008, p. 4)Thus, in this story, the dog and the female body meet in an entanglement of body significations. Both inhabit the troubled categories of woman and non- human, "properly pluralized, reformulated, and brought into constitutive intersection with other asymmetrical differences" (p. 17). Both are "the other" in front of the division of the rational and universalistic male body. As their animal companion, women woven into the category of species "as this singular and typological female is reduced to her reproductive function." (p. 17)
} 
cope with, adjust to or manage. Even more, menstrual tales about dirt, particularly within a system that expresses male superiority, position it as an offense against purity and order. In this sense, "society does not exist in a neutral, uncharged vacuum" (Douglas, 1966, p. 4); and men will invent tales in order to protect themselves from danger. Consequently, the proliferation of taboos about menstrual blood as something unclean passively permeates women's discourses about menstruation as part of a male-dominated society that claims to seek "the safety of the entire society" (Douglas, 1966, p. 5), wherein menstruation constitutes a problem in need of control and management.

\subsubsection{Hegemonic Tale \# 2: Vagina Horror and Virginity Loss.}

Yolanda (68): I do not remember telling Elka to wear tampons. M-m-m-m, I knew they existed but they were extremely linked to virginity. Thus, they were not really recommended for little girls. There was a risk of losing their virginity. So, it was never in my mind to offer them to her.

Virginity is quite a story in my family. Funnily, it is not a story that is told, it is implicit. Not all menstrual stories are visible. Certain stories appear precisely when they are not told, that is, they appear by omission. In a country like Mexico, where modernity clashes with pre-Colombian traditions, virginity stories get trapped "at the limit of primal repression" (Kristeva, 1982, p. 12); that is, the division or the separation between the abject and the subject (male), and the vagina and all its fluids become the last boundary of the body, the borderline state that functions as a site of possible pollution or contamination.

Julia Kristeva's (1982) "Power of Horror: An Essay on Abjection" introduces the term abjection to denote "[s]omething rejected from which one does not part, from which one does not protect oneself as from an object. Imaginary uncanniness and real treat, it beckons to us and ends up engulfing us" (p. 4). Thus, the abject represents the conditions in which a body, when out of the demarcations of the clean and proper order, is rejected form what is a valuable body according to the social object (male). In this sense and following Kristeva's thoughts, the vagina is what causes abjection because it disturbs identity, system, and order. As result, the vagina, its fluids and its symbolic significations are the abject state that does not respect border, positions, and rules. They represent "The in-between, the ambiguous, the composite" (Kristeva, 1982, p. 4). They become the object of a "phobia" since they lead to the perverse, the prohibition, the misleading, and the corrupt (Kristeva, 1982).Consequently, introducing an object into the vagina represents the "metaphor of the want" (Kristeva, 1982), the force of sexuality becoming a symbolic object in itself, and as such a site of morality. Kristeva states: "It is within that undecidable space, logically coming before the choice 
of the sexual object, that the religious answer to abjection breaks in: defilement, taboo, or sin" (1982, p. 48). Thus, virginity as a symbolic order becomes the brutal separation from male sexual desire and sacred space.

In this context, tampons are the transgression of the "symbolic system of religious prohibitions" (Kristeva, 1982). Tampons place the sacred body, in my aunt Yola's words, at "risk of losing [...] virginity"; therefore, the vagina becomes the "place of social entry and exit, region of confrontation or compromise" (Grosz, 1994, p. 193). Even more, my aunt Yola's story reveals how virginity is still a vital condition for matrimony in my family. As Castañeda, García and Langer (1996) present in their study "Ethnography of Fertility and Menstruation in Rural Mexico," sexuality is only allowed for procreative purposes as justified by the Catholic Church, which is the dominant religion "in a syncretic universe that blends pre-Hispanic and European values" (Castañeda et al., 1996, p. 136). In this context, for my family virginity is a vital condition for the first experience of marital intercourse; the use of tampons menaces that virginity, the idea of an unpenetrated body.

This idea is reinforced by my cousin Elka. When asked about the use of tampons in her family, she says,

Elka (37): My mom (Yola) never offered them to me and they never crossed my mind. It is stressful. Imagine $[\ldots]$ it's like introducing something into that part of your body; a part that you just simply do not touch. I like [..] imagine the anxiety of losing the string, or that the tampon gets into your brain (Laughs). For me, the horror is watching all the blood when you remove the tampon away. No way! I was never fan of it.

The vagina and its flows are the horrors that need to be avoided. In this sense, my cousin's reflection that the vagina is "a part that you just simply do not touch," is in line with Irigaray's (1985) confirmation that women's sexual organs, within a phallic economy, do not represent part of women's sexual pleasure. In Irigaray's view, “Woman's genitals are simply absent, masked, sewn back up inside their "crack" (1985, p. 26). They are the horror that does not need to be seen. Consequently, if the vagina is a part that is not to be touched, does the woman have a sex organ? Is her sexuality denied? (Irigaray, 1985). The relevance of these questions resides in that women's pleasure "is denied by a civilization that privileges phallomorphism" (Irigaray, 1985, p. 26). This idea of the vagina as a place that is neglected of touch damages women's relations with their bodies and their own desires, positioning the vagina as a passive organ expecting the male penis to accomplish its sexual function. The harm of this script is how women learn, or better, do not learn to know and pleasure their own bodies. 
When I asked my cousin Elka's daughter about her relationship with tampons, her answer reflected precisely the vagina horror tale found in her mother's and grandmother's stories. She comments,

Elisa (19): I do not like tampons. Just the idea of putting them inside you, g-r-r-r [...] and they stay in there for a long time. I am sure that tampons affect you somehow. My mom (Elka) never offered them to me. I guess she was worried about me. And I do not want to lose it (virginity) because of a tampon. So the idea of using them and touching there [...] no, no, I don't like it.

Horror tales always do something. They can scare, traumatize, or even paralyze our ways of interpreting certain events. Menstrual horror tales create anxious bodies. The danger of those tales is that once they are transmitted, they have repercussions for how young women relate to their bodies. The vagina and virginity are ambiguous states that have several implications for how women's bodies are socially situated between male desire and male denial, the order and the chaos, ritual and symbolism, and the sacred and the profane. And when mothers pass on their own anxieties, their daughters take them for granted, causing permanent fear, shame, and disgust for their own bodies and sexualities. As a result, hegemonic menstrual tales about women's genitals and menstrual symbolisms may restrain women's abilities to take pleasure in their bodies and sexual experiences, situating women's bodies not as a site for personal pleasure but as objects of male desire.

\subsubsection{Hegemonic Tale \# 3: Menstrual Blood: Disgust, Odor and Shame.}

Dresda (32): Why do you think people can tell when you are menstruating?

Martha (65): Because of menstrual odor. It smells so [... ] mmm I do not know [..] disgusting. I am sure that men can tell when you are menstruating. This is why I used to change pads like every two hours and take showers constantly. I just cannot stand that smell. And I am sure I can tell when women are menstruating. I think it's like a super power (Laughs).

The above narrative, representative of the ways women internalize sentiments of disgust and abjection toward menstrual blood, was narrated by my aunt Martha. My aunt's account illustrates how blood disgust is part of a concealment, shame, and embarrassment system that encourages women "to go great lengths to hide evidence of their contamination from the potentially disapproving gaze of others" (Lee \& Sasser-Coen, 1996, p. 77), particularly men's disapproval. My aunt's story also shows how menstrual bleeding is perceived as a physical excrescence that needs to be "hidden as it constitutes 
evidence of body/genitals/sexuality" (Castañeda et al., 1996, p. 135). As such, internalized discourses of blood disgust and concealment lead women to pay attention to their own bodies, especially when they face an actual or virtual observation by others whose opinions are perceived as relevant - usually those of men.

For Paulo Vaz and Fernanda Bruno (2003), this mechanism of 'self-surveillance' (Foucault, 1985 ) includes, "individuals' attention to their actions and thoughts when constituting themselves as subjects of their conduct. The enlargement of the concept of self-surveillance implies associating it with practices of the care of the self" (Vaz \& Bruno, 2003, p. 273). My aunt's "super power" corresponds to the production of internalized scripts based on the association of menstrual blood with bad odors and with requiring practices of hygiene and care for their avoidance. Interestingly, the same concern about menstrual odor is found in the stories of my aunt's daughter Daniela:

Dresda (32): And Dany, why do you think that is? Why do you think your mom hates the smell?

Daniela (36). Well, it is not just her. I have always felt that menstrual odor is something that makes people realize that you are in your period. Menstrual blood does have a distinct odor. From a dog coming close to you to sniff your tail and attack (laughs), to you being able to smell your own odor; particularly if you use pads for hours. I think menstrual odor has a smell for sensitive noses, especially if you go on public transport, I am sure that it does not go unnoticed.

The idea that certain bodily scents are unwholesome comes from an "odor avoidance hypothesis" that traces back "the origins of hunting-related menstrual taboos against activities such menstrual sex, which spread the odor to hunters, or against menstruators' women touching men's hunting gear or cooking for hunters" (Buckley \& Gottlieb, 1989, p. 22). However, contemporary ideas are also related to menstrual odors and animals attacks. My cousin's comment about a "dog coming close to you to sniff your tail and attack" is in line with concerns regarding animals' attraction to menstrual odors.

For instance, Lynn L. Rogers, Gregory A. Wilker, and Sally S. Scott (1991) have published a study regarding general concerns about bear attraction to menstrual odors, following attacks on menstruating women. In 1967, two menstruators were attacked by grizzly bears in Glacier National Park, which motivated the U. S. government to print brochures warning women to avoid bear country during periods of active menstruation (Rogers et al., 1991). This study was a reaction against this concern, and found no evidence that related bear attacks to menstrual scent. However, even when scientific evidence discards such scripts, new generations continue to be educated with these kinds of menstrual myths, taboos, and odor disgust. In this sense, my niece Zabdi (17) remembers the information she received in her school. 
Zabdi (17): At the school, the teacher told us that women bleed and that it was normal; that that was a process for all our lifespan [...] I remember my Spanish teacher telling us that when we have our periods we need to use perfume because it smells. So we all have our bottles of perfume. It is kind of our hygiene kit.

Zabdi's story shows how tales about menstruation are not restricted only to mothers. As Marván \& Molina-Abolink (2012) argue, in Mexico, particularly in urban areas, a large part of menstrual education is provided by the media and school educators. When school teachers are incapable of handling the topic, they rely on misleading information promoted by sanitary product manufacturers, who tend to "capitalize on the menstrual taboo by making concealment and secrecy a primary selling point for their products" (Costos, Ackerman, \& Paradis, 2002, p. 51). Therefore, by selling perfumed sanitary pads, the sanitary industry is reinforcing the social mandates of menstruation, constructed around the idea that women's corporeal odors are a shameful form of pollution that must be contained.

Menstruation, then, is constituted as a problem in need of a solution, creating women's alienation and detachment from their bodies. As Linda Phelps argues, alienation refers "to the progressive state of separation between ourselves or personalities and everything around us that occurs when we are powerless" (quoted in Lee \& Sasser-Coen, 1996, p. 91). In this regard, my aunt, cousin, and niece have learned to hide their smells, and by doing so, disconnect menstruation from their bodies. Consequently, they experience bodily alienation by neglecting a part of it.

Thus, shame about menstruation is extended to the vagina and its surrounding areas, influencing one's conceptualization of the self. In this sense, menstrual shame "involves both negative evaluations of one's body and an emotional component, a desire to hide oneself and one's body... this includes other aspects of women's embodied selves, including smells, nakedness, and body hair" (Schooler, Ward, Merriwether, \& Caruthers, 2005, p. 325). When hegemonic menstrual tales teach women how to separate their bodies from their scents, women privilege male cultural impositions of cleanliness and order over —what they consider-- our messy and smelly bodies. Furthermore, as Schooler et al. (2005) argue, when "women perceive their genitals as dirty, smelly, and shamefully" they have "lower levels of participation in and enjoyment of sexual activity" (p. 325). Importantly, I am not suggesting that bodily detachment and shame are women's fault. Nevertheless, I concur with Bobel's idea that "when women participate in the silences around menstruation, they allow others to speak for them" (2010, p. 48). In this sense, when mothers participate in passing on these kinds of hegemonic tales, they contribute to girls' body shame, sexual disengagement, and menstrual odor disgust and alienation. 


\subsubsection{Hegemonic Tale \# 4: (Hetero) Sexualization of the Female Body.}

Dresda (32): Mom, how do you remember sharing with my dad that I got my period?

Mili (61): M-mm-, well, that you will [..] that you were [..] that you stopped being a girl. Your dad has always been really proud of you. So your menarche was something really important to us. We celebrate everything that happens to you. If you had a boyfriend, we celebrated. If not, well, you know, puberty was for you and us a really 'special' time.

Dresda (32): What do you mean by special?

Mili (61): Well, you know, you experienced 'things' that we did not approve. But we knew that you were our little girl. We always dressed you like that. Your dad tried to buy you nice dresses all the time, so you could feel beautiful and you could have a nice boyfriend.

Menarche and menstruation are at once sexualized and reproductive processes. According to Lee, "within patriarchal and heterosexist societies menarche signifies both the emerging sexual availability and reproductive potential" (1994, p. 344). In this context, the process of sexualization whereby women experience themselves as sexual beings responds entirely to a process of heterosexual identification; that is, "women are taught to live and discipline their bodies in accordance with prescriptions of heterosexuality, experiencing themselves as sexual objects for heterosexual male" (Lee, 1994, p. 344). Furthermore, during the transition from 'child' to 'women,' girls start to negotiate the overwhelming forces of gender and sexual identification.

My mom's story symbolizes how the process of femininity is linked to heterosexual and reproductive discourses. When my mother argues that she and my father bought me nice dresses "so [I] could feel beautiful and that [I] could have a nice boyfriend," my mother is speaking of how females' bodies are thrown into the social and sexual order as "part of the discourses and practices of menarche that heterosexuality and 'hetero-reality' [have] constructed in everyday life" (Lee \& SasserCoen, 1996, p. 86). That is, women's bodies are set as objects for heterosexual male viewing and pleasure. Furthermore, for my mother, my process of puberty represents a "special" time in my parents' lives, meaning that my fluid sexual orientation has been experienced as a transitional phase. Thus, by disciplining my body with beautiful dresses, they intended to give me doses of cloth heteronormativity as a form of regulating my body and, therefore, my sexual orientation.

Heterosexist societies also construct menarche and menstruation as a signifier of women's reproductive potential. The following excerpts of oral stories illustrate the potentially-reproductive idea linked to the perception of teenage girls as sexual and reproductive beings. In these stories, my aunt Lupe, my cousin Susana, and my niece Zabdi reflect on what menstruation means to them. 
Lupe (68): For me, menstruation was a synonym for getting pregnant. So I think that you need to take menstruation seriously. For me, menstruation meant having children and having more responsibilities. So, I told Susana she needed to be careful.

Susana (43): I told her (Zabdi) that she needed to be careful to not get pregnant. Her dad also spoke to her and told her that now she was able to get pregnant so she needed to be careful with men.

Zabdy (17): For me, menstruation represents that from that moment your life changes and you need to be careful of what do you do because now you can get pregnant. So, because now you are a women, you can have babies now, and a baby is something like oh-h-h-h-h! It is something cute.

These stories show how, in terms of potential sexual relationships with boys, the risk of pregnancy becomes a menstrual panic companion. In this sense, "parents tend to see their daughter's emerging sexuality as problematic" (Lee \& Sasser-Coen, 1996, p. 134), in my family's case, as a process to be careful with. Menstruation is also the assurance of a functioning body (a body that is healthy) and fertility (a body that can have babies). As the next story will show, the hegemonic tale of the lack of menstruation as a failure, as an unhealthy body, is present in my family's considerations of what is to have a 'working' body.

Dresda (32): Aunt, do you remember what mom told you when you had your menarche?

Martha (65): M-m-m, I do not think mother told me anything. I think it was my sister Lupe that told me that it was going to be a monthly bleeding. That I did not need to be scared; that it meant that I was healthy. That this was something that happened to all women.

Dresda (32): When your mom arrived home after working, do you remember who she told you?

Dany (36): Well, she told me that I was not a little girl anymore. When I finally got my period I thought I was OK, healthy, that I did not have any problems. My body was working as it was supposed to work, wasn't it? I stopped being a little girl and realized that I had a whole word of opportunities, that I had the opportunity to be a mom, for example.

These stories are in line with Martin's ideas of medical metaphors referring to women's bodies. She argues that in order to understand women's bodies we need to look carefully to how the "analogies 
taken from the realm of production in factories are being applied to birth" (Martin, 1987, p. 57). In this realm, bodies are seen as machines; machines that needs to produce. A body that does not produce is considered a kind of failure in the productive system. Therefore, the construction of the idea of lack of menstruation as failure contributes to women's negative views of their bodies and menstruation itself. Martin calls this, "the horror of the lack of production: the disused factory, the failed business, the idle machine" (1987, p. 45). This metaphor has been captured in medical discourses and situates "woman's body [as] the machine and the doctor [as] the mechanic or technician who "fixes' it" (Martin, 1987, p. 54). Once again, women's bodies and menstruation become something to be fixed so the productive machinery keeps going. By controlling and fixing women's body, men can control processes of life, labor, and efficiency.

As such, at menarche we tend to internalize the responsibility for controlling access to our bodies. However, in this process we also receive contradictory messages. For instance, my mom's story refers to menstruation and my entrance into womanhood as to attract boys and the power that comes from looking for attention from them. Thus, menstruation and women's sexuality become, at the same time, something to have and show, but also to hide and protect. Consequently, girls' sexuality is presented as being a natural, normal, and important in maturing, but at the same time the information given by parents highlights the importance of concealing and denying sexuality (Marván \& MolinaAbolnik, 2012). Furthermore, menstruation presents itself as a feature of a healthy body, a body that can produce. Bodies that lack this feature are out of control and require medical intervention. Whatever the case, a body that does not fulfill the requirement of a heterosexual and heteronormative body becomes "the ultimate horror, a condition to be avoided at all costs" (Martin, 1987, p. 45). As a result, menstruation and sexuality are at once celebrated and a secret, and the lack of it controlled and fixed.

\subsubsection{Hegemonic Tale \#5: Menstruation as Mother - Daughter Disconnection}

\section{and Blame}

Dresda (32): Can you describe your menarche?

Elka (37): M-m-m-m, I was in my aunt's Lupe house. I slept over in her house [...] I do not remember why. I remember that I did not have the best information and I do not remember my mom sitting with us to have a conversation about it. It happened at night, my stomach began to hurt and I got to the bathroom, and surprise! I was excited but at the same time I was confused because it did not happen in my house and with my mother. My aunt did the best she could to make me feel good but at the same time I felt alone and disconnected from my mom.

Dresda (32): Have you ever discussed this feeling with your mom (Yolanda)? 
Elka (37): We have occasionally talked about it. My sister and I felt that she never was with us in our special moments. She was always working. But it is not that, it is the fact that she never talked to us about how we felt, she never talked about anything.

Menarche and menstrual communication from mother to daughter is a source of either connection or disconnection. The ways mothers relate and communicate issues of menarche and menstruation to their daughters can determine how intimate and open the daughters will be with their mothers in future years (Gillooly, 2004). According to Jackson and Falmage (2013), when girls are deprived of motherdaughter menstrual communication, they miss "a potential connection with one another and may even distance themselves from other menstruating girls and women" (p. 380). Menstrual communication between mothers and daughters can contribute to the daughters' dissatisfaction with their menstrual experiences, and eventually strain their relationships with their mothers, and by extension, with other women.

In my cousin Elka' story, the absence of my aunt during her first menarche is perceived as a form of menstrual loneliness and motherly disconnect. Not only because of the physical absence of my aunt but also for the lack or inadequate preparation of information regarding menarche. Furthermore, my cousin's story refers to a lack of emotional maternal support in how to deal with the emotions or sensations that accompany her menarche, emotions "about desires or fantasies, about shame or pride concerning the body, about inner sensation during menstruation, or about the desire to explore the changing body or sexual preferences" (Lee \& Sasser-Coen, 1996, p. 115). Consequently, my cousin's story is not a story of searching for accurate information about menstrual facts, it is about wanting emotional responses from her mother. The absence of emotional care is, to my cousin, a site of fracture in the mother-daughter bond.

When my aunt Yola told me about her relationships with her daughters, it was clear that a feeling of disconnect is also present. However, her story also reveals the difficulties of balancing being a single mother and a working woman.

Dresda (32): Aunt, do you think that not being present affected your relationship?

Yolanda (68): Look, at that time the family condition was really difficult. I was in the middle of a divorce and I had to work a lot, thus, I was really absent as a mother in my daughters' adolescence. It is hard for me to remember. I have the sensation of their little faces in my memory... but as I told you, menstruation was something really normal, it was like $[. .$.$] well [.$.$] it was special but not something extraordinary.$ So for me it was just giving them the instrumental instructions at that time. 
My aunt Yola's attitude of "giving the instrumental instruction" of menstruation to my cousin is in line with the study by Marván et al. (2002) that presents how Mexican mothers have an important role in the negative and positive attitudes of girls toward menstruation. The authors write, "[m]others are more likely to advise their daughters about how to be prepared for and cope with the practical aspects of menstruation, but will not necessarily deal with their feelings" (Marván, et al., 2002, p. 93). Consequently, mothers' attitudes toward menstruation become girls' menstrual experiences, more as a "hygiene" crisis than an event of maturation (Marván, et al., 2002). By focusing on my cousin's menstruation as needing merely instrumental instruction, my aunt does not address any emotional response to menarche and menstruation, influencing the intimate connection of my aunt and cousin.

A different perspective on the lack of mother and daughter engagement can show the maternal anxiety of facing ambiguities and insecurities regarding menstruation and sexual organs. Commonly, mothers are not prepared to talk about this new and confusing subject. As Marván and Trujillo argue if Mexican mothers "think that they are not well informed, they may feel uncomfortable talking with their daughters" (2010, p. 63). Even more, because "menstruation and sexual activity often share the same intimate location in women's bodies" (Schooler, et al., 2005, p. 324), shame regarding menstruation might influence mothers' general communication about sexuality. If mothers do not receive any information about menstruation, the vagina is experienced more as a virtual orifice than a physical part of the body. The vagina is a space that is not (Irigaray, 1985). Therefore, the vagina and any possible explanation of it become a horror and blaming, become a scapegoat for not dealing with their own dilemmas.

The same kind of mother-daughter disconnection has been found in the stories of my aunt Martha and my cousin Daniela. In their stories, the absence of my aunt in my cousin's first menarche is really significant for both, but it has been especially emotional for my aunt. When relating her story, my aunt could not resist crying by imagining "how she [Daniela] had felt without me." She also has expressed a form of "motherly failure" for not being able to be with her daughter and not being able to be a better mother.

Martha (65): I had already talked to her (Daniela) about menstruation. So one day she called me on the phone. She must've been like 11 years old. And she called the office and told me what had happened to her. I was so scared about not being able to be with her. I had already talked to her but it is not the same, a phone-call, as being with her in that moment.

Dresda (32): Did you feel that you miss something for not being there with her?

Martha (65): Yes, I think so. The fact that the only thing she had was a phone and not her mother [Sobs][...] I could've been a better mother. 
The tale of "being a better mother," according to Adrienne Rich (1986), is a tramp of patriarchy that tries to idealize women, and, by extension, motherhood. Because patriarchal attitudes toward motherhood as an institution are designed to get women under control, a working mother figure is punished with the image of a "mother at home" (Rich, 1986, p. 45). Thus, "at the core of patriarchy is the individual family unit originated with the idea or property and the desire to see one's property transmitted to one's biological descendants" (Rich, 1986), therefore, the absence of the responsible woman, not being with her child is what is attacked when the mother-daughter relation is lost. In my cousin Daniela's story, a sentiment of maternal disillusion is present.

Dresda (32): Do you remember your menarche experience, how was it?

Daniela (36): My parents were working. I woke up and there it was. I remember that I was really excited. I remember that I called your mom, because I knew she was always at home, and I knew I would find her. She told me what to do.

Dresda (32): Do you remember calling your mom?

Daniela (36): She was always working and I understood she needed to work. But, well, I am not sure if I called her or waited until she got home. But it was not important anyway, I mean, your mom had already told me everything. If there is any story here, it's the story of your mother helping me and my mother missing it. [Laughs]

My cousin's story speaks of a sense of loss of the daughter-mother relationship. Even as my cousin is aware that her mom's work has been important to the household, a sentiment of disillusion accompanies her words. In this sense, Rich argues that it is easier for daughters to blame their mothers than "to see beyond her to the forces acting upon her" (1986, p. 235). The institution of motherhooddaughterhood within cultural and patriarchal scripts "only helps to split, to polarize these images, and to project all unwanted guilt, anger, shame [...] onto the 'other women'” (p.253). The hegemonic tale of mother-blaming is thus one of the most dominant cultural narratives aimed at idealizing and endorsing the fixed notion of mothering. Both motherhood and daughterhood have traditionally been charged with patriarchal, demanding expectations that, when not fulfilled, are used against us even more (Rich, 1986), creating a tale of mother-daughter rivalry and disconnection, which affects women's attitudes and beliefs about their menstrual experiences. 


\section{Conclusion}

The experience of menstruation depends on the cultural, social, and familial environment in which the menstruator grows up, and thus, this influences their beliefs about and attitudes toward menstruation. By situating menstrual attitudes and beliefs in Mexico, and particularly within Mexican households, it is possible to explore Mexican cultural beliefs regarding menstruation and the influence these beliefs have on women's menstrual experiences. Particularly, by focusing on my family's menstrual stories it is possible to analyze how our menstrual stories are performed within and in tension with the existence of hegemonic tales, and how our stories are a response to the system in which they have originated; hence, revealing its oppressive dynamics.

As such, this section has presented five hegemonic tales resulting from intergenerational conversations with women in my family. The tales are part of a complex system of cultural taboos, myths, attitudes, and beliefs regarding menstruation. My focus on exploring the transmission of hegemonic tales from mothers to daughter is not to suggest that anything is a mother's fault or to be mother-blaming. On the contrary, my main objective is to portray how menstrual stories have been handed down from mother to daughter for generations as part of a male-dominated system that situates women as weak and, therefore, justifying men's right to dominate and control the discourses about women's bodies.

Within this panorama of hegemonic cultural scripts, it is possible to understand how resistance and more positive representations of menstruation do not come easily. However, alongside culturally dominant narratives of menstruation, there are also stories that are "effective sources of counterhegemonic insights because they expose the viewpoint embedded in dominant ideology as particular rather than universal, and because they reveal the reality of a life that defies or contradict the rules" (Personal Narrative Group, 1989, p. 7). The next chapter presents my family's menstrual stories of resistance. These stories are the result of both the transmission of mother-daughter stories and the uniqueness of each generation's capacity to face dominant constructions of menstrual meanings. 


\section{Chapter 4. Counter-storying Hegemonic Menstrual Tales}

It is a highly radical and subversive act to tell a familiar story in a new way. Once you start to do it you realise that what you call history is another such story and could be told differently and has been. And then the authoritative tradition starts to crack and crumble. It too, it turns out, is nothing more than a particular selection of various stories, all which have at one time or another been believed and told. (Chernin, quoted in Harris, Carney, \& Fine, 2001, p. 9)

What makes a counter-story? Where does a counter-story come from? How does a counter-story crack and crumble other stories? In this final chapter, I want to draw attention to the power of counterstorying and its narrative features, which are important for understanding counter-stories' potential to subvert hegemonic menstrual tales. Therefore, the task of this chapter is to present menstrual counterstories by three generations of women in my family. I present their counter-stories as narratives that refuse "dominant constructions of social realities, reveal[ing] the fractures in structures, discourses and practices of domination" (Harris et al., 2001, p. 6). In this sense, my aim is to elucidate how my family's counter-stories resist and subvert hegemonic menstrual tales.

In order to develop my argument, I proceed in three steps. In part one, I present a brief review of the performativity of stories as developed in Chapter One, focusing principally on constitutive instabilities in the narrative process. As such, I present how "gaps and fissures"” (Butler, 2011; Nelson, 2001) reveal that hegemonic tales do not exist as unified wholes; on the contrary, hegemonic tales live in continuous tension, and this can fracture their harmful, dominant power. In part two, I introduce the definition of counter-stories. I recognize that definitions are always problematic; they never satisfy. However, for the purpose of this thesis, I intend to offer what can be used as a common ground for understanding the relations between counter-stories and hegemonic tales. Finally, in part three, I introduce excerpts of oral narratives from my family. I focus on the specific events my family has described in oral interviews, in which they take strong issue with some specific menstrual tales. My

final aim is to elucidate how even when our stories suggest an apparent resort to and corroboration of hegemonic tales, our stories can also resist and subvert them. 


\subsection{The Performativity of Hegemonic Tales}

In Chapter One, I have argued that stories are "active doings" (McKenzie-Mohr \& Lafrance, 2014) to denote the potential of stories' performativity. The concept of performativity is taken from J. L. Austin to suggest stories' capacity to perform utterances; that is, in saying a story, the story does something in the world (Austin, 1979). Consequently, telling a story is a performative act in which a story becomes an active force, an active doing. Building upon the work of Arthur W. Frank (2010), I have described the shape-shifting capacity of stories. Stories are not only words, they do something in the world because they take the form of objects, and they can do so because they are performative: "Stories enact realities: they bring into being what was not there before [...] first, each person has a story, and then, in consequence of that story, she or he has a life that is enacted by that story" (Frank, 2010, p. 75). Then I have built upon Judith Butler's work on gender performativity to understand performativity "not as a single or deliberate 'act,' but, rather, as the reiterative and citational practice by which discourse produces the effects that it names" (Butler, 2011, p. xii). Consequently, gender performativity is read as a repetition of dominant conventions of gender discourse that materialize sexual difference (Butler, 2011).

Transferring gender performativity to the narrative field, Butler's account of gender recognizes the power of performativity as a "discursive practice that enacts or produces that which it names" (2011, p. xxi). So, in the narrative field, performativity can be read as a reiterative practice that situates stories within the power of discourse, and, therefore, within social relations of gender, sexuality, class, race, age, and networks of power relations. In this tone, I have introduced the term 'hegemonic tales' to refer precisely to dominant social narratives that reproduce "existing ideologies and hegemonic relations of power and inequality" (Ewick \& Silbey, 1995, p. 212), which become internalized and taken for granted. Later, I elaborate upon this meaning by referring to 'hegemonic menstrual tales' as the dominant narratives - taboos, attitudes, and beliefs — of menstruation that have a determinant influence on how women experience menstruation during their lifespans.

As such, even when the performativity of stories shapes and situates menstruation within these social relations and discourses, it also reveals how dominant menstrual narratives are "multiple, polysemic, complexly interconnected, and contradictory," and in doing so, performativity works in "contingent and destabilizing ways" (Langellier, 2001, p. 150). As a result, the repetitive nature of stories creates possible "gaps and fissures" (Butler, 2011; Nelson, 2001) that can expose, reveal, revise, and disrupt power and discourse. Therefore, the stories' performativity can destabilize 
hegemonic menstrual tales in the course of their reiteration. In this sense, the repetition of stories brings about their performative capacity for transgression.

As an attempt to illustrate stories' performativity, I have proposed mother and daughter intergenerational storytelling as a form of narrative repetition that highlights the different and conflicting views each generation has regarding certain family stories, practices, or rituals. As a result, mother and daughter storytelling shows how the same story cannot be repeated twice without creating fissures and gaps that allow for the beginning of new narratives. In this sense, mother and daughter intergenerational storytelling can be counter-hegemonic since, in its performative nature, the retelling of a story reveals details that hegemonic tales have suppressed. Consequently, mother and daughter intergenerational storytelling in my family shows how a story can be performed in different ways, revealing constitutive narrative instabilities, appearing from one performance to the next.

In order to understand more specifically how a counter-story functions, it is necessary first to get a clear sense of how hegemonic tales work. According to Hilde Lindemann Nelson (2001) in Damage Identities, Narrative Repair, dominant narratives, or what she calls "'master narratives" present strong and weak points in their own narrative structures. She argues that the strength of a master narrative "tell[s] us what a counter-story is up against, while the weakness shows us the most promising avenues of resistance" (Nelson, 2001, p. 157). Accordingly, the next section examines the strong and weak features of hegemonic tales, which gives an account of how gaps and fissures make vulnerable the prevalence and durability of hegemonic tales.

\subsubsection{The Narrative Constitutive Instabilities of Hegemonic Tales.}

In our everyday lives, women tell and hear stories that make sense of who they are, what they are doing, or where they want to be. In this sense, women's lives are shaped and constituted by different kinds of stories, full of creativity and intention. Since stories are out in the world, they are social constructions embedded in individual, social, and political contexts, and commonly reflect the power and the interest of dominant ideologies. These stories become dominant narratives that "legitimize claims, justify, provoke, explain, and bring something into view ignoring others" (McKenzie-Mohr \& Lafrance, 2014, p. 2), and, therefore, become normalized and internalized. These stories maintain "the power of the interest they serve" (p. 2), and more importantly, depending on the context - who is doing the telling, at what time, and to whom (Fine \& Harris, 2001) - they can carry hegemonic framings, holding the potential for both "utility and harm" (McKenzie-Mohr \& Lafrance, 2014, p. 4). In combination, these features produce a strong narrative force allowing the existence of hegemonic narratives. 
Notably, as Nelson (2001) reminds, hegemonic narratives are simple "stories, drawn from the cultural store, that circulate widely within society and embody its shared understanding" (p. 152). These stories can be "fragments of history, biography, films, fables, jokes, and similar narrative forms ring changes on the theme, as do proverbs, music, advertisement, and other" (Nelson, 2001, p. 158). Remarkably, a story of this kind gains its force by its "familiarity and rhetorical power" (McKenzieMohr \& Lafrance, 2014, p. 3), which is the reason why it can easily be taken for granted. Hegemonic narratives are based on uncontested versions of reality; that is, hegemonic narratives are based on fictive storylines with the sole purpose of becoming understood as legitimate knowledge, regarded as truth. In this sense, by using the term referring to 'hegemonic tales' I address the fictive features of male-oriented, dominant narratives that find sanctuary within this form. As such, the word 'tale' denotes the fictional attributes of these stories.

Importantly, these fictive features of hegemonic tales are their major weaknesses. When a hegemonic tale is repeated, its fictional feature reveals that certain elements of the story "don't pull all together" (Nelson, 2001, p. 165), conceding spaces of resistance by questioning their veracity. This means that hegemonic tales are at the intersection of fictional discourses and the realities of experiences, creating tensions between them; making the role of a counter-story "to take advantage of that fact" (2001, p. 165). The tension creates constitutive instabilities within these tales, undermining the credibility of some of their parts. Accordingly, the next section explores the constitutive instabilities - gaps and fissures — of hegemonic tales, focusing particularly on how these elements work together in counter-storying those tales.

\subsubsection{Gaps.}

Hegemonic tales gain and retain their narrative potential in their processes of transmission because it is through their repetition and daily interaction that they reinforce their power, becoming internalized and taken for granted as truth. However, in this same process, dominant narratives are performed in different ways, which allows for new interpretations. This suggests that a narrative "gap" can be produced from the moment a hegemonic tale is told, continuing as the tale is listened to, assimilated, and retold. This gap reveals a space for contestations, questionings, doubts, and contradictions. Candace Spigelman (2004) argues that gaps undermine narrative strength as they highlight the failure of the "multiple truths that might be gleaned" from the telling (p. 79). In this sense, these narratives are ultimately less credible precisely because of the complexity and the contradictions they offer.

A gap can be defined as "the crack between what a master narrative demands of certain people and what those people actually do or are" (Nelson, 2001, p. 165). Hence, a gap is a constitutive narrative 
instability that shows how these tales are not solid wholes or truths, but can be contested. Gaps create spaces "for alternate versions and visions that highlight the complexities of persons' lives" (McKenzie-Mohr \& Lafrance, 2014, p. 8). Gaps demand the listener to begin questioning the dominant frames of hegemonic tales, and, as a result, possible transformations of those tale.

\subsubsection{Fissures.}

Fissures can be defined as "the poor fit between one master narrative and the others to which it is connected" (Nelson, 2001, p. 165), which become even more conspicuous when the larger narratives are juxtaposed to one another. The importance of these narrative fissures is that they expose the weaknesses of hegemonic tales. As Nelson (2001) writes dominant narratives can have weak points,

because no oppressive master narratives can absorb all disconfirming evidence - there is simply too much of it. No matter what the narrative distorts or paper over, there are always more inconvenient facts that it hasn't yet caught up with, and these are visible from some perspective or other, (Nelson, 2001, p. 168)

Just as gaps reveal spaces of resistance in the performances of hegemonic tales, fissures reveal how hegemonic tales does not always work perfectly when interconnected with others. Nelson (2001) writes, "when several master narratives work together to constitute a world view, a counterstory can be lodged in the fissures and cracks that are formed at the interstices, since the narratives are almost sure not to fit together smoothly" (p. 166). Spigelman (2004) writes that the existence of competing master narratives is not only inevitable, but also undermines the narratives' credibility since they “overlap and complicate each other" (p. 79), from one interpretive construction to another.

When two or more dominant narratives clash and compete with each other, they reveal incongruity and the fictiveness of the storylines upon which they are enacted. Fissures reveal the unrealistic representations and uncontested versions of reality of a group or an experience. When the narratives sustaining these act together, at the same time, they can no longer be epistemologically justified and therefore turn discreditable. Thus, a counter-story can emerge from these contradictory narratives. 


\subsubsection{Counter-Stories.}

As aforementioned, what gaps and fissures reveal is that hegemonic tales are not solid, incontestable wholes. On the contrary, hegemonic tales have internal instabilities that create spaces for narrative resistance. As such, narrative resistance is a generative force that counters the impact of hegemonic tales by questioning their veracity and their dominant assumptions. In this sense, counter-narratives, or counter-stories, contradict, expose, challenge, interrupt, or deny dominant discourses. Counterstories expose "the fractures in structures, discourses and practices of domination" (Harris et al., 2001, p. 6). As a site of resistance, counter-stories work "under the covers" (Fine \& Harris, 2001) of dominant discourses. As Nelson (2001) assertively describes, counter-stories are rooted in the tissue of dominant narratives and from there they "supply the necessary means of resistance" (p. 150). In this sense, according to Harris et al. (2001), counter-stories constitute "a new form operating in/from strange place" (p. 11). Counter-stories respond to a new kind of resistance; the resistance from the margins, the corners, the borders, the footnotes (Harris et al., 2001). Counter-stories operate from marginal places and from there they resist.

Importantly, counter-stories and hegemonic tales are not in a binary, true-or-false narrative system. Counter-stories do not represent absolute veracity in front of the falsity of a hegemonic tale. On the contrary, both "may diverge, then, not because one is true and another false, but rather because they are both self-believed descriptions coming from different points of view, informed by different backgrounds assumptions about how to make sense of events" (Scheppele, 1989, p. 2082). In this sense, tales and counter-stories interact together, they move together and they are told together. At first glance it may appear that a counter-story resorts to and corroborates the ideology of dominant narratives, however, looking closely into even the most normative seeming counter-storying makes visible the different forms that dominant narratives use to suppress any subversive details. Counterstories are subversive because they offer possibilities for story re-significations.

Taking into account the aforementioned, the next section presents how gaps and fissures function in counter-storying hegemonic tales. I present menstrual counter-stories. These stories are the result of my oral conversations with women in my family, and their stories illustrate how other stories capable of resisting and counter-storying hegemonic tales exist within them. My family's counter-stories are the result of both the transmission of mother-daughter stories and the uniqueness of each generation's ability to face dominant constructions of menstrual meanings. In this sense, my family's counter-stories are dynamic, flexible, and open to discussion. Important to mention, the 
counter-stories I present here are the result of my own counter-discursive perception ${ }^{19}$, and I take full responsibility if this limits the scope of other possible interpretations these counter-stories could offer.

\subsection{Counter-Storying Hegemonic Menstrual Tales}

Within feminist scholarship, counter-storying comes from several decades of exploring the potential of women's linguistic resistance. Particularly during the 1970s and 1980s, the focus was on how to move away from women's exclusion in language toward making women's voices visible and hearable, and subjecting it to political analysis. For instance, feminist scholars in Critical Race Theory such as Patricia Williams (1997), Kimberlé Williams Crenshaw (1993), and Mari Matsuda (1989) consider counter-storying as a feminist-narrative practice that aims to "expose race neutral discourse to reveal how white privilege operates within an ideological framework to reinforce and support unequal societal relations between whites and people of color" (Hunn, Guy, \& Manglitz, 2006, p. 244).

In 1990, the scholarship debate regarding the use of counter-storytelling focused on the intersection of linguistic changes and material effects, challenging "the dichotomizing of 'words' and 'things' [... Instead, they] demonstrated how [...] discursive practices can themselves have material effects" (McKenzie-Mohr \& Lafrance, 2014, p. 7). Recently, according to several authors (Frank, 2010; Nelson, 2001; Harris et al., 2001), feminist counter-storytelling is used as a method of telling stories of those whose experiences are not often told or as a form of "disrupt[ing] hegemony by 'expos[ing] the lies which hold together the ideological armour of privilege, domination and oppression" (Harris et al., 2001, p. 14), allowing other stories, — including those of people of color, women, gay, and the poor - to be heard. Particularly, women's stories can be read as counternarratives,

because they reveal that the narrators do not think, feel, or act as they are 'supposed to.' Such narratives can serve to unmask claims that form the basis of domination or provide an alternative understanding of the situation. (Personal Narrative Group, 1989, p. 7)

This suggests that even if some women's stories materialize dominant menstrual discourses, which situate them within expected gendered behaviors, they also have the potential to disrupt normative discourses, offering new possibilities for new stories, new meanings, and new practices. In this sense, the stories of women in my family do more than reflect the ideologies of hegemonic tales; they

\footnotetext{
${ }^{19}$ By counter-discursive perception I refer to the way in which I understood, described, or interpreted the stories narrated by my family. More theoretically, the counter-stories I present here are the result of how I perceived the outcomes; that is, the counter-arguments of my family stories based on my personal interpretation of their words.
} 
transgress them. Even when some of their stories accept social norms and expectations, their narratives also offer critical exercises in resistance. As such, my family's menstrual stories are not innocent; they do something in the world. This is why their stories matter.

In what follows, I analyze my family's menstrual stories to elucidate what kinds of gaps and fissures are revealed when hegemonic menstrual tales are transmitted, and how each story has found a way of counter-storying menstrual discourses. For the purpose of this chapter, I have grouped my family's counter-stories into broad categories: menstruation and odor as awesome; menstruation as sexual decision-making; menstruation as women's bonding and solidarity; resisting medicalization; and menstruation as positive re-appropriation. As in Chapter Two, I take full responsibility for having chosen these categories and no other stories that might also been important to present. However, I consider the chosen counter-stories to contribute to illustrating how gaps and fissures shape the ways in which a hegemonic tales can be subverted.

\subsubsection{Counter-story \#1: Menstrual Blood and Odor as Awesome.}

Zabdi (17): Well, I like the blood. Sometimes I look at it, and there have been times where I like how it smells. But then, I say, no-o-o-o, and I think that I am crazy and I feel ashamed. But for me it is not that weird. I like how it smells. It's like, OK. But it is not like I smell it all the time, it is just when I am seated in the bathroom, and it is, like, awesome. I do not know, I like it, but then I remember that my mom (Susana) thinks it is weird and then I stop.

As analyzed in Chapter Three, menstrual blood and odor as bad is one of the most harmful hegemonic menstrual tales that affect women's menstrual experiences. As Mary Douglas (1996) argues, the idea of menstrual blood and odor represents the "holy terror" (p. 3) in a male-dominated society that tries to oppress, control, influence, and order bodies into a hierarchical social system. Within this system, tales of cleanness have been enacted to separate bodies that offend the order. As Douglas states,

ideas about separating, purifying, demarcating and punishing transgressions have as their main function to impose a system of an inherently untidy experience. It is only by exaggerating the difference between within and without, above and below, male and female, with and against, that a semblance of order is created. (Douglas, 1966, p. 4)

Consequently, a body that bleeds and smells is posed as a menace to this order; the proliferation of taboos about menstrual blood and menstrual odor as something unclean or polluted helps to alienate bodies from being considered in "normal schemes of classifications [...] ignoring it, just not perceiving 
it, or perceiving so we can condemn it" (Douglas, 1966, p. 36). Women's menstrual bodies are not included in the idea of a normal, neat, and controlled society to the point that they are considered out of the order of structures, in the margins, as an external boundary and eternal reminder of what needs to be avoided. Hence, women's menstrual bodies become an anomaly that needs to be treated. As a result, women learn to internalize a profound disjoint of their bodies - smells and fluids - renouncing a vital part of their bodily experience. As such, menstrual fluids and odors are cleaned, hidden, and deodorized."

But what happens when women reject this tale? What if instead of discarding menstrual blood and odor, women had a different type of engagement with their bodily processes? As my niece relates in her story, she has a different story to tell about menstrual blood and odor: she likes them; she "looks at it and smells it." For something that is supposed to be hidden, to look and to smell can be considered acts of resistance. In this sense, Vivian Sobchack (2013) reminds us how the "smell (as sense and odour) has been aligned in Western culture with the primitive, erotic and uncontainable - and hence with animals, savages and women" (p 122). For her, it is because of these alignments that "smell has been long singled out as the sense 'most threatening to the social order' of the West” (Sobchack, 2013, p. 122). Particularly, smell and odor bring into light the 'who,' the 'what,' and the 'smell itself' (Sobchack, 2013); that is, smell and odor reveal the body that is supposed to be erased.

Therefore, when my niece says, "I like how it smells [...] it's awesome," she is creating a gap in the menstrual tale that allows for a re-signification of the body's aesthetics ${ }^{20}$. In her story, she is creating an opportunity to renounce the body's deodorization, homogenization, and the elimination of her menstrual scent. This is particularly surprising since in the same conversation I had with her, she explains that her "mom thinks it is weird and then [she stops]." The contradiction in her story shows how my niece articulates her menstrual experience between the unmediated menstrual tales transferred by her mother and involuntary acts of resistance.

Another example of a gap in the menstrual tale is storied by my cousin Daniela. In her story, she describes her relationship with menstrual blood with a genuine inquisitiveness and fascination. She comments,

Daniela (36): I like to touch it and see it. I like to see how different it is during my cycle. It is like crumbly sometimes or sometimes more liquid, and with different colors of red. I really like to look at it. Although,

\footnotetext{
${ }^{20}$ By 'body aesthetics' I refer, building upon Bettina Pepenburg and Marta Zarzycka (2013), not only as a merely expression of 'beauty' as quality of bodies, but to an understanding of aesthetics "as perception, sensibility or sensation, emphasising the cultural formation of the senses" (Papenburg \& Zarzycka, 2013, p. 3). This implies an encounter between the senses and the object, where not only one sense work dismissing the others, but all senses participate in a dialectic relation with the object -the body-. As a result, an embodied encounter is produced shaping the sensorial faculties of the body and the affective forces they produce.
} 
I remember one day my mom (Martha) saw me touching it, and she freaked out. But I felt always curious about it.

In her narrative, my cousin creates a new bridge between the eye and the blood. She uses her sight to explore her bleeding, and by extension her body. Interestingly, my cousin is reclaiming her vision as a tool of self-exploration, avoiding the binary opposition between menstrual blood and the clean body. This claim is in line with Haraway's (2002) ideas in "The Persistence of Vision." Haraway calls for taking back "the vision" as a sensory system against the masculinist and patriarchal gaze, which tends to use sight in a perverse capacity - "tied to militarism, capitalism, colonialism, and male supremacy - to distance the knowing subject from everybody and everything in the interest of unfettered power" (2002, p. 677). She reclaims the gaze, "to find our way through all the visualizing tricks and power of modern sciences and technologies that have transformed the objective debates" (Haraway, 2002, p. 678). Even when her claim is a call for feminist theoretical and political positioning within academia, her theoretical account gains back the senses as embodied participants in how we experience the world.

Significantly, Haraway (1998) calls "vision" a tool for a partial perspective; that is, as a form of "particular and specific embodiment" (p. 582) in order to be accountable in the generation of knowledge. In a similar vein, in my cousin Daniela's story, her vision makes her accountable to her body as well. My cousin's 'curious eye' (Rogoff, 2002) for menstrual blood is crucial in offering a counter-viewing of her menstrual experience in a different and situated perspective, since it opens a window for examining and unpacking the power systems preserved in the male-constructed category of 'menstruation,' in which female fluids symbolize an intrinsic relationship of dirt, pollution, and concealment. Furthermore, she is using her senses to defy a transmitted hegemonic tale that considers blood as disgusting, messy, and polluted; something to 'freak out' about. Even more, the curiosity she describes implies, as Irit Rogoff argues,

a certain unsettling; a notion of things outside the realm of the known, of things not yet quite understood or articulated; the pleasures of the forbidden or the hidden or the unthought; the optimism of finding out something one had not known or been able to conceive of before. (Rogoff, 2002, p. 19)

My cousin's curiosity offers 'optimism,' which can be occupied to avoid women's disconnect from their bodies. In patriarchy, women's curiosity about their bodies is guided by sexist oppressions; men are in charge of providing the pleasure of women's physicality. Women's curiosity - touching, 
smelling, seeing, tasting - their bodies, and by extension those of others, represents a threat to a system that strongly opposes women's rights to control their own bodies. Consequently, by arousing curiosity and amazement in their menstrual stories, my cousin and niece create new narrative gaps of bodily perception and sensibility, and, with it, they unconsciously counter-story hegemonic tales.

\subsubsection{Counter-story \#2: Menstruation as a "Way Out".}

Dresda (32): Mom, talking about that, have you had sexual intercourse when you were menstruating? Mili (61): No, never.

Dresda (32): Why?

Mili (61): First, because I was ashamed. However, for me, it also had to do with the confidence you have with the person you are with. So, menstruation served for me as a way to avoid having sex. Sometimes I just wanted to sleep or I was simply not in the right mood.

Yola (68): I remember that when I was having trouble with my ex-husband and he wanted to have sex I said I was menstruating, and he stayed out of the bed (laughs).

Lupe (68): Well, Roberto (ex-husband) was a musician. He used to play in a band and sometimes he had all these parties at night. I have always hated to go with him. So sometimes, I pretended, I was menstruating or that I had a lot of pain and I stayed at home watching TV.

Using menstruation as pretext for not engaging in sexual intercourse has been widely studied. For instance, Delaney, Lupton, \& Toth (1976) call this sexual avoidance a “woman's way out” (p. 19); an admissible excuse to decline sexual activity. My mother and aunt stories reveal how this excuse is commonly used in my family as a legitimate way out of sex that does not require too many questions or justifications. As the same authors argue, "Using 'the curse' as an excuse, many women have enjoyed a dinner date free from the bothersome knowledge that she herself might be the dessert" (Delaney et al., 1976, p. 19). By using menstruation as a pretext, my mother and aunts have taken advantage of the hegemonic tale that considers menstruation as messy, sloppy, painful, or dirty to achieve more personal freedom and attain control over their bodies.

Interestingly, another 'way out' is also found in their daughters' stories about sexual intercourse:

Susana (47): They (men) always want sex. And sometimes we don't. For them is very easy, they only last two minutes (laughs), and we need to invest more time and energy. So, if I feel tired, I just say that 
I am having my period. Poor Pepe (husband), sometimes he must ask himself why I menstruate for 30 days (laughs).

Elka (37): Sometimes I just want to sleep. That's it. I have to wake up really early to get to work or take the kids to school. So at times, even after I finish bleeding, I say that I am menstruating, and I can sleep.

Significantly, my cousins' stories present an important fissure from their mother's previous stories. In my cousins' case, they are actually prolonging their menstruation in order to avoid tedious sexual intercourse. They use menstruation as a "practical masquerade" (Buckley \& Gottlieb, 1989, p. 23) for sexual decision-making. This term is particularly interesting because, in feminist theory, the term 'masquerade' has been principally studied as a defensive mask against gendered social conventions.

In "The Female Proteus," Sophie Carter (1999) explores how in the eighteenth-century masquerade was inextricably linked to a menace of the social order. She argues that because prostitutes were ubiquitous and indistinct in the balls, masquerades were perceived "to create a space in which specifically illicit sexualities were enacted" (Carter, 1999, p. 63). Further, in Masquerade and Civilization: The Carnivalesque in Eighteenth-Century English Culture and Fiction, Terry Castle (1986) shows how the masquerade played a subversive role in the eighteenth-century English imagination. It was part of conventional wisdom about masquerades "that someone donning a mask, especially a woman, experienced an abrupt loss of sexual inhibition" (Castle, 1986, p. 35). In a maledominated society where women normally have to obey very strict societal rules regarding morality, sex, and sexuality, masquerades have offered an opportunity to cross sexual boundaries and experience sexual freedom.

My cousins use prolonged menstruation as a defensive sexual masquerade, as a bodily protective mask to obtain a 'way out' of marital sex duties. Laura Fingerson (2006) calls this action, "agency over the body" (p. 23), referring to women's faculty to manage their own bodies. As such, women in my family create their own strategies to actively manage their menstruation in response to the exigencies imposed by the dominant narratives of women's bodily sexual availability. Although my family's stories do not dismantle completely these narratives, their strategies "work within the system and exert power over their bodies by managing menstruation" (Fingerson, 2006, p. 23). In this sense, they are using the oppressive narratives of hegemonic menstrual tales (i.e. no sexual intercourse during menstruation) to their own benefit, obtaining bodily autonomy, dignity, and sexual freedom. 


\subsubsection{Counter-story \#3: Menstruation as Women Bonding and Solidarity.}

There are many impediments to women's bonding, says Janice G. Raymond (2001) in her book Passion for Friends. She writes, "the most blatant obstacle to female friendship is the prevailing patriarchal adage that "women are each other's worst enemies"” (Raymond, 2001, p. 151). In this sense, women's rivalry has been one of the most effective arguments in patriarchal societies. Patriarchy is nourished by the "women-hating-women" tale (Raymond, 2001, p. 151) and benefits from women's disconnection from the world, their bodies, and from other women; making women constantly focus on men. Raymond suggests that women bonding or "Gyn/affection" (2001) is an important tool for eradicating women's friendship obstacles. She writes,

Friendship gives women a point of crystallization for living in the world. It gives the form, shape, and a concrete location to women who have no state or geographical homeland and, in fact, no territorial ghetto or diaspora from which to act. Friendship provides women with a common world that becomes a reference point in a larger world. The sharing of common views, attraction, and energies gives women a connection to the word so that they do not lose their bearing. Thus a sharing of personal life is at the same time a grounding for social and political existence. (Raymond, 2001, p. 152)

In this regard, in Girls in Power: Gender, Body, and Menstruation in Adolescence, Fingerson (2006) studies menstruation as a shared signifier, a source of power that allows women to share a common world. In her findings, menstruation enables women to participate in a larger social discourse where friends support and help each other (Fingerson, 2006). Similarly, Lee (1994) finds that stories recount "how female friends and sisters [help each other] to find out what [is] happening to their bodies" (Lee, 1994, p. 358). Their findings are interesting for this thesis since in the interviews with my family similar forms of female bonding were found. For instance, in conversation with my aunt Lupe, she remembers how crucial it was for her to have female friends to get through adolescence. She recounts,

Lupe (68): My friends and I used to have a competition to see which of us had the biggest bobs. I won. We even had a club. The "Poppy Flower" Club and we shared all things that happened to us in those years: boys, menstruation, sex, and our bodies. Now that I think about it, it was like a support group (laughs). 
In this story, a narrative fissure can be detected. On the one hand, she talks about "competition" as part of women relating to each other. This part of her story reinforces the hegemonic discourse about women's rivalry. However, on the other hand, my aunt tells a story of women's friendships as a "support group," that allowed her to go through her bodily changes in company, as a part of a club that tied her experiences with others; a form of corporeal bonding.

Importantly, menstrual stories can also create opportunities to reflect on mother-daughter relationships. In Chapter Three, I show how the mother-blaming tale aims to separate mothers and daughters in antagonist positions, creating rivalry. However, when mothers and daughters have spaces to share their stories, they start to reassemble the parts of their experiences that were fragmented. As feminist theorist Marianne Hirsch argues, a revision of women's stories allows for reconfigurations in the mother/daughter plot (1989). For example, at the end of my conversation with my aunt Lupe, she mentions,

Lupe (68): Now that you are asking these questions, I can see that we (mothers) need to be more proactive in order to tell better information to daughters or granddaughters. There are many stories that I remember that are all misleading, with false information, and we tell those stories to our daughters. We need to know better, to know our daughters better.

In her final intervention, my aunt interweaves mothers, daughters, and menstrual narratives in a way completely oppositional to the hegemonic tale of mother-daughter disconnection. She is calling for a reconfiguration of the menstrual discourses within the contexts of patriarchy, which oppresses female plots and mother-daughter bonding.

In this tone, when my aunt comments, "we [mothers] need to me more proactive in order to tell better information to daughter or granddaughters," she is, building upon Hirsch's idea of “emancipatory strategies," practicing a strategy for revisioning the endings, beginnings, and patterns of progression in her relationships with her daughter (Hirsch, 1989, p. 8). Even more, the dynamics of my aunt's story pull apart the mother-daughter disconnection by replacing it with new possibilities for mother-daughter menstrual stories; that is, corporeal stories for blood connections. Nelson (2001) argues that "counter-stories serve as a practical tool for re-identifying persons. They serve to repair the damage identities" suffer (p. 186). Then, menstrual counter-stories also serve to repair narratives in mother-daughter relations.

Building upon Margaret Wetherell's (2012) book Affect and Emotion: A New Social Science Understanding, menstrual narratives can be interpreted as a form narrative-affective-practice, a form of embodied meaning-making that links "bits of the body" with "feelings and thoughts, interaction 
patterns and relationships, narratives and interpretative repertoires, social relations, personal histories, and ways of life" (Wetherell, 2012, p. 14). Thus, telling menstrual stories between mother and daughter can be considered as a particular form of narrative-affective-connection; an intimate, communicative, and affective practice of care and love in mothers' and daughters' ordinary storytelling. Furthermore, menstrual storytelling can be part of "affective routines" (Wetherell, 2012, p. 129), a monthly transmission of bodily lines of personal history, and an emotional experience that can "clearly stabilize, solidify and become and habit" (Wetherell, 2012, p. 14); and in doing so, bringing together relations and connections.

\subsubsection{Counter-Story \#4: Resisting Medicalization.}

The medicalization of menstruation is one more form of medicalization of women's lived experiences. The term 'medicalization' can be defined as “the process whereby everyday experiences and problems become framed as 'illness'. In the course of this process, behaviors and conditions take on medical meanings or are defined (or redefined) in terms of health or illness" (McHugh \& Chrisler, 2015, p. 3). As described in Chapter Three, Emily Martin (1987; 1991) explores how the "scientific fairy tale" creates the stereotypical belief that menstruation is a source of weakness, disability, or failed production, which needs to be treated. Despite the fact that women experience menstruation and premenstrual symptoms in different ways according to the particularities of their bodies, "the dominant menstrual discourse is one of pain, mess, and unpredictability” (Marván \& Trujillo, 2010, p. 55). By situating the menstrual body as a medical issue, women's bodies rely on the expertise of medical doctors, usually male, "rather than valuing women's own knowledge and care of their own bodies" (Fingerson, 2006, p. 57). Interestingly in my family, resisting medicalization is, without knowing it, a shared story.

Older generations (my mother and my aunts) all make reference to the absence of medical assistance or treatment to deal with menstrual cramps. Surprisingly, there is a recurring story where my grandmother and great grandmother prioritize their own knowledge for calming menstrual cramps.

Yolanda (68): I never had painful menstrual cramps. But I remember how, if we had real pain, my mother gave us shots of anise to warm the belly and stop feeling pain.

Dresda (32): Why anise?

Yolanda (68): Because it was a warm drink and it calmed the coldness of the belly. This is how we have always treated menstrual cramps. Family tradition.

Lupe (67): I always had pain the first day, but I dealt with it. It was the pain of the women. 
Dresda (32): And did you ever take anything?

Lupe (67): I never liked thee, and we never had pills or medicine. But I remember the shots of anise my mother gave me.

Martha (65): Menstruating was uncomfortable because sometimes I had menstrual cramps. The only thing I liked about those days were the shots of anise my grandmother used to give us.

Dresda (32): Why didn't grandmother give you medicine?

Martha (65): I suppose because my mother did not trust in medicine. But I also think that my grandmother and mother were more into traditional medicine and home remedies. It was how illnesses were treated, we trusted more in our bodies' capacity to heal themselves.

Mili (61): I had awful menstrual pain. I cried a lot. The only medicine I took were the shots of anise my mother gave me. I drank a shot and I fell sleep all afternoon, and I woke up without pain. My mother never gave us medicine. I like the shots. Now I remember it as a monthly tradition.

In these stories, a fissure is revealed at the intersection of hegemonic menstrual tales. In my aunt Yola's story, the ritual of drinking anise shots has to do with the idea that "it was a warm drink and it calmed the coldness of the belly." The concept of "coldness," as Castañeda, et al., (1996) highlight the "qualities of objects, foods, people, and diseases" (p. 137). This belief is a traditional Mexican cosmovision of a "mythical duality (hot-cold) [that] classifies everything in terms of hot and cold. Hot/cold reflects a taxonomic order, through which the characteristics of objects or subjects are classified according to this specificity" (Castañeda et al., 1996, p. 137). With regard to menstruation, the cold/hot duality is commonly related to menstrual illness. For instance, cold food or beverages are seen to hurt women's bodies because "they will cut [their] period" (Castañeda et al., 1996, p. 137); whereas "hot food (black beans, chili, broth, etc.) or cold beverages (thee, warm alcohol) are considered good for menstruation" (Castañeda et al., 1996, p. 137). In this pre-Colombian cosmovision, just like in my family's stories, menstrual pain is treated as an illness that needs to be equilibrated by eliminating the coldness of the body.

However, this pre-Colombian cosmovision is no far-fetched from naturalistic traditions in medieval Europe. In "Medicine and Naturalistic Philosophy", Katharine Park (2013) traces the most prominent scientific texts dated between 500 and 1500 B.C., focusing principally on Hippocratics, Aristotle, Soranus, and Galen. She explores how medieval scholars have forged a physical order based 
on fundamental differences between male and female bodies, concerning 'scientific' sex and gender facts. For instance, Park reviews the sexual difference ideas in early medieval West (500-1050), where Hippocrates, Aristotle, and Galen define sex differences based on "the polarities of hot and dry, cold and wet that were thought to distinguish male and female bodes respectively" (Park, 2013, p. 86). Similarly, in Arabic traditions (800-1300), following Galen's ideas, al-Majusi, Ibn al-Jazzar, and Ibn Sina draw the fundamental differences between male and female bodies based on "their complexions: males were hot and dry and females cold and wet" (Park, 2013, p. 88). Along the same lines of thought, in "Menstrual Bleeding According to the Hippocratic and Aristotle," Lesley Dean-Jones (1989) describes how both Hippocratic and Aristotle based their menstrual theories "on the unseen innards of a women" (p. 178). Hippocratic gynecological theories relate women's menstrual bleeding with “women's overly moist flesh" (Dean-Jones, 1989, p. 182). Coldness, therefore, is an unnatural bodily status for women that have an excess of moisture. Consequently, humidity is related with menstruation, and pain is attached to them, under the assumption that the "cold nature" (Castañeda et al., 1996, p. 137) of women is an illness that needs to be treated. In all cases, hot and cold are related to menstrual bleeding.

In this context, the fissure appears in the sense that even when their stories are not fully oppositional to the hot/cold duality of menstruation - perhaps even corroborate it - the ingestion of alcohol as a pain remedy goes against the prioritization of 'medical expert knowledge.' When my aunt Martha says, "I suppose [...] my mother did not trust in medicine" and "my grandmother and mother were more into traditional medicine and home remedies. It was how illness were treated, we trusted more in our bodies' capacity to heal themselves," my aunt is positioning my family's menstrual practices, and therefore their bodies, as forms of "subaltern knowledge" against the "scientific fairy tale" of medicalization as a form of helping women to cope with menstrual pain and PMS. According to Spanish feminist Rosa Medina-Doménech (2014), "subaltern (non-hegemonic) knowledge" is "knowledge that is not traditionally considered as a form of 'expertise' and which lie outside of accepted or authorized 'centers' of scientific knowledge production” (p. 180-1).

In these terms, to trust in the capacity of the body to heal itself, paraphrasing Susan Bordo's essay "Bringing Body to Theory," is a form of bringing the body back to the realm of evidence; that is, locating women's experiences "as the origin of knowledge" (Scott, 1991, p. 777). This idea can be better illustrated by my cousin Daniela's story.

Daniela (36): I try not to use any medication. I just try to avoid anything that can cause me pain. For example, when I was little I used to jump a lot the first day so all the blood came down once for all. Now, I listen to my body, and I try not to drink cold liquids or eat spicy food because I know that will bring 
me pain. And if I have pain, I use a bag of hot water on my belly. Also, in the first day, I try to drink a lot of water because the more I drink, the more blood comes out when I go to the bathroom. These are my little tricks.

In this story, by "listening to [her] body," my cousin fissures the medical tale that situates medical expertise as the authorizing source of women's bodily knowledge. By "listening," my cousin challenges medical decision-making and expertise, seeking alternative forms, or tricks, of care, based on the notion of the knowledge of her body. In privileging the knowledge of her own body, my cousin is breaking the tale of women's bodies as passive receptors of medical representations and knowledge expertise, reconstructing women's bodily experiences as a form of knowledge production. In this regard, my family's stories can help to visualize how every women's body contains their own knowledge and practices to define their own well-being. This type of bodily knowledge, the one that comes from within, reveals alternative/subaltern forms of (non-hegemonic) knowledge; that is, to listen to our menstrual experiences is a counter-hegemonic practice of care against scientific tales of women's menstrual medicalization.

\subsubsection{Counter-story \#5: Menstruation as Positive Re-appropiation.}

Dresda (32): Can you describe why you feel uncomfortable saying the word (menstruation)? Why you do not like it?

Zabdi (17): I do not know why. I just hate the word. So, I do not say it.

Dresda (32): Why not?

Zabdi (17): I do not know. Maybe because the word reminds me how much it hurts and that I am going to bleed and that a part of me is now dead. A part of me that was meant to be a baby.

As stated in Chapter One, words have power. As Austin (1979) argues, words have the capacity to do something in the world. Words within speech acts, according to Austin, have a performative, illocutory and perlocutory force. In Butler's (1997) reading of Austin' work, Butler describes the difference between 'illocutioary' and 'perlocutionary' speech acts as follows,

The former are speech acts that, in saying, do what they say, and do it in the moment of that saying; the latter are speech acts that produce certain effects as their consequence; by saying something, a certain effect follows. The illocutionary speech act is itself the deed that it effects; the perlocutionary merely leads to certain effects that are not the same as the speech act itself. (Butler, 1997, p. 3) 
In this sense, words are "acts with consequences" (Butler, 1997, p. 7). They have meaning, and in their performance, they affect the world. However, in order to have power words need to gain force through historicity. That is,

the history which has become internal to a name, has come to constitute the contemporary meaning of a name: the sedimentation of its usages as they have become part of the very name, a sedimentation, a repetition that congeals, that gives the name its force. (Butler, 1997, p. 36)

The force of the name relies on its historicity. In addition, the force is also gained by the word's iterability (repetition). As a result, the repetition of the word's historicity propagates what she calls "traumatic events" (1997, p. 36). Historicity, therefore, reveals "connotations that exceed the purposes for which they may be intended and can thus work to afflict and defeat discursive efforts to oppose such speech” (Butler, 1997, p. 38). Words can afflict pain; words can injure.

Following this line of thinking, as the story of my niece illustrates, the word 'menstruation' is, for her, a word charged with "traumatic events." For Butler, a traumatic event is not a casual effect of the word's historicity but its powerful capacity to be encoded on memory. Butler writes,

If we understand the force of the name to be an effect of its historicity, then that force is not the mere causal effect of a an inflicted blow, but works in part through an encoded memory or a trauma, one that lives in language and is carried in language. The force of the name depends not only on its iterability, but on a form of repetition that is linked to trauma, on what is, strictly speaking, not remembered, but relived, and relived in and through the linguistic substitution for the traumatic event. (Butler, 1997, p. 36)

When she says, "the word reminds me how much it hurts and that I am going to bleed and that I part of me is now dead," she is expressing the negative cultural, social, and historical tales (menstruation as failure, menstruation as illness) commonly associated with the word menstruation. The mere act of naming menstruation brings to light the hegemonic capacity of tales to penetrate language. In this sense, menstruation is not a simple word. Because it cannot be separated from culture, menstruation becomes a vehicle of negative connotations. In this regard, menstruation has a perlocutionary force, because its utterance produces an effect in the person that hears it. As a result, my niece is affected by the negative connotations of the tales contained in the word menstruation. Even when she is not experiencing it at the moment of hearing the word, she is immediately injured by what the word represents. 
However, this does not mean that words that are charged by negative intentions are always affective. If menstruation gains its force through the repeated negative invocation by which it has become linked (disability, pathologization, pollution), reverse citation can "break with the historicity to which it is in thrall" (Butler, 1997, p. 38). In this sense, menstruation is open to new resignifications. For instance, in my cousin Daniela's story, she appeals for a resignification of the word.

Daniela (36): I have always thought that the word menstruation is too long and strong. If I were able to change it, I would name it more simply, with a name that represents it. I do not know, 'liberty.' [...] That even when we have our period for many years, it does not necessarily mean that menstruation is a life sentence. Think about it, it is an awful word (menstruation), a lot of consonants together, and the combination of sounds. I do not know who created that word, men I guess (laughs).

My cousin's socio-linguistic background allows her to call for a reappropriation of menstruation's negative historicity. By rearticulating its negative force, my cousin is finding "repetition of an originary subordination for another purpose, one whose future is partially open" (Butler, 1997, p. 38). In this sense, because menstruation is a term that is constrained within dominant social narratives, reappropriation is produced when the word is repeated "in directions that reverse and displace their originating aims" (Butler, 2011, p. 123). Consequently, by re-naming menstruation as "liberty," my cousin brings to light a constitutive failure of the word's performativity. She is providing a "linguistic occasion and index for a consequential disobedience" (Butler, 2011, p. 122). The re-signification of the word menstruation is a fundamental step in changing its harmful signification. By naming menstruation as "liberty," my cousin's narrative action is definitely doing something in the world.

\section{Conclusion}

Telling stories about menstruation is a way of perpetuating hegemonic tales in everyday life, but retelling a story creates spaces for recounting the impact of those tales. The aim of this chapter has been to draw attention to the power of counter-storying and its potential to subvert hegemonic tales. By exploring stories' performativity, a set of constitutive instabilities are exposed as narrative features that can fracture the harmful, dominant power of hegemonic menstrual tales. In this sense, I have presented narratives "gaps and fissures" that reveal the nonexistence of unified, solid hegemonic tales, and expose, rather, tales that live in continuous tension within themselves and amongst each other. 
In order to illustrate how gaps and fissures work in dismantling the veracity of hegemonic menstrual tales, I have presented intergenerational menstrual counter-stories by three generations of women in my family. I have described these counter-stories as narratives that resist the oppressive powers of hegemonic menstrual tales. These counter-stories live within hegemonic menstrual tales, "neither fully oppositional nor untouched" (Andrews, 2004, p. 2), but capable of countering menstrual tales without undermining the particularities of women's experiences. In the oral-narrative excerpts of my family's menstrual stories, counter-stories do not completely oppose or refute the discursive power of hegemonic tales as much as they seek to reappropiate them. My family's stories reveal: 1) how the sensory system can function to reconnect with our bodies, to familiarize again with the abjected (Kristeva, 1982), with the rejected parts and with bodily functions that do not belong to us anymore; 2) how our bodies can be (un)consciously used as 'masquerades' to help our sexual decisionmaking processes and bodily validation; 3 ) how menstruation as a shared experience can help women to find a common ground with other women, opening up spaces to contest the tale of women's rivalry; 4) how listening to our bodies can function as a form of subaltern knowledge, a knowledge within the body that challenges the scientific tale; and 5) how, by re-signifying menstruation, we can change menstruation's negative connotations. By appropriating again menstruation, that is, by re-naming it in our own terms, women can subvert the hegemonic tales attached to this women's experience.

In this sense, intergenerational storytelling can be seen as a performative act that promotes a strategy of resistance, restores women's personal experiences of menstruation, and also as a form of menstrual practice and discursive story-transmission throughout different generations that makes possible a counter-storying of taboos, myths, and beliefs about menstruation. These have a direct effect on how women story their lives. In this regard, my family's storytelling shows how even when our menstrual stories suggest an apparent resort and corroboration of hegemonic tales, in the tissue of those tales, our stories resist and subvert them. 


\section{Final Conclusion}

In this investigation, I respond to my central research hypothesis which proclaimed that certain stories in my family gain force because they are sustained by a series of myths, rituals, taboos, secrets, routines, practices, and discourses that affect women's lives. This investigation demonstrates that specific tales about childbirth, marriage, menstruation, abortion, or menopause are predominantly harmful to women because in their constitution and transmission they regulate and legitimize male dominated assumptions regarding women's social behavior and women's bodies. Particularly, this thesis focused on menstrual tales as part of specific and dominant sociocultural and historical narratives that shape women's thoughts and behaviors regarding their menstrual and bodily experiences. Significantly, the qualitative analysis of this thesis was grounded on mother-daughter narratives of menstruation; revealing the challenges, complexities, and the compelling powerdynamics of stories and thereby contributing to feminist scholarship theorizing women's discursive resistance.

To sustain my response, I grounded my debate using performance and performativity theories to denote the powerful potential of stories for change. I proved that women's stories have a shapeshifting capacity to either corroborate or disrupt hegemonic tales. With this intention, I situated narratives as an embodied performance, highlighting how the body is the primordial condition that shapes how women give meaning to their bodily experiences and tell stories about it. Then, performativity theories situated women's stories as a powerful narrative strategy that recognizes the power of reiteration, and in this process, it creates narrative spaces - gaps and fissures - to stimulate alternative meanings of hegemonic tales.

The use of this theoretical framework framed my response in two primary formulations: First, the potential of comprehending women's stories as an extensive part of their bodies, combining the body as the source of performance but also as a narrative. This can open further opportunities to explore and question to what extent dominant discourses affect how women embody experiences, and the ways women can change the meanings of those experiences. Second, by claiming the potential of stories' performativity, I was able to situate women's intergenerational storytelling as a generative narrative strategy since it allows the reiteration of stories through generations with the potential of reestablishing new bonds and new signifiers.

For the purpose of elucidating the potential of intergenerational storytelling, I analyzed my own family transmission of menstrual stories, focusing on mother - daughter menstrual storytelling. I wanted to explore what kind of menstrual taboos and myths have been created, storied, retrieved, 
experienced, and signified in my family, and if we either corroborated or subverted these myths in transmitting menstrual stories throughout generations. Several methodological and theoretical reasons led me to draw on my family and their menstrual experiences as a case study for this investigation. Theoretically, I wanted to bring menstruation back to theory and into the public domain in order to facilitate a feminist theoretical and socio-historical understanding of menstruation. As such, my objective was not to promote an essentialist understanding of women based on menstruation, nor is it meant to idealize the menstrual experience. Conversely, my theoretical contribution is to offer concrete gendered discourses and normative practices that affect families' menstrual experience.

As such, my family stories revealed important insights into how menarche and menstruation are lived and embodied particularly in a culture that combines pre-Colombian cosmologies with contemporary cultural narratives. In this regard, I believe this investigation significantly contributes to offer an important overview of how women in Mexico are exposed to specific discourses and practices regarding menstruation. This includes an understanding of a contemporary Mexican society as the product of mixed cultures, in which indigenous practices and traditional beliefs join Western elements. In this varied society, ideas in relation to women's reproductive bodies are anchored in specific traditional systems of beliefs. Ideas and beliefs such as the 'hot/cold' duality or illness and sickness treatments, collide with contemporary ideas of women's medicalization giving an account of the symbolic universe in which Mexican menstrual stories are normally produced. By extension, this account showcases how the reproduction of oppressive gendered discourses that accompany menstruation affect women's transmission of menstrual stories.

In this Mexican mixed system of menstrual beliefs, my family stories showed how sociocultural and ideological structures have significant influence on the particularities of our menstrual narratives. Our stories expressed tales of secrecy, pollution, mother - daughter disconnection, blood disgust, and vagina-and-bodily-liquids-horror, according to past and present existing menstrual ideologies. However, even when my family's menstrual stories are produced discursively within misogynist beliefs, my family's everyday experiences and intergenerational stories revealed different degrees of menstrual consciousness and awareness of resistance. There is an understanding that despite the strong pressure that hegemonic tales put on us to internalize negative scripts about menstruations, there is also the potential to subvert and disrupt these scripts. When women tell stories to each other, more specifically, when mothers share stories with their daughters, this constitutes a transgressive act in remembering and telling stories differently, and through them, learning to cope with life in a female body.

In offering a situated exploration of mother - daughter transmission of menstrual stories, this investigation endorses the liberatory and subversive character of intergenerational storytelling. By 
telling their stories, my mom, aunts and nieces where able to chronicle their own body. Even further, they were invited to think about the internalized oppression of their bodies. As such, this investigation shows how the process of mother and daughter storytelling proved to be an effective form of gaining insight into my family body and into the body politics that affects women's daily lives. In this way, some of our stories spoke of an increasing mother and daughter relationship; others of menstruation as a protective shield against sexual pressure, and others about reconfiguring a new form to engage with the body and particularly, its bodily fluids. What these stories have in common is that all have diluted the negativity that surrounds menstruation by offering new forms of rethinking negative scripts. As such, this investigation contributes to a powerful comprehension of the intersection of women's liberatory intergenerational storytelling potential and subversive corporeal stories, allowing women to be aware and respond discursively to this.

To obtain this comprehension, this research showed the importance of combining methodologies in order to deal with certain dichotomies such as body/narration. Methodologically speaking, by using dialogical narrative inquiry and phenomenological research I provided a solid platform to situate bodily stories and bodily experience both as data gathering method and theoretical framework. Furthermore, both methodologies contribute to reinforce qualitative narrative research predominantly centered on bodily experiences, demonstrating that it is extremely difficult to methodologically separate the body, the experience and the stories, since the three are so delicately interweaved throughout all phases of the research. Both methodologies contributed to locate the body and the stories not as independent particles but as embodied narratives, making evident that a story cannot escape from the bodily experience. I believe this investigation proves that an interdisciplinary use of methodologies can benefit the crafting of qualitative methods by diluting determinate models of doing research based on categorical or monolithic approaches to the body, stories or experiences. But most importantly, the methodological contribution of this investigation is to offer the strengths and challenges of conducting qualitative research when the researcher is member of the population she is studying. Rather than considering this issue from a dichotomous perspective, both methodologies explore a more incarnated form to approach family research that other forms of analysis do not always provide.

With all these contributions in mind, perhaps the most compelling contribution of this investigation is not so much with the academic body of knowledge as it is with my family's own knowledge and self-discovering. The stories shared in this investigation created new bodily frames in my family storybook. The narrated blood stories have regenerated my family's tissues. Through telling our bodily stories, the communicative veins of my family have irrigated not only mother and daughter communication but they have also flowed through family intervals, gaps, fissures and silences 
repairing family injuries and damaged relations. Blood stories have offered a transfusion of harmful stories for others of belonging, connections, and forgiveness. I hope these stories can inspire positive impacts in the bodily experiences and stories of future generations of women in my family. But most importantly, I hope these stories can help to highlight the importance of intergenerational storytelling to repair and generate family tissues and blood relations.

At this stage, it seems that I am closing definitely this chapter of my life, but before reaching the end, I would like to explore some important details that came up along these pages and that have encouraged me to continue my personal $\sim$ theoretical academic interests in a not too distant future. I was really engaged with new forms of using the senses' curiosity to explore women's bodily fluids. I have found how the emotions, body spaces (cavities), and the embodied senses configure new bodily encounters and intersections. I am compelled by the study of the insides/outsides and the body boundaries, this includes asking questions about how corporeal fluids evoke, constrain or are composed by the senses and emotions; the ways in which emotions are generated or transformed by body spaces and fluids, and the process through which the embodied senses configure new aesthetics of body spaces. I want to continue focusing on the intersections among bodily spaces and sense, approaching the historicity of the body and the affective weight of its liquids. I want to continue listening, hearing and writing emergent counter-stories of women's lives. I want to keep looking for women's narrative strategies to re-story bodily experiences (Period) 


\section{Bibliography}

Agnew, C. (2012). The Discursive Construction of Menstruation within Puberty Education. University of Otago, Education. New Zealand: University of Otago.

Armeni, E. (1996). Menstruation Goes Public: Aspects of Women's Menstrual Experience in Montreal, 1920- 1975. Thesis submitted to the Faculty of Graduate Studies and Research. Department of History. Montreal, CA: University of McGill.

Austin, J. (1979). J.L. Austin: excepts from How to do Things with Words. Cambridge MA: Harvard University Press.

Aysa-Lastra, M. (2016). Mexico, Families in. The Wiley Blackwell Encyclopedia of Family Studies, $1-5$.

Bamberg, M. (2006). Stories: Big or Small. Narrative Inquiry, 16(1), 139-147.

Bates, T. R. (1975, April-June). Gramsci and the Theory of Hegemony. Journal of the History of Ideas, 36(2), 351-366.

Bauman, R. (1989). Let Your Words Be Few: Symbolism and Silence among Seventeenth-Century Quakers. Cambrigde University Press.

Benhabib, S. (1995). Feminism and Postmodernism: An Uneasy Alliance. Feminist Contentions: A Philosophical Exchange. London: Routledge.

Berger, R. J., \& Quinney, R. (2005). The Narrative Turn in Social Inquiry. In Storytelling Sociology. Narrative as Social Inquiry (pp. 1-12). Colorado: Lynnw Rienner Publishers.

Berns, U. (2009). The Concept of Performativity in Narratology. European Journal of English Studies, 13(1), 93-108.

Bobel, C. (2010). New Blood: Third-Wave Feminism and the Politics of Menstruation. Rutgers University press.

Bordo, S. (1998). Bringing Body to Theory. In Body and Flesh. A Philosophical Reader (pp. 84-97). Massachusetts: Blackweel Publishers.

Bruner, J. (1991). The Narrative Construction of Reality. Critical Inquiry, 18, 1-20.

Bruner, J. S. (1986). Actual Minds, Possible Worlds. Cambridge, Mass: Harvard University Press.

Buckley, T., \& Gottlieb, A. (Eds.). (1989). Blood Magic: The Anthropology of Menstruation. California: University of California.

Burns, M. (2003). Interviewing: Embodied Communication. Feminism \& Psychology, 13(2), 229-236.

Busra, U., \& Sultana, F. (2011). The Imageries of Menstruation in Sanitary Napkin Ads: Representation and the Practice of Discourse as a Marketing Strategy. Advertising \& Society Review, 11(4).

Butler, J. (1997). Excitable Speech. A Politics of the Performative. New York: Routledge. 
Butler, J. (2011). Bodies that matter: On the Discursive Limits of Sex. New York/London: Routledge. Carman, T. (2008). Merleau-Ponty. New York: Routledge.

Carter, S. (1999). 'This Female Proteus': Representating Prsotitution and Masquerade in EighteenCentury English Popular Print Culture. Oxford Art Journal, 22(1), 57-79.

Castañeda, X., García, C., \& Langer, A. (1996). Ethnography of Fertility and Menstruation in Rural Mexico. Soc. Sci. Med., 42(1), 133-140.

Castle, T. (1986). Masquerade and Civilization: The Carnivalesque in Eighteenth-Century English Culture and Fiction. Stanford: Stanford University Press.

Chodorow, N. (1978). The reproduction of mothering: Physicoanalysis and the sociology of gender. Berkley, CA: University of California Press.

Chrisler, J. C., \& Gorman, J. A. (2015). Chapter 4. The Medicalization of Women's Moods: Premestrual Syndrome and Premestrual Dysphoric Disorder. In M. McHugh, \& J. Chrisler (Eds.), The Wrong Prescription for Women: How Medicine and Media create a "Need" for Treatments, Drugs, and Surgery (pp. 77-98). Santa Barbara California: Praeger an imprint of ABC-CLIO.

Chrisler, J. C., Marván, M., Gorman , J. A., \& Rossini, M. (2015). Body appreciation and attitudes toward menstruation. Body Image, 12, 78-81.

Clifford, J., \& Marcus, G. E. (1986). Writing Culture: The Poetics and Politics of Ethnography. University of California Press.

Cohan, S., \& Shires, L. M. (1988). Telling Stories: A theoretical analysis of narrative fiction. New York: New Accents.

Comaroff, J. (1985). Bodily Reform as Historical Practice: The Semantics of Resistance in Modern South Africa. International Journal of Psychology, 20, 541-567.

Connell, R. W., \& Messerschmidt, J. (1995). Hegemonic Masculinity: Rethinking the Concept. Gender and Society, 19(6), 829-859.

Connelly, F. M., \& Clandinin, J. D. (1990, Jun.-Jul.). Stories of Experience and Narrative Inquiry. Educational Researcher, 19(5), 2-14.

Costos, D., Ackerman, R., \& Paradis, L. (2002, January). Recollections of Menarche: Communication Between Mothers and Daughters Regarding Menstruation. Sex Roles, 46(1/2), 49-59.

Coutinho, E. M., \& Segal, S. J. (1999). Is Menstruation Obsolete? New York: Oxford University Press.

Crenshaw, K. W. (1993, June). Mapping the Margins: Intersectionality, Identity Politics, and Violence Against Women of Color. Stanford Law Review, 43, 1241-1299. 
Dauenhauer, B., \& Pellauer, D. (2014). Paul Ricoeur. (E. N. Zalta, Ed.) Retrieved March 16, 2016, from The Stanford Encyclopedia of Philosophy: http://plato.stanford.edu/archives/sum2014/entries/ricoeur/>

Davies, A., \& Fitchett, J. (2015). In the Family Way: bringing mother- daugther (matrilineal) perpective to retail innovation and consumer culture. Environment and Planning, 47, 727-743.

Dean-Jones, L. (1989). Menstrual Bleeding according to the Hippocratics and Aristotle". Transactions of the American Philological Association (1974-), 119, 177-191.

Delaney, J., Lupton, M., \& Emily , T. (1976). The Curse. A Cultural History of Menstruation. New York: New American Library.

Derrida, J. (1972). Limited Inc. Evanston, IL : Northwestern University Press .

Douglas, M. (1966). Purity and Danger: An Analysis of Concepts of Pollution and Taboo. New York: Praeger.

Dwyer, S. C., \& Buckle, J. L. (2009). The Space Between: On Being an Insider-Outsider in Qualitative Research. International Journal of Qualitative Methods, 8(1), 54-63.

Eichler, M. (1981). Power, dependency, love and the sexual division of labour. Women's Studies International Quarterly, 4(2), 201-219.

Esteban, M. L. (2004, June). Antropología encarnada. Antropología desde una misma. Papeles del CEIC, $12,1-21$.

Ewick, P., \& Silbey, S. S. (1995). Subversive Stories and Hegemonic Tales: Toward a Sociology of Narrative. Law \& Society Review, 29(2), 197-225.

Fine, M., \& Harris, A. (Eds.). (2001). Under the Covers: Theorising the Politics of Counter Stories (Vol. 4). London, UK: Lawrence \& Wishart.

Fingerson, L. (2006). Girls in Power: Gender, Body, and Menstruation in Adolescence. New York, NY: State University of New York Press.

Finlay, L. (2006). The Body's Disclosure in Phenomenological Research. Qualitative Research in Pshycology, 3(1), 19-30.

Flax, J. (1990). Thinking Fragments: Psychoanalysis, Feminism, and Postmodernism in the Contemporary West. Berkeley: University of California Press.

Foucault, M. (1981). The Order of Discourse. In R. Young (Ed.), Untying the Text: A PostStructuralist Reader (pp. 48-78). Boston, MA: Routledge.

Foucault, M. (1985). The Use of Pleasure. New York: Pantheon.

Frank, A. W. (1995). The Wounded Storyteller: Body, Illnes, and Ethics. Illinois: University of Chicago Press. 
Frank, A. W. (2010). Letting Stories Breathe. A Socio-Narratology. Chicago: The University of Chicago Press.

Frank, A. W. (2012). Practicing Dialogical Narrative Analysis. In J. A. Holstein, \& J. F. Gubrium (Eds.), Varieties of Narrative Analysis (pp. 33-50). SAGE Publishing.

García-Pérez, H., Harlow, S. D., Erdmann, C. A., \& Denman, C. (2010, June). Pelvic Pain and Associated Characteristics Among Women in Northern Mexico. International Perspectives on Sexual and Reproductive Health, 36(2), 90-98.

Geiger, S. N. (196). Wome's Life Histories: Method and Content. Signs, 11(2), 334-351.

Georgakopoulou, A. (2015). Small Stories Research. In A. Fina, \& A. Georgakopoulou (Eds.), The Handbook of Narrative Analysis (pp. 256-271). John Wiley.

Gillooly, J. B. (2004). Making Menarche Positive and Powerful for Both Mother and Daughter. Women \& Therapy, 27(3-4), 23-35.

Gleaves, D. D. (2008). The role of Mexican folklore in teaching and learning. Retrieved from Learn NC: http://www.learnnc.org/lp/editions/brdglangbarriers/1913

Gonzalez, B. J. (2006). The Politics of Translation in Sandra Cisneros's Caramelo. Differences. Journal of Cultural Feminist Studies, 17(3), 1-17.

Grosz, E. (1994). Volatile Bodies. Toward a Corporeal Feminism. Bloomigton: Indiana University Press.

Hagberg, G. (1984, August). Aristotle's "Mimesis" and Abstract Art. Philosophy, 59(229), 365-371.

Hall, K. (2000). Performativity. Journal of Linguistic Anthropology, 184-187.

Haraway, D. (1988). Situated Knowledges: The Science Question in Feminism and the Privilege of Partial Perspective. Feminist Studies, 14(3), 575-599.

Haraway, D. (2002). The Persistance of Vision. In N. Mirzoeff (Ed.). New York: Routledge.

Haraway, D. (2008). When Species Meet. Minneapolis: University of Minnesota Press.

Haraway, D. J. (2013). SF: Science Fiction, Speculative Fabulation, String Figures, So Far. Ada: A Journal of Gender, New Media, and Technology(3).

Harris, A., Carney, S., \& Fine, M. (2001). Counter work: Introduction to 'Under the covers: theorising the politics of couter stories. In M. Fine, \& A. Harris (Eds.), Under the covers: theorising the politics of couter stories (pp. 6-18). London, UK: Lawrence \& Wishart.

Hayward, E. S. (2014, December 17). Trans $\sim$ Waters $\sim$ Coalitional Thinking on Art + Environment. Retrieved June 30, 2016, from A Journal of the Buil+ Natural Environments: http://www.terrain.org/2014/currents/trans-waters-coalitional-thinking-on-art-andenvironment/ 
Heavey, E. (2015). Narrative Bodies, Embodied Narratives. In A. D. Fina, \& A. Georgakopoulou (Eds.), The Handbook of Narrative Analysis (pp. 429-446). John Wiley \& Sons, Inc.

Hedva, J. (2015). Mask MAgazine. Retrieved 2016, from Sick Woman Theory: http://www.maskmagazine.com/not-again/struggle/sick-woman-theory

Hemmings, C. (2011). Why Stories Matter: The Political Grammar of Feminist Theory. Durham: Duke University Press.

Hennessy, R. (2012). Materialist Feminism and the Politics of Discourse. Routledge, Chapman \& Hall Ltd.

Herman, D., Jahn, M., \& Ryan, M.-L. (Eds.). (2005). Routledge Encyclopedia of Narrative Theory. New York: Routledge.

Hirsch, M. (1989). The Mother/daughter Plot : Narrative, Psychoanalysis, Feminism. Bloomington: Indiana University Press.

Hunn, L. R., Guy, T. C., \& Manglitz, E. (2006). Who Can Speak for Whom? Using CounterStorytelling to Challenge Racial Hegemony. Adult Education Research Conference (AERC), (pp. 244-250). Retrieved from http://www.adulterc.org/proceedings/2006/proceedings/hunn_et_al.pdf

Hyvärinen, M. (2010). Revisiting the Narrative Turns. Life Writing, 71, 69-82.

Irigaray, L. (1985). This Sex Which Is Not One. (C. Porter, \& C. Burke, Trans.) Ithaca, NY: Cornell University Press.

Jackson, T. E., \& Falmagne, R. J. (2013). Women wearing white: Discourses of menstruation and the experiene of menarche. Feminism \& Psychology, 23(3), 379-398.

Jeffries, L. (2007). Textual Construction of the Female Body. London: Palgrave MacMillan.

Kearney, R. (2002). On Stories. New York: Routledge.

Keen, S. (1998). Stories We Live By: Personal Myth Guide Daily Life. Pshycology Today, 22(12), 42-46.

Kristeva, J. (1982). Powers of Horror: An Essay on Abjection. (L. S. Roudiez, Trans.) New York, NY: Columbia University Press.

Lambrou, M. (2014). Narrative, text and time: Telling the same story twice in the oral narrative reporting of 7/7. Language and Literature, 23(1), 32-48.

Langallier, K. M., \& Peterson, E. E. (2006). Narrative Performance Theory: Telling Stories, Doing Families. In L. A. Baxter, \& D. O. Braithwaite, Enganging Theories in Family Communication (pp. 99-114). Sage Publications.

Langellier, K. M. (1989). Personal Narratives: Perspectives on Theory and Research. Text and Performance Quarterly, 9(4), 243-276. 
Langellier, K. M. (1999). Personal narrative, performance, performativity: Two or three things I know for sure. Text and Performance Quarterly, 19(2), 125-144.

Langellier, K. M. (2001). "You're marked": Breast cancer, tatoo, and the narrative performance of identity. In J. Brockmeier, \& D. Carbaugh (Eds.), Narrative and Identity: Studies in Autobiography, Self and Culture (pp. 145-184). Amsterdam: John Benjamins Publishing.

Langellier, K. M., \& Peterson, E. E. (1993). Family Storytelling as a Strategy of Social Control. In D. K. Mumby, Narrative and Social Control (pp. 49-76). SAGE Publications.

Langellier, K. M., \& Peterson, E. E. (2004). Storytelling In Daily Life: Performing Narrative. Philadelphia: Temple University Press.

Langellier, K. M., \& Peterson, E. E. (2006). Family Storytelling as Communication Practice. In R. L. West, \& L. H. Turner (Eds.), The Family Communication Sourcebook (pp. 109-128). Sage Publications.

Langer, M. M. (1989). Merleau-Ponty's Phenomenological of Perception. London: The MacMillan Press.

Leder, D. (1998). Lived Body. In D. Welton (Ed.), Body and the Flesh. A Philosophical Reader (pp. 117-129). Massachusetts: Blackwell Publishers.

Lee, J. (1994, September). Menarche and the (Hetero) Sexualization of the Female Body. Gender and Society, 8(3), 343-362.

Lee, J. (2008, October). "A Kotex and a Smile": Mother and Daughters at Menarche. Journal of Family Issues, 29(10), 1325-1347.

Lee, J., \& Sasser-Coen, J. (1996). Blood Stories: Menarche and the Politics of Female Body in the Contemporary U.S. Society. New York: Routledge.

Loewen, M. A. (2010). My Mother's Story as a Narrative of Contradictions. Journal of Memories Studies, 28, 103-115.

Lupton, D. (2003). Medicine As Culture : Illness, Disease and the Body in Western Societies (2 ed.). London: SAGE Publications Ltd.

Lyotard, J.-F. (1979). The Postmodern Condition: A Report on Knowledge. (G. Bennington, \& B. Massumi, Trans.) Manchester: Manchester University Press.

Manen, M. V. (2014). Phenomenology of Practice: Meaning - Giving Methods in Phenomenological Research and Writing. Walnut Creek, CA.: Left Coast Press.

Martin, E. (1987). The Woman in the Body: A Cultural Analysis of Reproduction. Boston: Beacon Press.

Martin, E. (1991). The Egg and the Sperm: How science has constructed a romance based on stereotypical male-female roles. Journal of Women in Culture and Society, 16(3), 485-501. 
Marván, M. L., \& Alcalá-Herrera, V. (2014). Age at Menarche, Reactions to Menarche and Attitudes towards Menstruation among Mexican Adolescent Girls. North American Society for Pediatric and Adolescent Gynecology, 27, 61-66.

Marván, M. L., \& Molina-Abolnik, M. (2012). Mexican Adolescents' Experience of Menarche and Attitudes Toward Menstruation: Role of Communication Between Mother and Daughters. North American Society for Pediatric and Adolescent Gynecology, 25, 358-363.

Marván, M. L., \& Trujillo, P. (2010). Menstrual Socialization, Beliefs, and Attitudes Concerning Menstruation in Rural and Urban Mexican Women. Health Care for Women International, 31, 53-67.

Marván, M. L., Cortés-Iniestra, S., \& González, R. (2005, August). Beliefs About and Attitudes Toward Menstruation Among Young and Middle-Aged Mexicans. Sex Roles, 53(3/4), 273279.

Marván, M. L., Espinoza-hernández, G., \& Vacio, A. (2002). Premenarcheal Mexican girl's expectations concerning peri menstrual changes and menstrual attitudes. Journal of Psychosomatic Obstetrics \& Gynecology, 23(2), 89-96.

Marván, M. L., Morales, C., \& Cortés-Riestra, S. (2006). Emotional Reactions to Menarche Among Mexican Women of Different Generations. Sex Roles, 54, 323-330.

Matsuda, M. J. (1989, August). Public Response to Racist Speech: Considering the Victim's Story. Legal Storytelling, 87(8), 2320-2381.

McCormick, M. L. (2010). The Lived Body: The Essential Dimension in Social Work. Qualitative Social Work, 10(1), 66-85.

McGinn, N. F. (1966, August). Marriage and Family in Middle-Class Mexico. Journal of Marriage and Family, 28(3), 305-313.

McGregor, I., \& Holmes, J. G. (1999). How Storytelling Shapes Memory and Impressions of Relationship Events. Journal of Personality and Social Psychology, 76(3), 403-419.

McHugh, M., \& Chrisler, J. (2015). The Wrong Prescription for Women: How Medicine and Media Create a "Need" for Treatment, Drugs, and Surgery. Santa Barbara, CA: ABC-CLIO.

McKenzie-Mohr, S., \& Lafrance, M. N. (2014). Women Voicing Resistance: Discursive and Narrative Explorations. New York: Routledge.

Medina-Doménech, R. M. (2014). 'Who were the experts?' The Science of Love vs. Women Knowledge of Love During the Spanish Dictatorship. Science as Culture, 23(2), 177-200.

Mehrez, S. (2007). Translating Gender. Journal of Middle East Women's Studies, 3(1), 106-127.

Menary, R. (2008). Embodied Narratives. Journal of Consciousness Studies, 15(6), 63-84. 
Mitchell, M. C., \& Egudo, M. (2003). A Review of Narrative Methodology. Sidney, Australia: DSTO Systems Sciences Laboratory.

Moi, T. (1999). What is a Woman? and Other Essays. New York: Oxford University Press.

Montgomery, R. E. (1974). A Cross-Cultural Study of Menstruation, Menstrual Taboos, and Related Social Variables. Ethos, 2(2), 137-170.

Moustakadas, C. (1994). Phenomenological Research Methods. California: Sage Publications.

Nelson, H. L. (2001). Damaged Identities, Narrative Repair. Ithaca, NY: Cornell University Press.

Norrick, N. R. (2000). Conversational Narrative: Storytelling in Everyday Talk. Amsterdam: John Benjamins Publishing.

O'Brien, L. (2010). Storytelling: an approach that can help to develop resilience. Nurse Researcher, 17(3), 17-25.

Papenburg, B., \& Zarzycka, M. (2013). Introduction. In Carnal Aesthetics. Transgressive Imagery and Feminist Politics (pp. 1-18). Nw York, NY: Palgrave Macmillan.

Park, K. (2013). Medicine and Natural Philosophy: Naturalistic Traditions. In J. Bennett, \& R. M. Karras (Eds.), The Oxford Hanbook of Women and Gender in Medieval Europe (pp. 84-98). Oxford: Oxford University Press.

Personal Narrative Group. (1989). Interpreting Women's Lives. Feminist Theory and Personal Narratives. Indiana : Indiana University Press.

Pillow, Wanda S. \& Mayo, Cris. (2007). Towards Understandings of Feminist Ethnography. In S. N. Hesse-Biber (Ed.), Handbook of Feminist Research. Theory and Practice (pp. 155-172). California: Sage Publications.

Plummer, K. (1995). Telling Sexual Stories: Power, Change adn Social Worlds. New York, NY: Routledge.

Poland, B. (2002). Transcription quality. In J. Gubrium, \& J. Holstein (Eds.), Handbook of interviews research: Context and method (pp. 629-659). Thousand Oaks, California: Sage.

Polany, L. (1981). Telling the same story twice. Text, 1, 315-336.

Polkinghorne, D. E. (2004). Narrative Theory and Postmodernism. In L. E. Angus, \& J. Mcleond (Eds.), The Handbook of Narrative and Psycotherapy. Practice, Theory and Research (pp. 5363). California: Sage Publications.

Puetz, M. (2002). The University of Chicago: Theories of Media: Keywords Glossary: mimesis. Retrieved May 2016, from http://csmt.uchicago.edu/glossary2004/mimesis.htm Punday, D. (2003). Narrative Bodies. Toward a Corporeal Narratology. New York: Palgrave.

Raymond, J. G. (2001). A passion for friends: toward a philosophy of female affection . North Melbourne, Vic. : Spinfex. 
Reese, L. (2012). Storytelling in Mexican Homes: Connections Between Oral and Literacy Practices. Bilingual Research Journal, 35(3), 277-293.

Reulecke, J. (2008). Generation, Generationality, Generativity and Memory. In A. Erll, \& A. Nünning (Eds.), Cultural Memories Studies: An International and Interdisciplinary Handbook (pp. 119125). Berlin: Walter de Gruyter.

Rich, A. (1986). Of Women Born: Motherhood as an Experience and Institution. New York: W. W. Norton \& Company.

Riessman, C. K. (1993). Narrative analysis. Newbury Park, CA: Sage Publications.

Riessman, C. K. (2002). Analysis of Personal Narratives. In J. F. Gubrium, J. A. Holstein, A. B. Marvasti, \& K. D. McKinney (Eds.), The SAGE Handbook of Interview Research. The Complexity of the Craft (pp. 367-380). California: Sage Publications.

Riessman, C. K. (2008). Narrative Methods for the Human Sciences. California: Sage Publications.

Ritchie, S. (1993, Apr - Oct.). Ventriloquist Folklore: Who Speaks for Representation? Western Folklore, 52(2/4), 365-378.

Rogers, L. L., Wilker, G. A., \& Scott, S. S. (1991, October). Reactions of black bears to human menstrual odors. The Journal of Wildlife Management, 55(4), 632-634.

Rome, E. (1986). Premestrual Syndrome (PMS) Examined Through a Feminist Lenses. In V. L. Olsen, \& N. Fugate Woods (Eds.), Culture, Society, and Menstruation (pp. 145-151). Washington: Hemisphere Publishing Corporation.

Ronald. (2005). The Narrative Turn is Social Inquiry. In R. J. Berger, \& R. Quinney (Eds.), Storytelling Sociology. Narrative as Social Inquiry (pp. 1-12). Colorado: Lynne Rienner Pubishers, Inc.

Rosaldo, M. Z., \& Lamphere , L. (Eds.). (1974). Woman, Culture, and Society. Stanford University Press.

Rubin, G. (1975). The Traffic in Women: Notes on the "Political Economy" of Sex.

Russell, P. (2011). The History of Mexico: From Pre-Conquest to Present. Routledge.

Saloul, I. A. (2009). Performative narrativity : Palestinian identity and the performance of catastrophe. In Telling memories : Al-Nakba in Palestinian exilic narratives (pp. 139-170). Amsterdam: Amsterdam School for Cultural Analysis (ASCA).

Sandelowski, M. (1991). Telling Stories: Narrative Approaches in Qualitative Research. Journal of Nursing Scholarship, 23(3), 161-166.

Scheppele, K. L. (1989, August). Foreword: Telling Stories. Michigan Law Review, 87, 2073-2098. 
Schooler, D., Ward, M. L., Merriwether, A., \& Caruthers, A. S. (2005, November). Cycles of Shame: Menstrual Shame, Body Shape, and Sexual Decision-Making. The Journal of Sex Research, 42(4), 324-334.

Scott, J. W. (1991). Th Evidence of Experience. Critical Inquiry, 17(4), 773-797.

Shuman, A. (2015). Story Ownership and Entitlement. In A. D. FIna, \& A. Georgakopoulou (Eds.), The Handbook of Narrative Analysis (pp. 38-56). John Wiley \& Sons.

Smith, B., \& Sparkes, A. C. (2006). Narrative inquiry in psychology: exploring the tensions within. Qualitative Research in Psychology, 3(3), 169-192.

Sobchack, V. (2013). The Dream Olfactory: On Making Scents of Cinema. In M. Zarzycka, \& B. Papenburg (Eds.), Carnal Aesthetics : Transgressive Imagery and Feminist Politics (pp. 121143). London: I.B.Tauris.

Spigelman, C. (2004). Personally Speaking: Experience as Evidence in Academic Discourse. Carbondale: Southern Illinois: UP.

Squire, C., Andrews, M., \& Tamboukou, M. (2013). Introduction: What is narrative research? In M. Andrews, C. Squire, \& M. Tamboukou (Eds.), Doing Narrative Research (pp. 1-26). Los Angeles: SAGE Publications.

Stone, E. (1988). Black Sheep and Kissing Cousin. New York: Penguin Books.

Svob, C., \& Brown, N. R. (2012). Intergenerational Transmission of the Reminiscence Bump and Biographical Conflict Knowledge. Psychological Science, 23(11), 1404 -1409.

The Free Medical Dictionary. (2012). Retrieved January 22, 2016, from Farlex Partner Medical Dictionary: http://medical-dictionary.thefreedictionary.com/detoxification

Todres, L. (2007). Embodied Inquiry. Phenomenological Touchstones for Research, Psychoterapy and Spirituality. New York: Palgrave Macmillan.

Trebilcot, J. (Ed.). (1983). Mothering: Essays in feminist theory. Totowa, NJ, Rowman \& Allanheld.

Tuin, I. v. (2015). Generational Feminism: New Materialist Introduction to a Generative Approach. Maryland: Lexington Books.

Uskul, A. K. (2004). Women's menarche stories from a multicultural sample. Social Science \& Medicine, 667-679.

Vagle, M. D. (2014). Crafting Phenomenological Research. Walnut Creek, California: Lelf Coast Press.

Vault, M. L. (1997). Personal Writing is Social Research. In R. Hertz (Ed.), Reflexivity \& Voice. Thousand Oaks: SAGE Publications.

Vaz, P., \& Bruno, F. (2003). Types of Self-Surveillance: from abnormality to individuals 'at risk'. Surveillance \& Society, 1(3), 272-291. 
Walker, A. E. (1997). The Menstrual Cycle. London: Routledge.

Wells, K. (2011). Narrative Inquiry. New York, NY: Oxford University Press.

Wertz, F. J., Josselson, R., Anderson, R., \& McSpadden, E. (Eds.). (2011). Five Ways of Doing Qualitative Analysis. New York, NY: The Guilford Press.

Wetherell, M. (2012). Affect and Emotion. A New Social Science Understanding. London: Sage Publications.

Williams, P. (1997). Seeing a Color-Blind Future: The Paradox of Race. New York: The Noonday Press.

Wilson, E. A. (2015). Gut Feminism. Durhaim and London: Duke University Press.

Wolff, L. O. (1993). Family Narrative: How Our Stories Shape Us. Annual Meeting of the Speech Communication Association (pp. 1-20). Miami Beach, Florida: ERIC.

Young, I. M. (1980, April). Throwing like a Girl: A Phenomenology of Feminine Body Comportament Motility and Spatiality. Springer, 3(2), 137-156.

Young, I. M. (1990). Throwing like a Girl and Other Essays in Feminist Philosophy and Social Theory. Bloomington and Indianapolis: Indiana University Press.

Young, I. M. (2005). On the Female Body. "Throwing like a Girl" and Other Essays. Oxford University Press.

Zimmermann, K. A. (2010, February 10). Mexican Culture: Customs \& Traditions. Retrieved from Live Science: http://www.livescience.com/38647-mexican-culture.html 